\title{
Performance and calibration of high-resolution daylight-integrated and occupancy-based lighting systems in open-plan offices
}

by

Daniel D. Lowcay

A thesis submitted to the Faculty of Graduate and Postdoctoral Affairs in partial fulfillment of the requirements for the degree of

Master of Applied Science

in

Civil Engineering

Carleton University

Ottawa, Ontario

(C) 2021, Daniel D. Lowcay 


\section{Abstract}

A significant portion of the energy buildings consume is spent providing sufficient lighting for occupant happiness, health, comfort, and productivity. Intelligent control of lighting systems featuring high-resolution daylight and occupancy sensing has the potential to conserve a large portion of this energy, reducing or eliminating energy wasted illuminating spaces that are already daylit or are unoccupied. This thesis explores intelligent lighting systems through two related studies. In the first, the energy savings potential of such systems is quantified by simulating system performance under a variety of conditions. Savings are found to be between $61 \%$ to $91 \%$ relative to a conventional schedule-based lighting controller when high-resolution control is utilized, with the greatest savings occurring when occupancy is low and daylight penetrates deeply into a space. Estimated savings decrease to less than $35 \%$ with coarser lighting zones. The study's proposed workflow can assess the energy savings of occupancy- and/or daylightbased controls for open-plan offices of any common configuration. In the second study, the problem of required labour-intensive manual calibration is addressed by evaluating an automated calibration process that does not directly measure workplane illuminance, and so may be performed without human intervention or assistance. Data from electric lighting and daylighting simulations is used to calibrate and subsequently evaluate two distinct lighting systems: one which utilizes workplane illuminance data and another which does not. Systems calibrated automatically are found to perform similarly to those calibrated manually. The study concludes that automated calibration should therefore be considered to enable commercial viability for high-resolution daylight-controlled lighting systems. 


\section{Preface}

This thesis is an integration of two journal papers, the first has been published and the second has been submitted for review. Should readers wish to refer to materials from this thesis, the current thesis is required to be cited. The articles included in this thesis are as follows:

- Article 1: D. Lowcay, H. B. Gunay, and W. O’Brien, “Simulating energy savings potential with high-resolution daylight and occupancy sensing in open-plan offices" J. Build. Perform. Simul., vol. 13, no. 5, pp. 606-619, 2020, doi: 10.1080/19401493.2020.1807604.

- Article 2: D. Lowcay, W. O’Brien, H.B. Gunay, "Evaluating sensor calibration of high-resolution daylight-controlled lighting in open-plan offices"

Use of copyrighted material from the published articles is acknowledged as per the corresponding publisher's permission guidelines with respect to the authors' rights. In the aforementioned articles, Daniel D. Lowcay was the principal contributor to the research methodology, data analysis, and preparation of written material and figures presented in the articles, under the supervision of Dr. H. Burak Gunay and Dr. Liam O’Brien. 


\section{Acknowledgements}

I would first like to extend my gratitude and thanks to my supervisors, professors Burak Gunay and Liam O'Brien. Burak, you took in a struggling undergraduate student and provided me opportunity after opportunity to learn, to develop my skills, and to prove to myself that I could do more. This thesis could not have existed without your support and your belief in me. Liam, your constant commitment to my success and to the success of all your students has made all the difference. The Building Performance Research Centre and all the professionals it has produced would not be what it is without your leadership.

I extend my gratitude to Dr. Jayson Bursill. You opened a door for me that ended up defining the course of my education and my career. Your continued guidance, support, and friendship have been invaluable.

I also extend thanks to the entire BPRC community. Your commitment to achieving great things and support of one another have made for the best environment to learn and grow in I could have asked for. Special thanks to Brodie Hobson, Connor Brackley, and Mohammad Derakhti.

Finally, I would like to thank all the people in my life who have given me their love and support while I pursued my education. My wife Roselyn Fernandes, my friends Garrett Lecoq and Arthur David, and all of the members of my family who have stood beside and behind me - thank you. 


\section{Table of Contents}

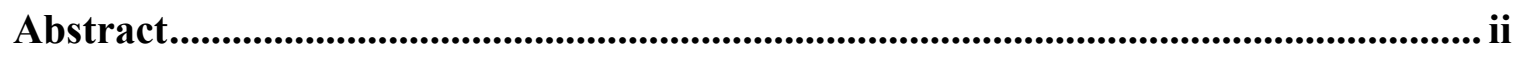

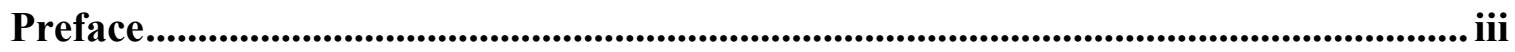

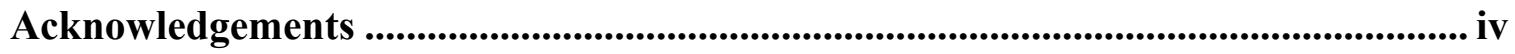

Table of Contents ........................................................................................................ v

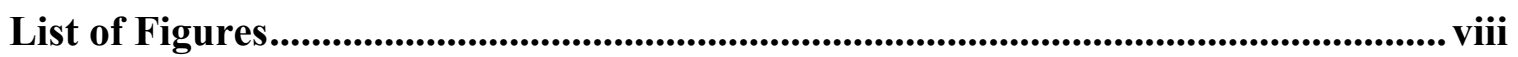

List of Tables ................................................................................................................................ $\mathrm{x}$

Chapter 1: Introduction ................................................................................................... 11

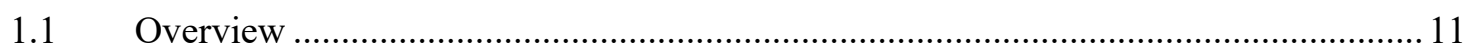

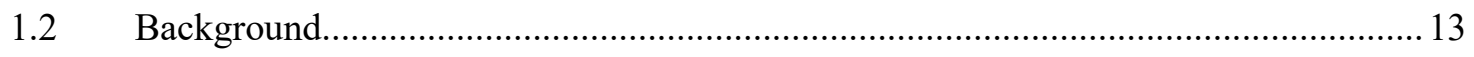

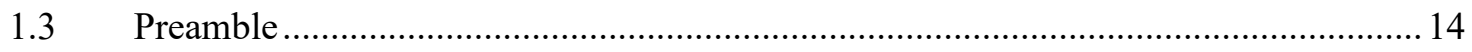

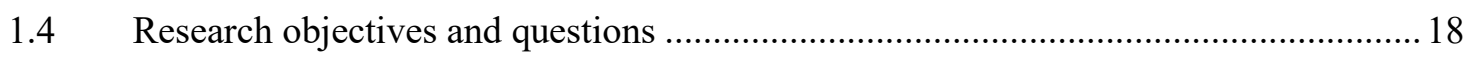

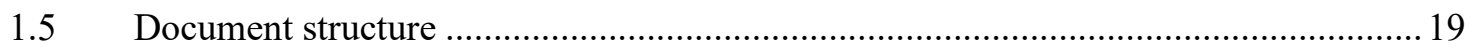

Chapter 2: Simulating energy savings potential with high-resolution daylight and occupancy sensing in open-plan offices.............................................................. 21

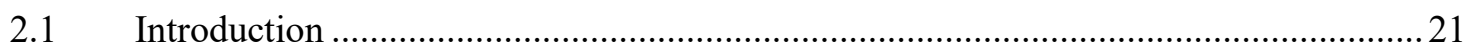

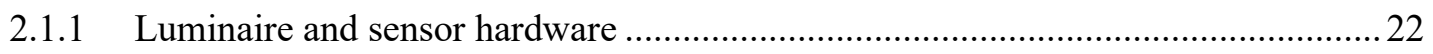

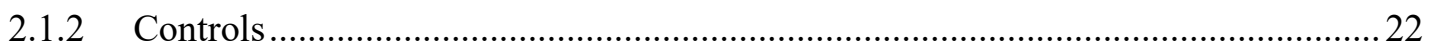

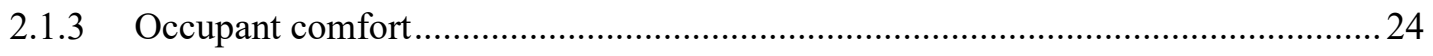

2.1.4 Energy savings from daylight harvesting and occupancy sensing .........................25

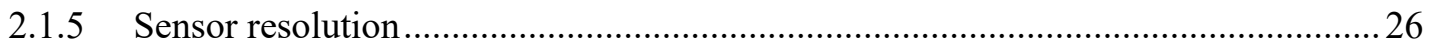

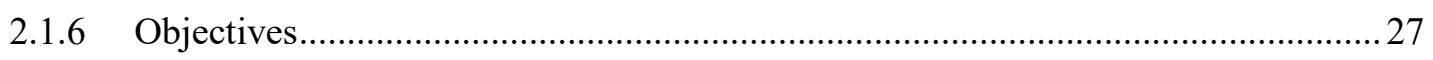

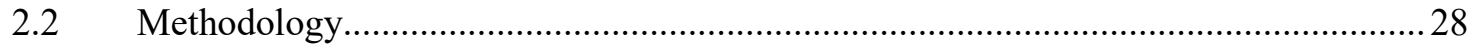

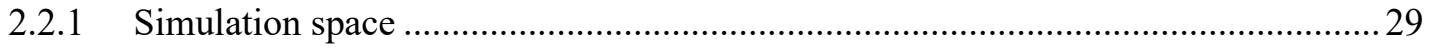

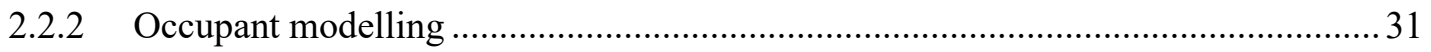




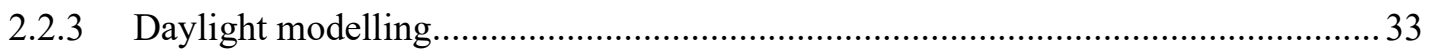

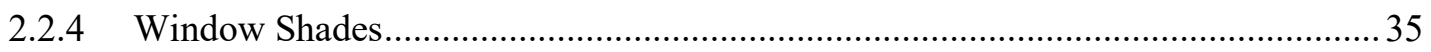

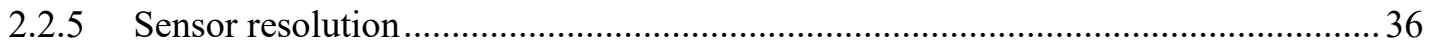

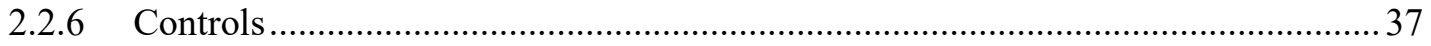

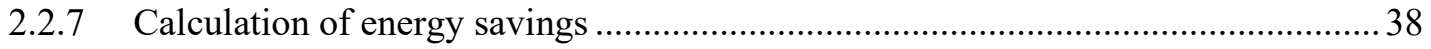

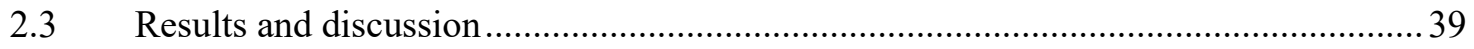

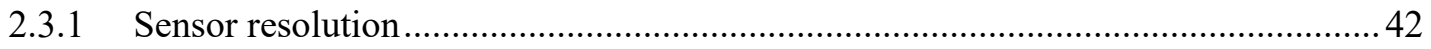

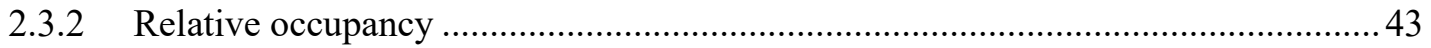

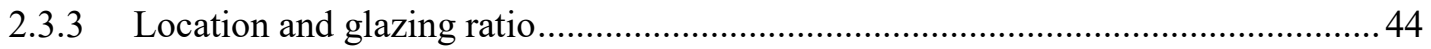

2.3.4 Room orientation and single façade vs corner space .......................................... 46

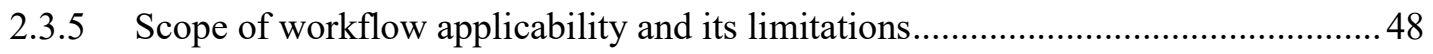

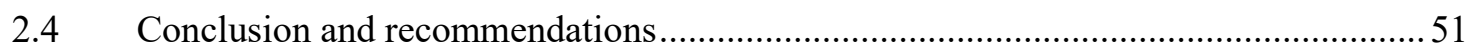

\section{Chapter 3: Evaluating sensor calibration of high-resolution daylight-controlled}

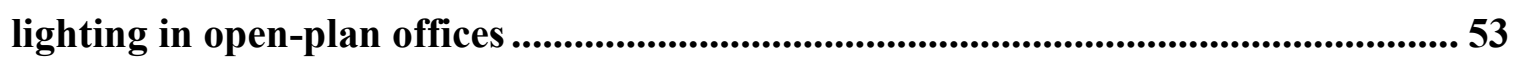

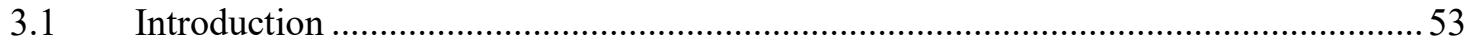

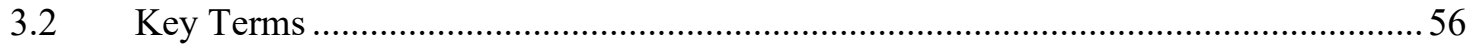

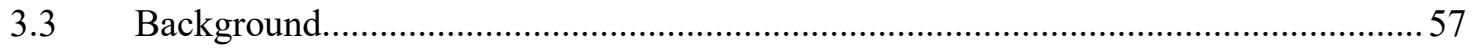

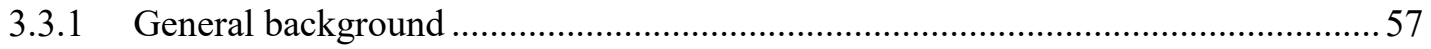

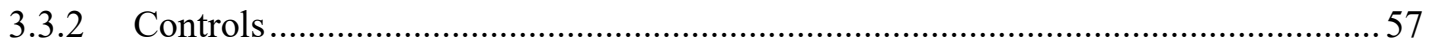

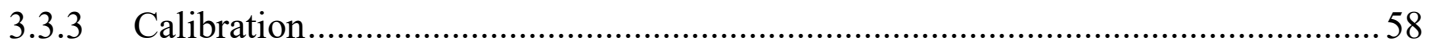

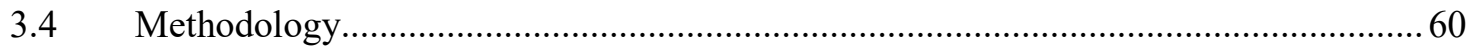

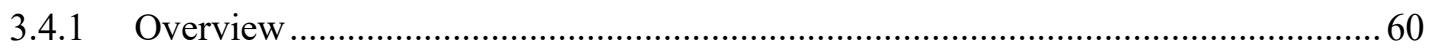

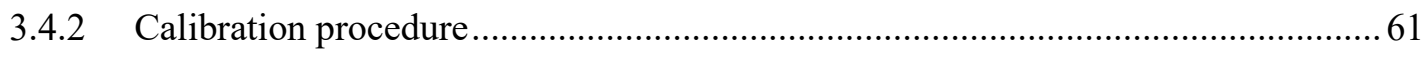

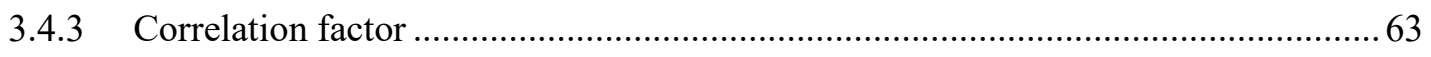

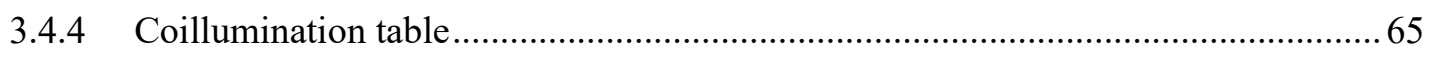

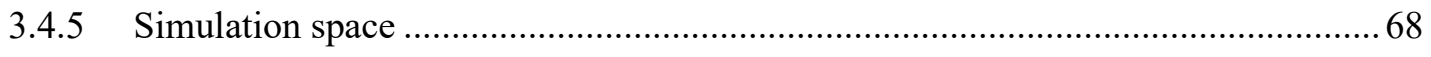




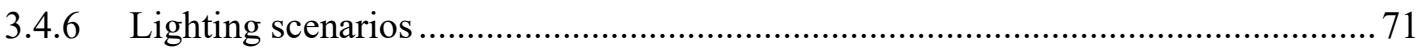

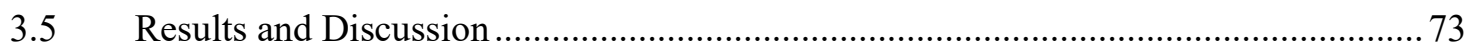

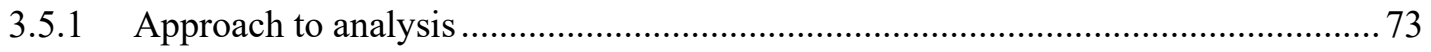

3.5.2 Correlation between workplane and ceiling illuminance levels ............................. 74

3.5.3 Determining correlation factors without workplane illuminance data ..................... 77

3.5.4 Coillumination table without workplane illuminance data .................................. 80

3.5.5 Comparison of conventional and automated calibration ...................................... 83

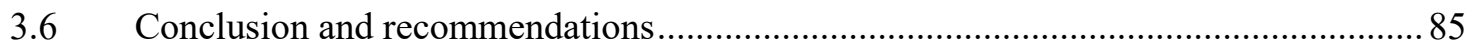

Chapter 4: Conclusion ...................................................................................... 87

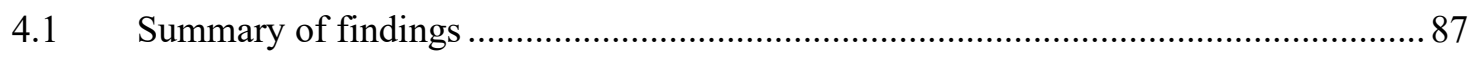

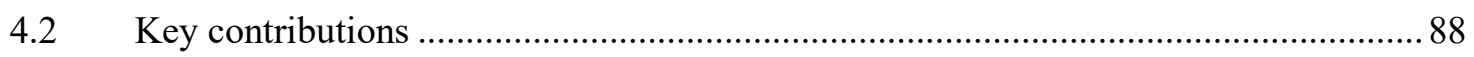

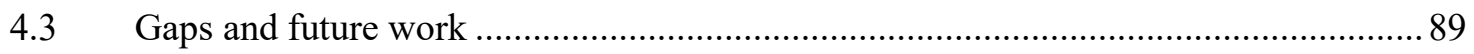

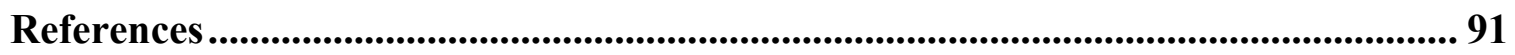




\section{List of Figures}

Figure 1.1, Nighttime illuminated office buildings …………....................................... 12

Figure 1.2, Prototype lighting system at Carleton University ……………………….... 15

Figure 1.3, Python simulated calibration process ………………….............................. 16

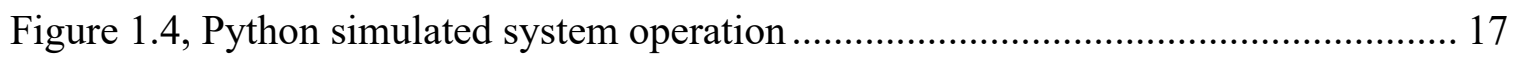

Figure 2.1, Simulation workflow for estimating annual energy savings .......................... 29

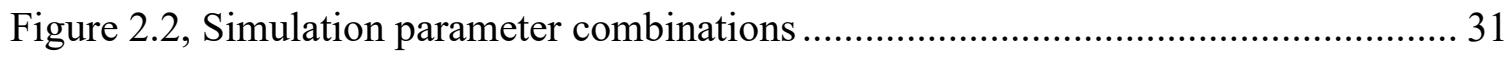

Figure 2.3, Geometry, occupancy, and workplane illuminance illustrations................... 32

Figure 2.4, NECB standard weekday occupancy schedule............................................ 33

Figure 2.5, Average global horizontal illuminance for Ottawa and Los Angeles ............ 35

Figure 2.6, Plan view of space divided into control zones ............................................. 37

Figure 2.7, Plot of results for all simulation permutations ............................................. 40

Figure 2.8, Simulation results presented as heatmaps .................................................... 41

Figure 2.9, Monthly plot of energy savings results ................................................... 42

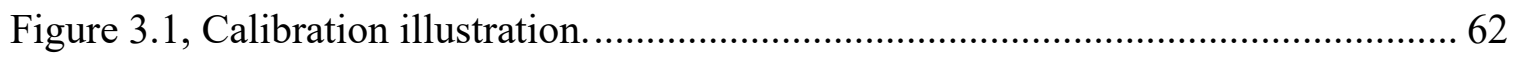

Figure 3.2, Flowchart describing the calibration procedure ……………………........... 65

Figure 3.3, DIALux evo rendering of simulation space ……….................................... 69

Figure 3.4, Floorplan with dimensions of simulation space ........................................... 70

Figure 3.5, Elevation view of simulation space with dimensions.................................. 70

Figure 3.6, Workplane illuminance due to daylight ....................................................... 72

Figure 3.7, Actual correlation between ceiling and workplane illuminance ................... 75

Figure 3.8, Correlation between ceiling and workplane illuminance ............................. 76

Figure 3.9, Conventional calibration process ……………......................................... 78 
Figure 3.10, Alternative calibration factors derived from the conventional calibration... 79

Figure 3.11, Automated calibration process ........................................................... 80

Figure 3.12, Error in estimating workplane illuminance in an automated calibration. .... 81

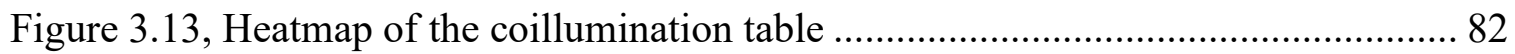

Figure 3.14, Error in the coillumination table from an automated calibration ................ 82

Figure 3.15 , Accuracy of conventionally and automatically calibrated systems............. 84 


\section{List of Tables}

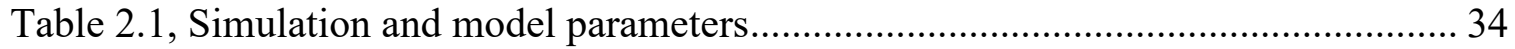

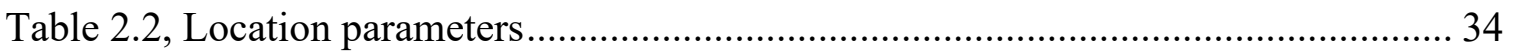

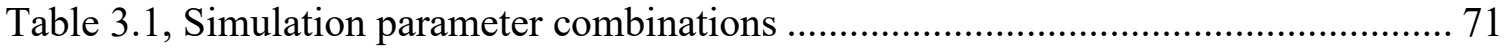




\section{Chapter 1: Introduction}

\subsection{Overview}

Adapting the built environment to be more energy efficient is a critical component of the broader goal of mitigating climate change. Providing sufficient illumination represents a large portion of the energy consumed by the built environment. In Canada, within the commercial and industrial sectors, lighting represents $14.5 \%$ of all energy use, and $31.6 \%$ of electricity usage [1]. The installation of more efficient lighting fixtures (particularly light emitting diode or 'LED' fixtures) in new construction or in retrofits has made, and continues to make, space lighting more energy efficient. To approach optimal efficiency and occupant comfort however, more efficient fixtures must also be more intelligently controlled. Inefficiencies in lighting control range in magnitude and complexity, and commercially viable solutions exist to solve some of the most glaring problems. Commonly, entire floors of office buildings are fully illuminated overnight despite sparse or zero occupation [2] (e.g., see Figure 1.1). Standards requiring the use of occupancy and illuminance sensors to prevent this kind of gross waste have been an important step forward. However, these systems, implemented at a very coarse spatial control resolution (typically an entire room) offer only a partial solution. More advanced controls operating at a higher spatial resolution can approach optimal lighting deployment and achieve significantly greater savings than coarse control.

Intelligent, high-resolution lighting control has the potential to generate significant energy savings and enhance occupant comfort [3]-[6]. Open-plan office spaces represent an ideal use case for such systems. Incumbent lighting solutions illuminate an entire space at one consistent level. Manual dimming, or dimming controlled by a single sensor for an entire space, offers some limited 
energy savings. However, greater savings may be attained by measuring illuminance and the presence of occupants in greater detail, up to the level of individual workstations. Utilizing an array of sensors collocated with luminaires provides the data required to control lights individually or in small clusters. If one portion of an open-plan office nearer to the façade is well illuminated by daylight but the rear of the room is not, only luminaires at the rear may be active. Similarly, if some workstations are occupied and others are not, only those luminaires in proximity to occupants are required to provide the desired workplane illuminance.

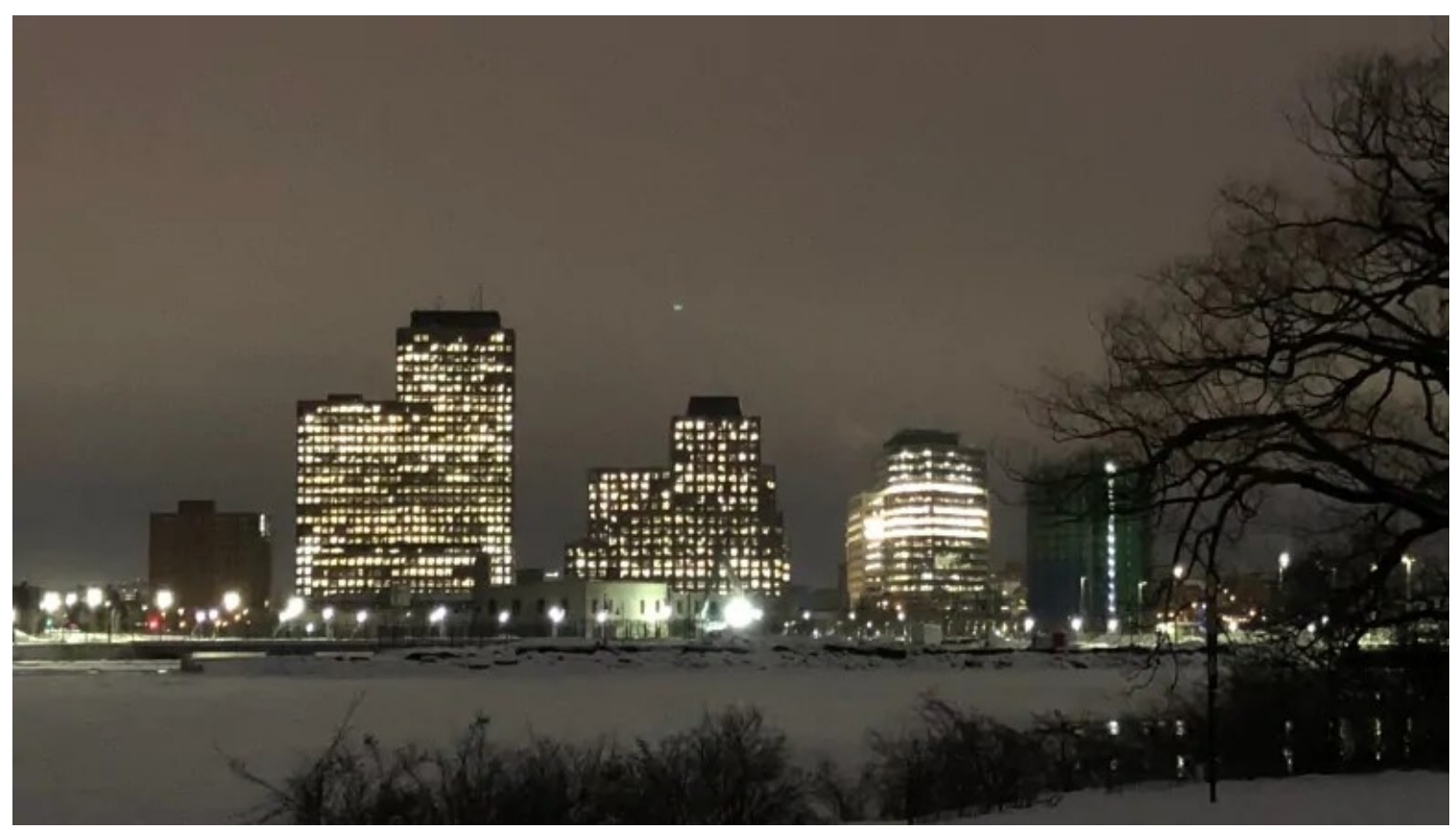

Figure 1.1, Government office buildings in Quebec illuminated despite sparse or no occupancy during the COVID-19 pandemic. (Chris Rands/CBC) 


\subsection{Background}

Sensor-array lighting systems operate by measuring occupancy and illuminance using sensors placed on the ceiling, which have a field of view restricted to their immediate area to localize readings. If an occupant is detected in a particular control zone, the luminaire in that zone and adjacent zones will dim to levels required to provide comfortable workplane and background illuminance to the occupant. Luminaires operate only at the intensities required to supplement available daylight at the workplane in each control zone, which is approximated by determining correlations between ceiling-mounted sensors and workplane illuminance. The determination of these correlations, and of the way each luminaire illuminates the entire space, are required for efficient centralized control, necessitating a calibration process.

Calibration involves measuring how illuminance at the ceiling and workplane change in response to each luminaire activating individually. A correlation between ceiling and workplane illuminance in each control zone, derived during calibration, is used during operation to estimate workplane illuminance using ceiling sensors. Measuring workplane illuminance directly during operation is ideal, but occupants will frequently obstruct or interfere with sensors on or near their desks. Calibration also provides the information required for the system to disaggregate workplane illuminance attributable to daylight from that due to electric lighting. This is necessary because systems controlled at a high-resolution rely on open-loop sensing, that is sensors which are placed indoors and thus measure both electric light and daylight. By understanding how each illuminance sensor reacts to each electric light, an intelligent system can subtract the expected contribution of each light from a sensor's reading and estimate the remainder to be the illuminance attributable to daylight. 
Once calibrated and operational, the amount of energy a system will save is dependent on several factors. A greater proportion of the space with significant daylighting will result in fewer luminaires being deployed, and at lower dimming settings. Fewer occupants will mean that less of the room must be illuminated at all. Controlling at higher resolutions will ensure that lighting is only deployed exactly where it is needed in exactly the amounts it is required. The more accurately a system is calibrated, the less it will underestimate workplane illuminance and subsequently deploy too much electric lighting - or worse, overestimate it and deploy too little. Understanding the factors governing how savings are achieved and optimizing those factors that are within a designer's control are active areas of research.

\subsection{Preamble}

The work that would eventually culminate in this thesis began when Carleton University was approached by a private lighting company to partner in the development and evaluation of a commercial intelligent lighting system. I was selected by my supervisors, Professors Burak Gunay and Liam O'Brien, to represent Carleton in this partnership. In this capacity I was assigned two primary responsibilities. First, I was to design and implement a control algorithm to take readings from illuminance and occupancy sensors collocated with LED luminaire panels and deploy lighting accordingly. Second, once the system was installed, I would run a series of experiments to ensure proper operation and quantify energy savings relative to established baselines. Figure 1.2 shows some of the lighting controls hardware during installation.

The lighting system utilized a power over ethernet connection for each luminaire. This enabled communication between luminaire controllers and the centralized control system, and provided power without requiring licensed electricians for installation. Once the project was 
cleared after acquiring necessary approvals from the Office of Research Ethics, Information and Technology Services, Facilities Management and Planning, and the Privacy Office, a demonstration system was installed on the campus of Carleton University in February of 2019. Further time was however required to resolve hardware and firmware problems and implement full sensing capability. Unfortunately, the arrival of the COVID-19 pandemic precluded experimentation and evaluation of the installed system for this thesis. For this reason, we decided to shift research efforts to simulated experiments while campus facilities remained inaccessible.

(a)

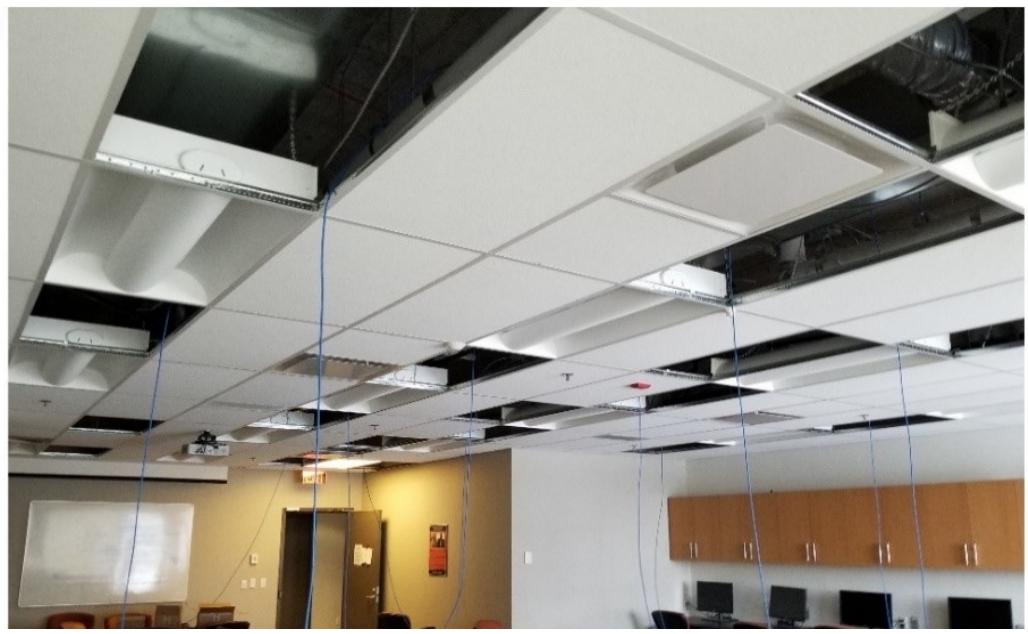

(b)

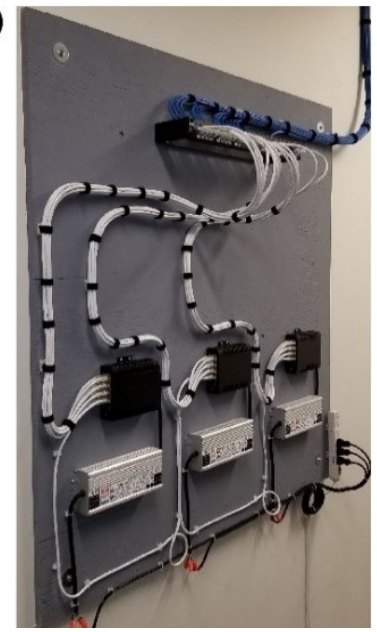

Figure 1.2, Demonstration installation of the prototype lighting system at Carleton University campus, (a) the drop ceiling in the installation space with panels removed to make space for LED luminaire panels, ethernet cables are visible in each luminaire position, and (b) the power over ethernet distribution system adjacent to the demonstration space.

In parallel to the experimental facility and to accelerate the development of a control algorithm for the commercial lighting system, I produced a simulated environment in which I could prototype and evaluate control solutions. This environment, using Python, enabled the development of a more advanced understanding of the elements involved in intelligent control of 
lighting systems utilizing a high-resolution sensor array. A calibration procedure (Figure 1.3) that could produce the data required for my control algorithm (Figure 1.4) to operate was developed.

The physics-based simulation I created served only as a prototyping environment, and included several simplifying assumptions. All luminaires and daylight were treated as directional point sources with intensities proportional to the cosine of the angle from normal. Daylight was modelled by creating several sources spaced along the window oriented horizontally. The floor was divided into a grid of $25 \mathrm{~cm} \mathrm{x} 25 \mathrm{~cm}$ segments, each of which tallied total workplane illuminance by summing the contribution of all light sources. Ceiling sensor measurements were then calculated by the same method, by treating each floor segment as perfectly Lambertian or ideally diffusing and approximating it as a point source, with intensity again proportion to the cosine of the angle from normal.
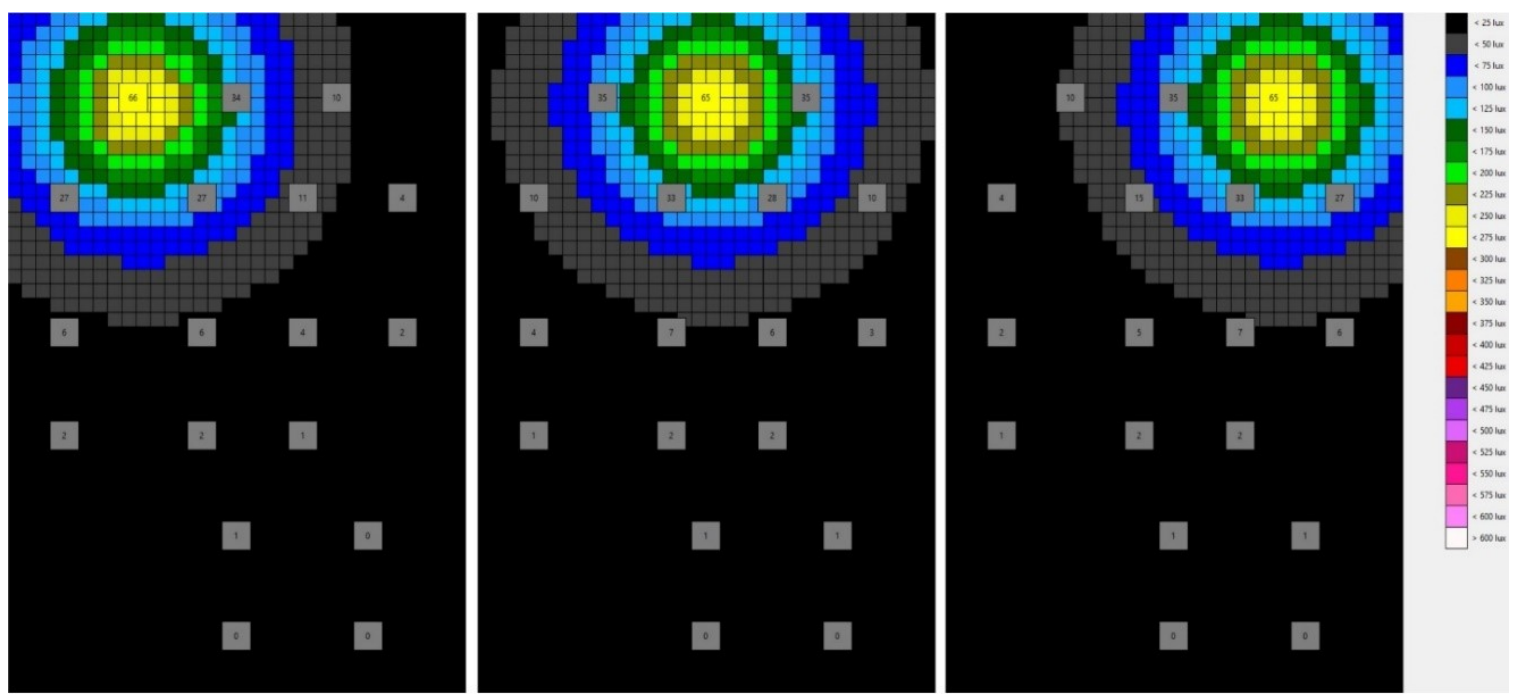

Figure 1.3, Python simulation of the calibration process for a sensor-array lighting system. Each luminaire is activated in sequence, one at a time. The change in illuminance at every sensor is recorded at each step of the sequence. This data is used to correlate workplane and ceiling illuminance to one another, and to build a coillumination table - a matrix that describes the expected change in each photosensor reading after activating a luminaire on every lighting zone in the space. 


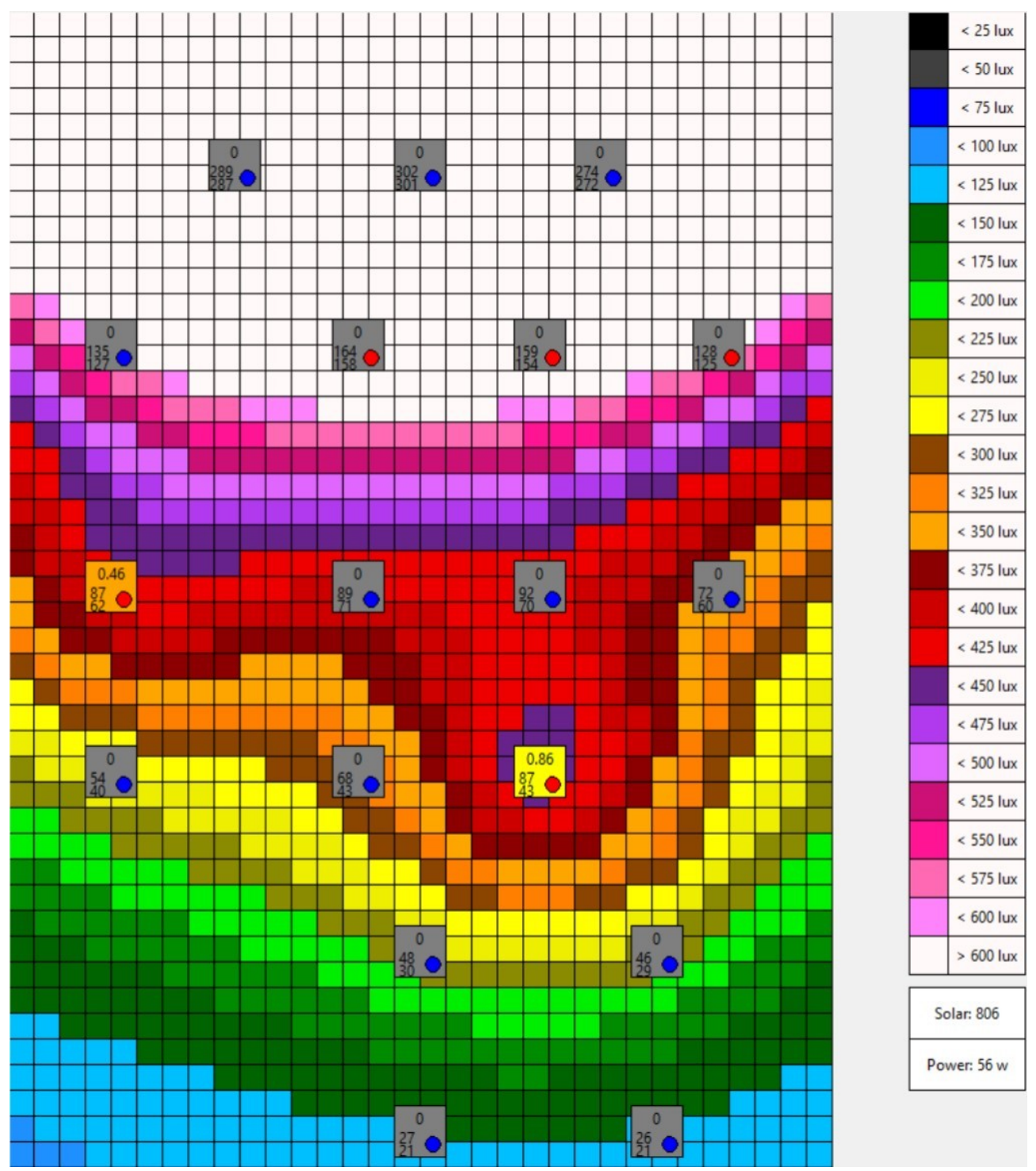

Figure 1.4, A simulation of lighting system response to daylight and occupancy. Within each square (representing a luminaire) a red circle indicates occupancy, the top value indicates luminaire dimming from 0 to 1 , the middle number represents actual ceiling illuminance, and the bottom number represents predicted ceiling illuminance. Due to significant daylight entering the room from the façade at the top of the figure, only two luminaires are active - the two that are both occupied and distant from the window. Smaller colored squares measure workplane illuminance. 
This simulation provided a good prototyping environment but was much too simple for research-grade simulation studies. More advanced simulation tools that include multiple reflections, full room geometry, can accurately model daylight, and which do not approximate surfaces as perfectly diffusing were required. Two tools, each having respective strengths and weaknesses, were utilized. DAYSIM is a tool designed to evaluate annual daylight availability powered by the RADIANCE engine. It can quickly and efficiently calculate the distribution of direct and reflected daylight in a space at sensor positions defined by the user [7]. DIALux evo is a lighting design software with a full graphical user interface. It allows the user to reproduce spaces in great detail and utilizes ray tracing calculations [8]. The cost of this greater precision is much higher computation time relative to DAYSIM.

\subsection{Research objectives and questions}

Advancing the understanding of intelligently controlled sensor-array lighting systems is the subject of this research. Given that commercial implementation of such systems is not yet a reality, developing an understanding of their potential, and of methods to enhance their practicality are considered. The inquiries posed by this thesis are broken down by chapter as follows:

- Energy savings potential of high-resolution control (Chapter 2)

○ How does control resolution impact savings?

○ How does partial occupancy impact savings?

- Which daylighting conditions are most conducive to effective daylight harvesting?

○ How do savings vary between zones within a given space? 
- Viability of automated calibration (Chapter 3)

- How variable is the correlation between ceiling and workplane illuminance?

- Can a reasonably accurate correlation between ceiling and workplane illuminance be derived without workplane sensors?

- Can a reasonably accurate understanding of how lighting zones assist in illuminating one another be derived without workplane sensors?

○ Is an automated calibration process a viable alternative to manual calibration?

This goal of this thesis is to demonstrate that sensor-array lighting systems are very effective in generating savings across all common scenarios, and that they can be installed reliably and economically. This work should help to provide a foundation for further economic analysis that demonstrates broad applicability and provokes greater commercial interest leading to wide adoption.

\subsection{Document structure}

This thesis is comprised of two interrelated studies designed to advance the understanding of smart, high-resolution lighting systems for open-plan offices. The study topics emerged based on gaps from the literature and technology and were also inspired by the design process of the experimental implementation at Carleton. The studies are written as journal manuscripts and thus are largely self-contained. For this reason, most of the literature review is described in each chapter.

Chapter 2 is the first study, Simulating energy savings potential with high-resolution daylight and occupancy sensing in open-plan offices, which was published in Journal of Building Performance Simulation in August 2020. The study began when, through literature review, a gap 
was identified in the understanding of sensor-array lighting system potential, particularly in identifying the circumstances in which they may provide the greatest benefit. Several studies quantified energy savings, but these studies varied significantly in how they approached lighting control, how rooms were laid out, and how savings were calculated. By providing a standardized environment and varying parameters systematically, this chapter develops a guide for understanding how, why, and when sensor-array lighting is most effective.

Chapter 3 is the second study, Evaluating sensor calibration of high-resolution daylightcontrolled lighting in open-plan offices. In all existing research on advanced lighting systems that was reviewed, including Chapter 2, there was a common requirement for manual calibration. To operate at full efficiency, intelligent controls need to be able to correlate ceiling-mounted sensors to workplane illuminance, and to understand how lighting zones interact with one another. The costs and labour associated with this manual calibration make sensor-array lighting systems a more difficult economic proposition. This chapter considers the viability of an automated calibration process that can be performed freely and at regular intervals. The intricacies and inherent uncertainty of system calibration and operation are explored, and the relative performance of lighting systems calibrated manually and automatically is considered within the context of that inherent uncertainty.

Chapter 4 summarizes findings from both of the studies that comprise this thesis. Recommendations based on these results are provided, and recommendations for future work are described. 


\section{Chapter 2: Simulating energy savings potential with high- resolution daylight and occupancy sensing in open-plan offices}

\section{This chapter has been published as:}

D. Lowcay, H. B. Gunay, and W. O’Brien, "Simulating energy savings potential with highresolution daylight and occupancy sensing in open-plan offices,” J. Build. Perform. Simul., vol. 13, no. 5, pp. 606-619, 2020, doi: 10.1080/19401493.2020.1807604.

\subsection{Introduction}

The implementation of lighting in open-plan offices today almost exclusively employs relatively coarse, room-level controls. Controls may be manual switching by occupants or maintenance staff, or automatic based on a set schedule. In more sophisticated systems, an occupancy sensor deactivates lighting if no movement is detected for a predetermined timeout period (generally 15 to 30 minutes) [9]. Moreover, though less commonly, an illuminance sensor may be utilized as an input to dim luminaires in perimeter spaces where useful daylight is adequate [10]. However, in open-plan offices, room-level control is unable to account for partial occupancy and spatial variability of daylight because light must be provided for the worst case (e.g. occupied cubicle far from windows).

Providing fine-grained lighting control zones equipped with an array of occupancy and illuminance sensors has emerged as an approach to address the inefficiencies of room-level control in open-plan offices. Sensor array networks measure occupancy and illuminance in real-time at individual desk level to dim or deactivate individual luminaires. A sensor array is less likely to fail to detect a present occupant because of the improved coverage; each sensor has a clearer line of sight and is closer to the occupants it is responsible for detecting. Arrays of occupancy sensors can 
therefore reduce the timeout period from between 15 and 30 minutes to as low as one to five minutes while simultaneously reducing the rate of false-negative occupancy [5], [11], [12]. Reducing the timeout period is a key factor in lighting energy conservation [5], [13]-[15]. While multiple sensors have been used to ensure accurate occupancy detection in single occupant private offices [11], the primary application for sensor arrays is in open-plan office spaces - especially those with partial occupancy and/or irregular occupancy patterns.

\subsubsection{Luminaire and sensor hardware}

Sensor array lighting systems generally utilize LED type luminaires which offer variable dimming and (unlike fluorescent bulbs) do not suffer reductions in service life due to frequent switching [16]. Panel or troffer light fixture types are installed where designers wish to spread the output of a fixture over a wide area. Conversely, downlights may be installed where concentrating the output of the fixture to the area directly underneath it is preferable. The latter option allows a designer to tightly target lighting energy to where it is required, the former provides more uniform illumination.

Unlike conventional wide-angle occupancy and illuminance sensors which are designed to see as much of the room as possible, the sensor arrays used in these systems localize readings by restricting each sensor's field of view so only data that is relevant for a given luminaire is utilized [5]. Passive infrared (PIR) sensors are most commonly installed, however ultrasonic sensors have also been used successfully [17].

\subsubsection{Controls}

The problem of how to optimize controls for high-resolution sensor-array lighting systems has been studied extensively [18]-[22]. Open-loop control approaches in which only daylight is 
measured (typically via a single sensor located on the façade) are not appropriate for highresolution lighting systems. Instead a closed-loop method is employed in which sensors (located throughout a space) measure the combined effect of both daylight and electric lighting. When daylight and occupancy conditions change, these systems go through a period of adjustment and correction to seek a dimming configuration appropriate to the new scenario [23]. Centralized, distributed, and isolated controls have been explored [24], [25]. Enabling communication between luminaires allows them to account for and assist one another to further improve efficiency and reduce the time required for the system to settle into a stable dimming configuration. Several studies have been published on the value of allowing control zones to communicate with each other directly, and of aggregating data from all sensors for central control. Distributed controls that still communicate data between zones are only marginally less effective than centralized control. In a simulation study with 16 zones, Wang et al. [26] found that inefficiencies caused by distributed control lead to an average of less than $4 \%$ higher power usage relative to centralized control. Van De Meugheuvel et al. [27] simulated an open-plan office utilizing DIALux software across 1560 scenarios and found an average difference in power consumption of less than $10 \%$ between networked and isolated controls.

The use of wireless sensors has been studied in [28]-[30]. Li et al. [30] used these sensors to study a closed-loop feedback neighbour-aided control approach, where the system was exposed to varying lighting conditions and its ability to quickly reach a stable configuration without overshooting illuminance targets was demonstrated. Pandharipande and Caicedo [31] reviewed control studies and illustrated that under-illumination can occur when luminaires are not able to communicate with and assist one another. Pandharipande and Caicedo also discuss the importance 
of correlating workplane and ceiling level illuminance with a calibration step. The level of illumination reaching a ceiling-mounted sensor is partially a function of the reflectance of the objects below it, which has the potential to change as furnishings are moved or replaced. The correlation between workplane and ceiling level illuminance may, therefore, have to be retuned periodically. More advanced control techniques which learn the behavior of individual occupants [32] or employ artificial neural networks to find optimal dimming configurations [33] have been tested, but lie beyond the scope of the present study.

\subsubsection{Occupant comfort}

Occupant comfort with sensor-array lighting systems is evaluated primarily with regards to direct occupant control and illuminance uniformity. Care must be taken to ensure occupants do not become dissatisfied with smart lighting systems, in which case users may circumvent or disable intelligent controls entirely [4], [34]. An ideal, universally applicable solution is difficult to obtain, as occupants often have different preferences or sensitivity to lighting levels and uniformity [35]. Some occupants may also be technically more proficient than others, and thus better equipped to interact with a more sophisticated system. One of the earlier studies of sensor array lighting systems [19] included user preference as a component of its control algorithm and found that after an initial selection, occupants rarely interacted with controls. Another field study [36] performed a lighting retrofit which granted occupants individual control of their lighting and found energy savings of $40 \%$ as well as a user preference for the new system. de Bakker et al. [37] studied the importance of uniformity of workplane illuminance in a controlled experiment by comparing nine scenarios in terms of both occupant acceptance and energy savings. In these scenarios, 68 to $84 \%$ of users reported being comfortable with non-uniform illuminance in the space. The scenarios with 
lower uniformity (and thus higher energy savings) were rated among the most comfortable. The scenario with $70 \%$ brightness in the surrounding area and $1 \%$ brightness in the background (the second most non-uniform configuration) achieved 65\% energy savings (the second highest savings) while achieving the highest average overall liking. As argued in [38], if such energysaving lighting systems are to be commercially viable, occupant comfort must be maintained or improved. Further research is required to study user sensitivity to lighting levels that readjust their dimming configuration regularly to optimize savings.

\subsubsection{Energy savings from daylight harvesting and occupancy sensing}

The relative importance of each component of sensor-array lighting systems (occupancy detection and daylight harvesting) has been quantified within the constraints of a single fixed environmental circumstance (glazing ratio, room orientation, etc.) in several studies. A comprehensive review article [3] provides a summary of energy savings found in each study, broken down into those that utilized only occupancy sensing, only daylight harvesting, and both. Occupancy-based systems are found to save anywhere from 3\% to $50 \%$ lighting energy in regular usage occupancy scenarios (such as fixed desk office space), and $17 \%$ to $60 \%$ in irregular occupancy scenarios (such as lecture halls and breakout spaces). Energy savings are found to be strongly correlated with a reduced timeout period before lights are automatically switched off. Daylight-linked systems are found to save between $20 \%$ and $92 \%$ lighting energy. Systems that combine both components are found to save $13 \%$ to $73 \%$ energy in offices. Galasiu et al. [39] found in a field study involving 86 workstations over one year that occupancy sensing systems yielded 35\% energy savings and, separately, daylight-harvesting systems saved 20\%. Dikel et al. performed a combined experimental and simulation study and determined that a reduction in 
timeout period enabled by the occupancy-sensor array from $20 \mathrm{~min}$ to $1 \mathrm{~min}$ resulted in $26 \%$ electricity savings. Separately, an array of daylight harvesting sensors generated $35 \%$ savings relative to a single room-level sensor. Combining both occupancy-sensing and daylight-harvesting then yielded a total of $79 \%$ savings [5].

As acknowledged by these studies, the range of energy savings reported is large, and the reasons for these discrepancies are not well understood. Both occupancy sensing and daylight harvesting technologies are very context-sensitive - any given set of occupancy, daylighting, glazing, room geometry, and sensor resolution conditions may yield dramatically different energy savings. Real-world experiments and simulation studies have also generated results inconsistent with one another. As reported in Chew et al. [3]'s review article, daylight-linked systems were found to save $40 \%$ to $92 \%$ in simulation studies versus $20 \%$ to $61 \%$ in real-world experiments.

\subsubsection{Sensor resolution}

Sensor resolution or zone sizing is a significant factor in the performance of sensor-array lighting systems. A review of studies employing occupancy-sensing [38] includes a breakdown of minimum and maximum energy savings categorized by sensor resolution. Energy savings are reported only for studies which employed occupancy-sensing alone (with no daylight harvesting). Counterintuitively, similar maximum energy savings are found regardless of sensor resolution. In fact, the three studies with the greatest savings utilize either zone or room control, rather than sensors for individual workspaces. The authors concluded that the significance of all other uncontrolled variables in system performance confounds these results, and that more work is required to isolate the importance of sensor resolution in energy savings. de Bakker et al.[15] examined occupancy sensor resolution by simulating a variety of occupant types (managers, sales 
representatives, etc.). The study found that with a strict office attendance policy savings of $\sim 40 \%$ are observed with desk level control, $\sim 20 \%$ at the subgroup level, and just over $10 \%$ when sensing is at the room-level. A 2019 simulation study [6] systematically broke down the importance of sensor resolution (as well as relative occupancy) with regards to lighting controls. Four occupancy scenarios were considered as the number of cubicles per lighting zone are continuously increased. All occupancy scenarios were found to converge towards (but due to timeouts, not quite achieve) a 1:1 relationship between occupied time and lights-on time as sensor resolution approaches one cubicle per lighting zone. In the case of the $60 \%$ occupancy scenario for example, approximately double the savings were observed when each cubicle has its own sensor, relative to five cubicles per sensor. This study did not however include simulations for daylight harvesting or dimmable lighting.

\subsubsection{Objectives}

The objective of the current chapter is to develop and apply a simulation workflow to estimate the potential energy savings of sensor-array lighting systems. The forty-eight scenarios simulated are used to quantify the relative importance of occupancy-sensing, daylight-harvesting, and sensor resolution under a variety of occupancy and daylight conditions. By applying this workflow with a custom set of simulation parameters, readers may estimate the potential effectiveness of a sensor-array lighting system within the context of their built or proposed openplan office space. Within the remainder of this chapter the simulation methodology will be described in detail with justification for experimental design decisions. Simulation results will then be presented to assist the reader in understanding the workflow of the current study and developing a frame of reference for potential energy savings. 


\subsection{Methodology}

This section describes the simulation framework (Figure 2.1) and the study to which it is applied: (1) Fixed and variable simulation parameters are defined to outline the scope of the study. (2) DAYSIM provides the illuminance at each cubicle (in a grid pattern) in the building at fiveminute timesteps during the year. (3) Similarly, MATLAB stochastically generates five-minute resolution occupancy patterns for each cubicle by using Page et al. [40] occupancy modelling approach. (4) Window shades are controlled to simulate occupants who close shades under glare circumstances. (5) Daylight and occupancy data are then replicated and processed to simulate lower sensor resolution scenarios. (6) Next, a MATLAB script simulates the controls by determining whether the lights over each cubicle should be on, off, or dimmed for each timestep of the year, depending on occupancy, daylight availability, and sensor configuration. (7) Energy savings are reported against a baseline case and (8) the process is repeated ten times to confirm model consistency. The value of ten was found to be adequate to consistently quantify the mean and variance of the simulations. With the exception of stochastically generated occupant profiles the process is deterministic and replicable. Annual energy savings relative to a simple reference case can then be calculated as a function of occupancy and illuminance data. 


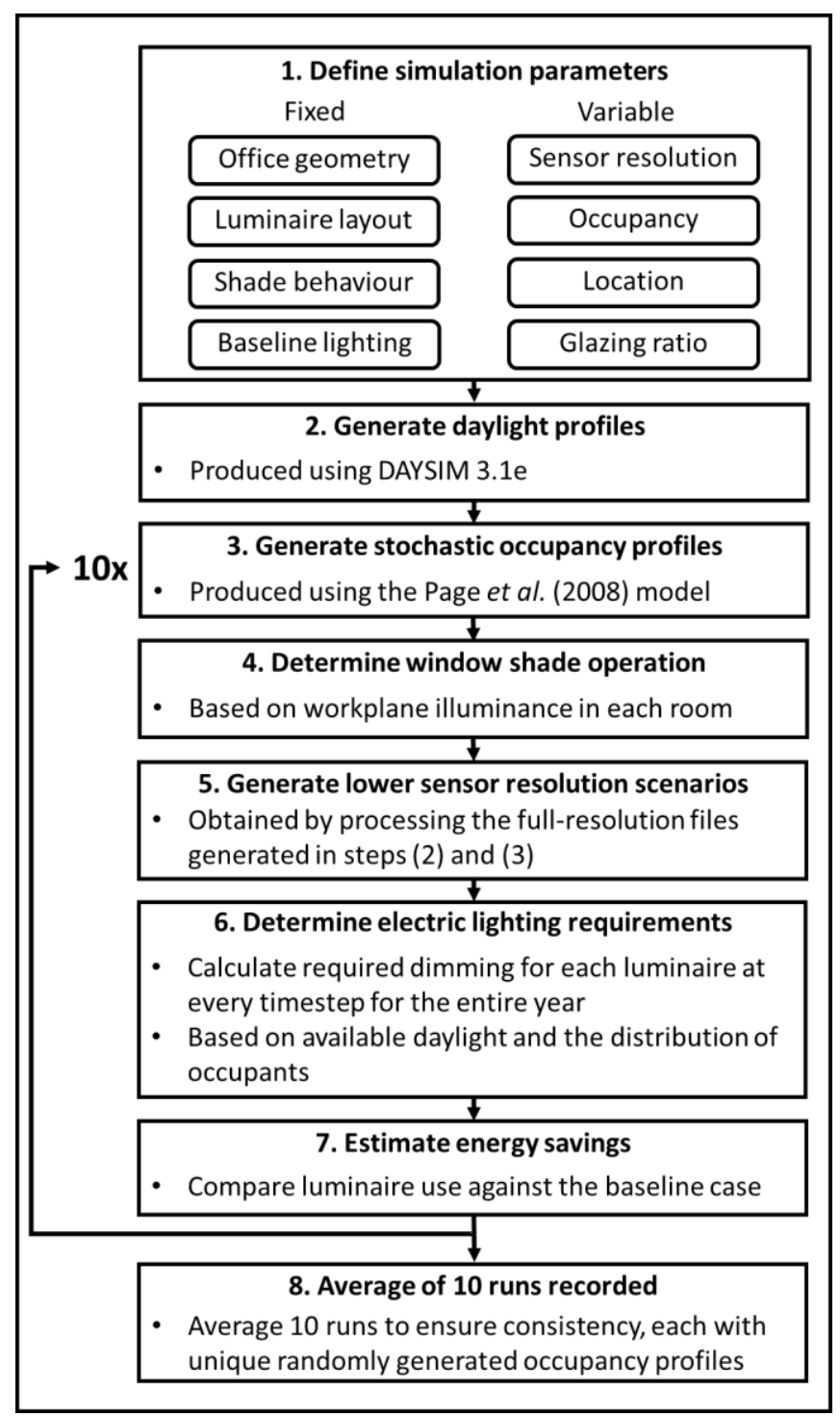

Figure 2.1, Overview of simulation workflow for estimating annual energy savings. All processes besides the generation of daylight profiles in DAYSIM were performed in MATLAB.

\subsubsection{Simulation space}

To illustrate the simulation framework, the example space is first described. The space consists of a single floor of an office building with continuous glazing around the perimeter, 
oriented along the cardinal directions. External shading from adjacent buildings or foliage is not present. The building has a square floorplate with each side measuring 24 meters. The space depicted in Figure 2.3.(a) is divided by full-height opaque partition walls into nine equally sized square rooms eight meters across, with a ceiling height of three meters. The perimeter and core spaces are all considered in the analysis. A rule of thumb for useful daylight penetration is 2.5 times the window head height [41]. In the current study the window head is located at the ceiling three meters above the floor, yielding an estimated 7.5 meters of daylight penetration - greater than $90 \%$ of the area of perimeter rooms. Dividing the floorplate into nine rooms allows for the collection of energy savings data that varies based on room orientation and glazing properties. There are four rooms with only one window, four corner rooms with two windows, and a core space that has no contribution from daylight harvesting and therefore isolates the effect of occupancy sensing.

A simple room layout is selected to represent one typical floorplate for an open-plan office. The corridors between cubicles are not explicitly modelled, but are assumed to be included within the square-shaped lighting control zones. The simulation workflow described in the current study may be applied to any floorplan that may be modelled using DAYSIM. Each room is an open-plan office consisting of 16 workstations divided by short cubicle walls one meter in height, each of which is equipped with a luminaire and co-located illuminance and occupancy sensors.

Figure 2.2 describes the variations to which the simulation framework described in Figure 2.1 is applied. In all, three levels of sensor resolution, four occupancy scenarios, two cities, and two window sizes were simulated - for a total of forty-eight combinations. Moreover, the analysis was performed for nine different orientations (described later). The range of simulation parameters is 
selected to represent a breadth of plausible scenarios. The simulation scenarios are not exhaustive, covering only a subset of possible configurations, but the methods described in the current study provide a framework that can be applied to evaluate any other scenario in the future.

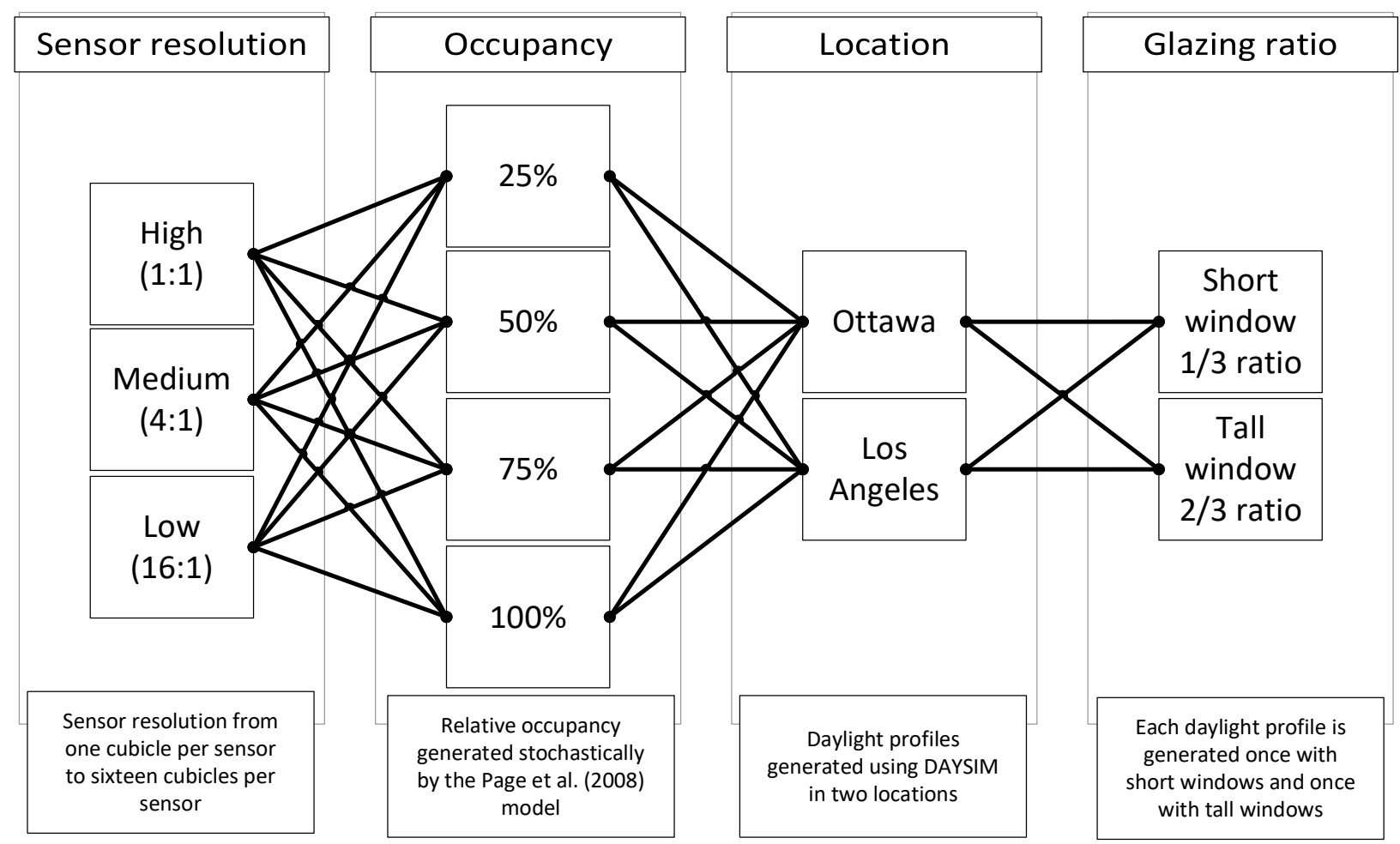

Figure 2.2, Forty-eight simulation parameter combinations of three sensor resolutions, four occupancy scenarios, and four daylight scenarios (comprised of cities and window sizes) used to simulate energy savings through a light utilization model.

\subsubsection{Occupant modelling}

Four occupancy profiles are generated to randomly distribute a $25 \%, 50 \%, 75 \%$, or $100 \%$ ratio of the National Energy Code of Canada for Buildings standard schedule [42] (Figure 2.4) across the entire floor of the office building. This schedule specifies typical office occupancy at an hourly timescale from $0 \%$ to $100 \%$ occupied. An inhomogeneous Markov chain model developed by Page et al. [40] and also utilized in by O'Brien et al. [6] was implemented, generating 
a unique annual occupancy schedule for each cubicle. Occupancy in each timestep is calculated based on predefined model constants, occupancy in the previous timestep, and the remaining duration of absences carried forward from the previous timestep and decremented. Occupants are modelled to have no preference for any lighting condition or space type (i.e., their location is independent of daylight levels). Additionally, each cubicle is an individual workspace and may only be occupied by one person at a time, i.e. the number of occupied cubicles is equal to the number of workers on the floor. Paths between cubicles (e.g. between the elevator and cubicle) are not considered because these periods are short compared to the time spent in cubicles. The stochastic nature of the occupancy model yields a different result with each run; the resulting variation was tested with the results presented in Section 3.7.
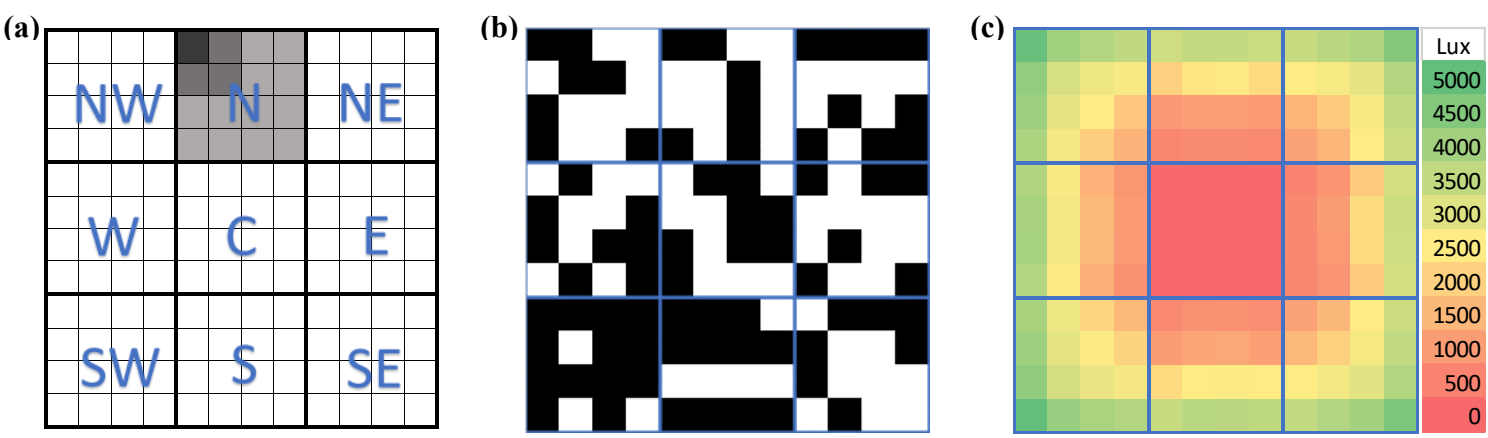

Figure 2.3, (a) Diagram of simulation space divided into nine rooms with orientation and cubicle distribution indicated. Three sensor resolutions considered are denoted by shade in the north room. (b) Illustrative plot of $75 \%$ occupancy distribution at the cubicle level where black indicates occupied. (c) Visualization of measured workplane illuminance in each cubicle. Note that core space receives no daylight. 


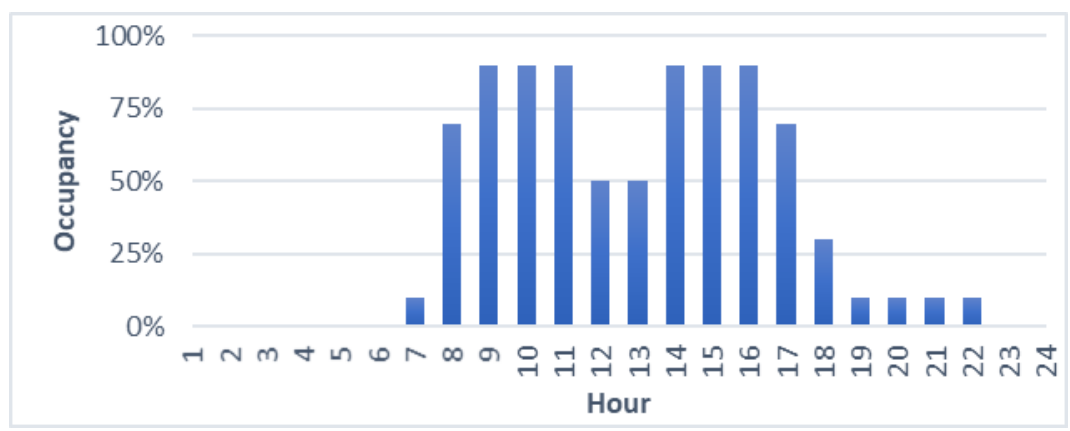

Figure 2.4, The NECB standard weekday occupancy schedule, where 16 hours have at least partial occupancy. No occupancy is observed on weekends.

\subsubsection{Daylight modelling}

The distribution of daylight in each room was modelled using DAYSIM 3.1. For each of the sixteen cubicles per room (for all nine rooms), an illuminance sensor was placed at a workplane height of 0.8 meters in the center of the cubicle to record illuminance at five-minute intervals for one year. This process was repeated four times - at two geographic locations with two window sizes. The building is located either in Los Angeles or Ottawa, selected for their difference in latitude and climate. Los Angeles experiences a higher solar elevation angle and more intense daylight. Ottawa on the other hand has more overcast days and a lower solar elevation angle. Window heights of either two meters ( $67 \%$ glazing ratio) or one meter ( $33 \%$ glazing ratio) are simulated, with the top of the window located at the ceiling. These represent the widest spread in realistic glazing ratios achievable without exceeding two possibilities. In real-world implementations of daylight harvesting systems, illuminance sensors are generally located on the ceiling for practicality and to prevent occupants from obstructing them, then correlated to 
workplane illuminance via a manual calibration. Note that core space receives no daylight and relies on occupancy-detection alone to conserve energy.

DAYSIM was used to generate lighting profiles using the parameters noted in Table 2.1, which correspond with the DAYSIM default pre-set \#1. Daylight autonomy and daylightharvesting systems have been shown to be sensitive to internal reflectance values [43]. Furnishings and objects like computer monitors, posters, plants, cabinets, etc. have a cumulative impact on the average reflectance values for indoor surfaces. The impact of these features was neglected in the current study - excepting one-meter tall cubicle walls included between each workstation. An exterior ground reflectance value of 0.2 is specified for both Los Angeles and Ottawa - the presence of snow cover in Ottawa is not included as a dense urban setting is expected for a typical open-plan office space, where snow is cleared from the surroundings [44].

\section{Table 2.1}

DAYSIM 3.1e RADIANCE simulation and model parameters

\begin{tabular}{|l|l|l|l|}
\hline Ambient bounces & 5 & Direct jitter & 0.0000 \\
\hline Ambient divisions & 1000 & Direct sampling & 0.200 \\
\hline Ambient super-samples & 20 & Direct relays & 2 \\
\hline Ambient resolution & 300 & Direct pretest density & 512 \\
\hline Ambient accuracy & 0.1 & & \\
\hline Limit reflection & 6 & Glazing transmittance & 0.65 \\
\hline Specular threshold & 0.1500 & Ceiling reflectivity & 0.6 \\
\hline Specular jitter & 1.0000 & Floor reflectivity & 0.2 \\
\hline Limit weight & 0.004000 & Wall reflectivity & 0.4 \\
\hline
\end{tabular}

\section{Table 2.2}

Location parameters

\begin{tabular}{|l|l|l|}
\hline & Los Angeles & Ottawa \\
\hline Latitude & $33.93^{\circ}$ & $45.32^{\circ}$ \\
\hline Longitude & $-118.40^{\circ}$ & $-75.67^{\circ}$ \\
\hline Site elevation & $32.0 \mathrm{~m}$ & $114.0 \mathrm{~m}$ \\
\hline Peak solar elevation angle & $79^{\circ}$ & $68^{\circ}$ \\
\hline Summer solstice day length & 14 hours $26 \mathrm{~min}$ & 15 hours $40 \mathrm{~min}$ \\
\hline Winter solstice day length & 9 hours $53 \mathrm{~min}$ & 8 hours $43 \mathrm{~min}$ \\
\hline
\end{tabular}




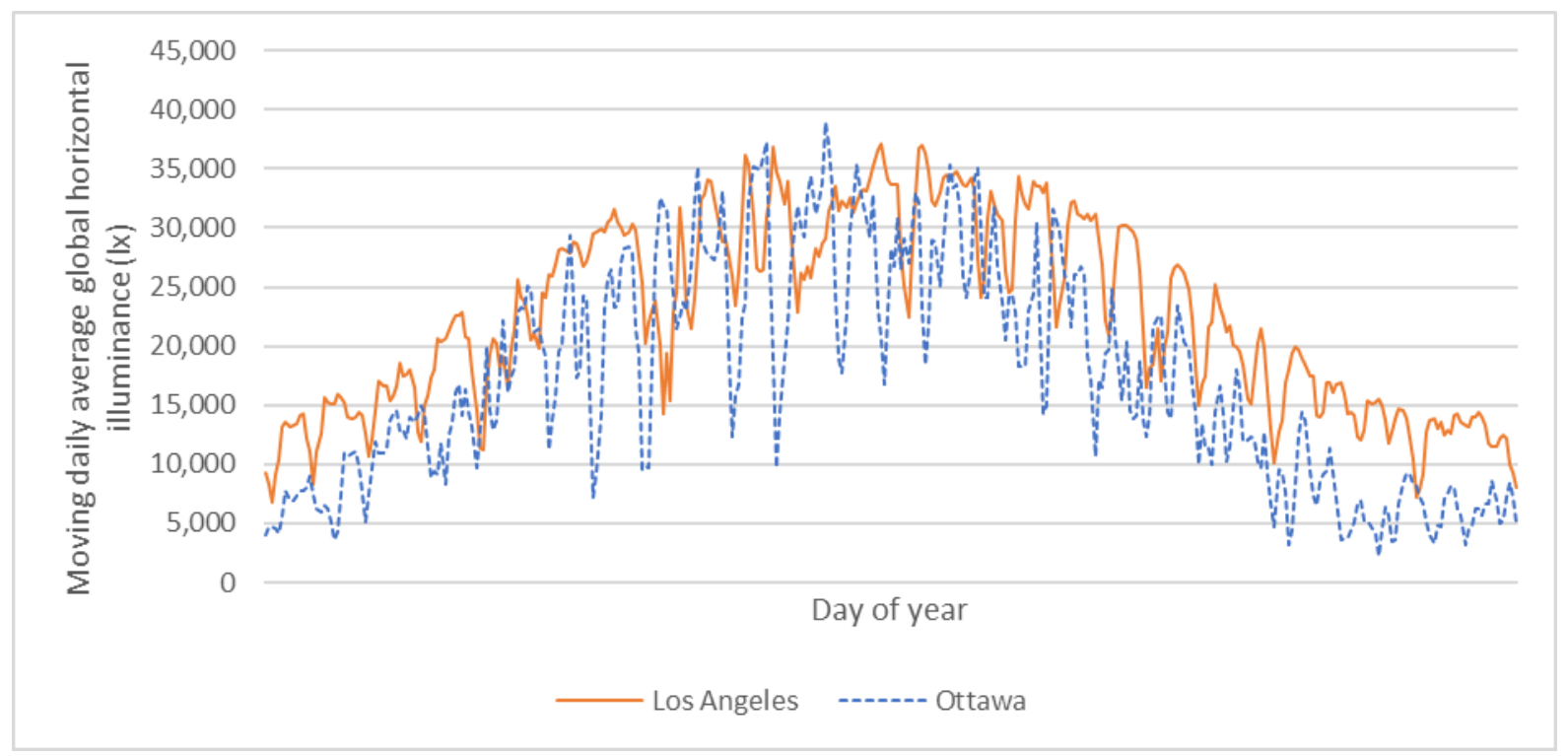

Figure 2.5, Moving daily average global horizontal illuminance for Ottawa and Los Angeles in EPW weather files utilized in simulation. Los Angeles receives approximately $30 \%$ more daylight than Ottawa over the course of one calendar year. Daily average values are taken over twenty-four hours, and the moving average includes the previous two days.

\subsubsection{Window Shades}

User operable window shades are included and are modelled to mimic the behavior observed in open-plan offices. If workplane illuminance exceeds $2000 \mathrm{~lx}$ in any occupied cubicle, the occupants are assumed to draw all shades in the room for the remainder of the workday, to prevent glare. Shades are fully raised automatically before occupants arrive the next morning (similar to [45], [46]). The net effect would be effectively the same if the occupants opened the shades immediately upon arrival or if the cleaning staff opened the shades before regular occupancy. This implementation is based on the fact that occupants generally do not make frequent adjustments to optimize accessible building controls (such as operable shades) for comfort or energy [47]-[51]. They intervene only when indoor environmental quality conditions transition beyond their band of acceptability, such as adjusting a thermostat setpoint if it becomes uncomfortably hot. In the case of operable window shades, occupants draw the shades for glare mitigation when it becomes bright 
and rarely interact with them otherwise until their next arrival. More complex shading models ([32], [45], [52]) are available that simulate in greater detail the shade interaction behavior of individual occupants, but these are appropriate only in the case of single occupancy offices where one person has exclusive control of all window shades.

In incorporating shade position into the daylight model, annual illuminance profiles are generated once with shades up and once with shades drawn. As described in the previous section, window transmittance in the base models is $65 \%$. For the shades drawn models, window transmittance is reduced to $6.5 \%$, representing the cumulative effect of the windows' $65 \%$ transmittance and roller shades with $10 \%$ constant transmittance (an assumption valid due to the low transmittance value [53]). This cumulative transmittance was verified using LBNL Window software by placing the shade inside the window and calculating the overall transmittance. The lighting utilization simulations then reference the appropriate illuminance profile depending on whether the shades have been drawn.

\subsubsection{Sensor resolution}

The nominal model configuration assumes there is one set of occupancy and illuminance sensors per cubicle. Variations on this include four cubicles per sensor (four sensors per room) and sixteen cubicles per sensor (one sensor per room). The small amount of energy consumed by each sensor (typically in the milliwatt range [54]) is not modelled.

To simulate reduced occupancy sensing resolution, it was assumed that if any of the individual cubicles in any given grouping were occupied, the entire group was considered occupied. A single occupant, therefore, may be solely responsible for activating the electric lighting above four separate cubicles, or in the case of room-level control - the entire space. 
To simulate reduced illuminance sensing resolution, the lowest reading from the sensors with the lighting control zone was taken to be representative of that zone. The logic of this approach is that in a daylight harvesting system, sufficient electrical lighting must be deployed to adequately illuminate the darkest workstation in the space. The average sensor readings will be inflated by the sensors nearest to the glazing and are not representative. Similarly, utilizing a sensor nearer to the center of the room would leave the cubicles farthest from the windows under-illuminated due to a lack of knowledge about their illuminance shortfall.

(a)

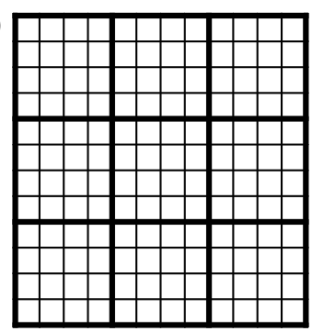

(b)

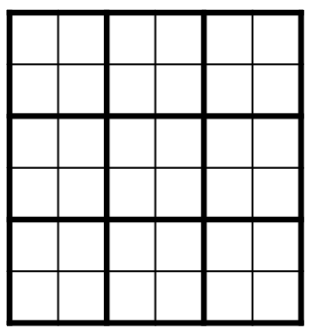

(c)

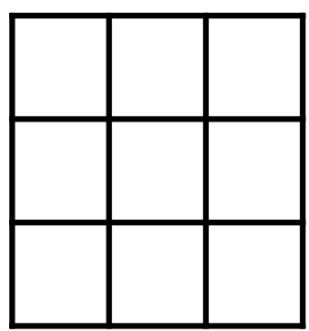

Figure 2.6, Plan view of space divided into control zones as per one of three levels of sensor resolution. (a) one cubicle per lighting zone, (b) four cubicles per zone, (c) sixteen cubicles per zone (one control zone per room).

\subsubsection{Controls}

MATLAB code was developed to simulate the lighting for each cubicle over the annual simulation period. The controls are configured such that a cubicle is only illuminated if an occupant is present in the current or previous five-minute timestep. This timeout period is somewhat conservative relative to what has been used experimentally (as low as one minute, more commonly five minutes). This conservative timeout offsets the fact that only the cubicle where an occupant settles to work is illuminated, in lieu of a more complex agent-based occupant model which activates luminaires along all zones an occupant visits while travelling [32]. 
Target workplane illuminance is set at 400 lx, within the range of commonly used values for computer based workstations [5], [55]-[57]. The LED luminaire for each cubicle is designed to provide an average of $400 \mathrm{~lx}$ of workplane illuminance at 100\% brightness. When daylight alone cannot achieve this target, luminaires are set to the necessary intensity such that daylight and electric lighting complement each other to achieve 400 lx. In lower sensor resolution scenarios, this logic is applied for the dimmest cubicle in the zone. Each workstation is modeled independently - a luminaire only illuminates its own respective cubicle, and adjacent luminaires do not assist in achieving required workplane illuminance. Electric lighting generally distributes its luminous output over an area wider than the size of its respective cubicle. In a conventional open plan office with coarse controls, there is little reason to concentrate luminaire output to only the area directly below it. With high-resolution controls, focused lighting allows for more precise targeting of the luminance.

\subsubsection{Calculation of energy savings}

Energy savings are calculated as a ratio of equivalent time luminaires are active at $100 \%$ intensity against a baseline case where all fixtures are assumed to be at full brightness for 16 hours each workday (the number of hours between first arrival and last departure in the NECB schedule). The relationship between energy consumption and emitted luminous flux in LEDs is assumed linear [58], LED efficiency has been found to be only 1-2\% poorer at the lowest dimming settings [59]. Workplane illuminance, dimming level, and electrical input power are therefore modelled to be directly proportional. $\mathrm{P}=\mathrm{P}_{\max } \times$ dimming level (\%), from 0 Watts per luminaire at $0 \%$ brightness ( 0 lx at the workplane) to 19.2 Watts per luminaire at $100 \%$ brightness (400 $1 \mathrm{x}$ at the workplane). For example, a luminaire set to $50 \%$ dimming for two timesteps is equal to another 
luminaire at $100 \%$ dimming for a single timestep. The baseline case is specified as $4.8 \mathrm{~W} / \mathrm{m}^{2}$, within the range of typical values for an office with $400 \mathrm{~lx}$ workplane illuminance and LED luminaires.

Because of the stochastic nature of the occupancy simulation, annual results may vary with each simulation run despite the other parameters (e.g., geometry, climate, sensor resolution) remaining constant. To test the significance of this variation, simulations were run ten times (each with a unique stochastically generated occupancy profile) and the average of these simulations is reported to ensure consistency. The maximum and average standard deviation for an individual energy savings result between runs is $0.52 \%$ and $0.20 \%$, respectively." Given that this is much lower than the absolute energy savings, the variations are not reported in the results.

\subsection{Results and discussion}

The simulation results shown in Figure 2.7 and as a heatmap with numeric values in Figure 2.8 demonstrate a wide range of performance levels and the sensitivity to design parameters. Floorlevel savings vary from $12 \%$ to $91 \%$, a slightly wider range than the $13 \%$ to $73 \%$ savings from similar studies reported by Chew et al [3], and greater than the 79\% savings achieved by Dikel et al. [5]. The most extreme savings are achieved only at very low occupancy levels. An even greater range is observed at the room level - varying between $6 \%$ and $94 \%$. These results illustrate how the performance of a sensor-array lighting system varies under changing circumstances of relative occupancy, available daylight, and sensor resolution. The generated result sets will be discussed in the remainder of this section to break down the logic of observed trends as well as the relative importance of each variable simulated. 


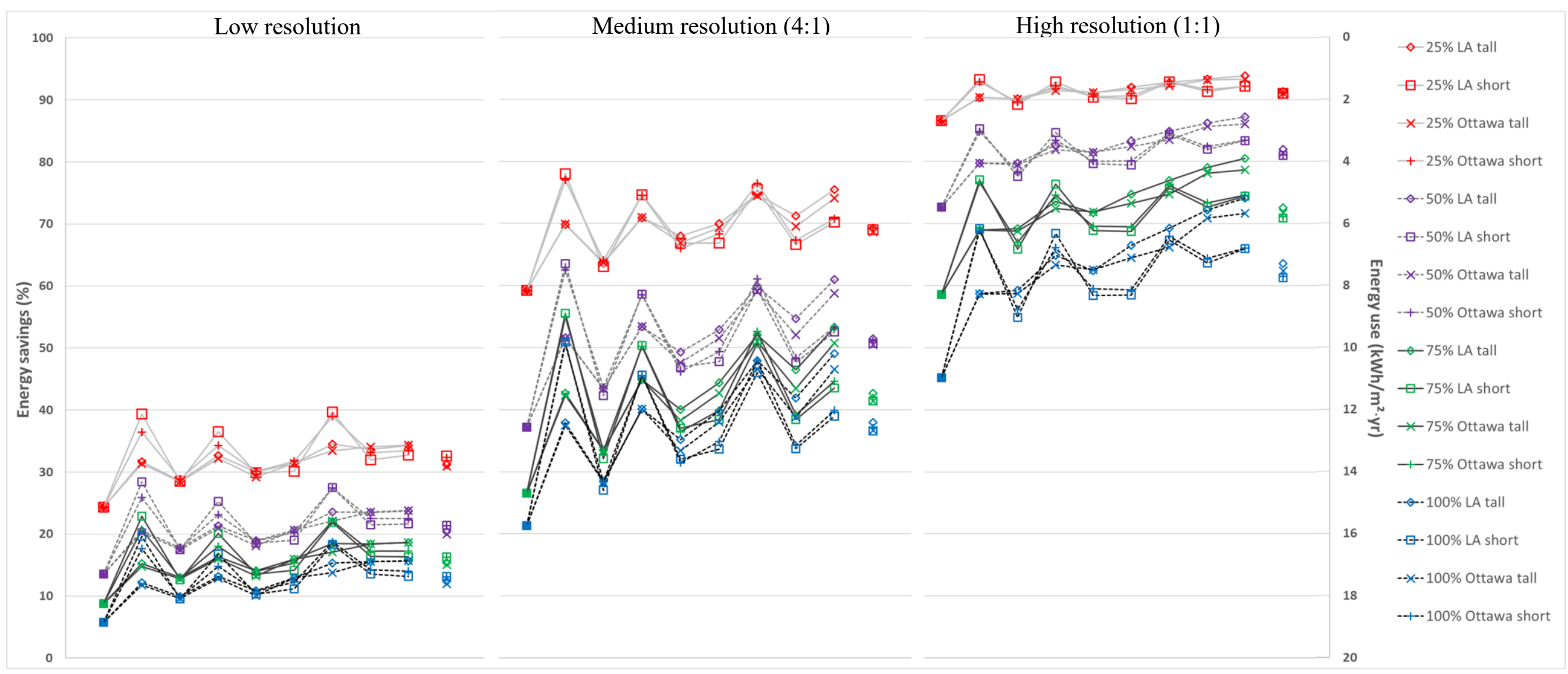

Figure 2.7, Plot of results for all simulation permutations at room and floor levels at high, medium, and low sensor resolution from left to right respectively. Results are quantified in the left axis as energy savings by percent and in the right axis as total annual energy use in $\mathrm{W} / \mathrm{m}^{2}$ where baseline case is $\sim 4.8 \mathrm{~W} / \mathrm{m}^{2}$. Columns representing room orientation (i.e. north, northeast, core) are organized by average energy savings in ascending order, according to the highresolution results. The rightmost column on each plot indicates the overall floor level energy savings for each of the forty-eight simulations. The relative importance of each parameter considered in this study can be discerned by following the plot along a specific axis. 


\begin{tabular}{|c|c|c|c|c|c|c|c|c|c|c|c|c|c|c|c|c|c|c|c|c|c|c|c|c|c|c|c|c|c|c|c|c|c|c|c|c|c|c|c|c|}
\hline \multirow{4}{*}{ Occupancy } & \multicolumn{12}{|c|}{ Low resolution } & \multicolumn{14}{|c|}{ Medium resolution $(4: 1)$} & \multicolumn{14}{|c|}{ High resolution (1:1) } \\
\hline & \multicolumn{6}{|c|}{ Ottawa } & \multicolumn{6}{|c|}{ Los Angeles } & \multirow{3}{*}{ Occupancy } & \multicolumn{6}{|c|}{ Ottawa } & \multicolumn{6}{|c|}{ Los Angeles } & \multirow{3}{*}{ Occupancy } & \multicolumn{7}{|c|}{ Ottawa } & \multicolumn{7}{|c|}{ Los Angeles } \\
\hline & \multicolumn{3}{|c|}{ short window } & \multicolumn{3}{|c|}{ tall window } & \multicolumn{3}{|c|}{ short window } & \multicolumn{3}{|c|}{ tall window } & & \multicolumn{3}{|c|}{ short window } & \multicolumn{3}{|c|}{ tall window } & \multicolumn{3}{|c|}{ short window } & & win & & & & tu & & & tall & wind & & & rtw & inds & & & winc & \\
\hline & 39 & 36 & 32 & 33 & 31 & 31 & 40 & 39 & 30 & 34 & 32 & 31 & & 76 & 77 & 68 & 74 & 70 & 69 & 75 & 78 & 67 & 75 & 70 & 70 & & 93 & 9 & & 91 & 92 & 90 & 92 & 93 & 93 & & 90 & 93 & 90 & 92 \\
\hline & 34 & 24 & 29 & 32 & 24 & 28 & 37 & 24 & 29 & 33 & 24 & 29 & & 75 & 59 & 64 & 71 & 59 & 64 & 75 & 59 & 63 & 71 & 59 & 64 & & 92 & 8 & & 90 & 92 & 87 & 90 & 93 & 87 & & 89 & 92 & 87 & 90 \\
\hline $2 \%$ & 33 & 30 & 33 & 34 & 29 & 34 & 33 & 30 & 32 & 34 & 30 & 34 & $25 \%$ & 71 & 66 & 67 & 74 & 67 & 70 & 70 & 67 & 67 & 75 & 68 & 71 & $2 \%$ & 92 & 9 & & 92 & 93 & 91 & 93 & 92 & 90 & & 91 & 94 & 91 & 93 \\
\hline & & 32 & & & 31 & & & 33 & & & 31 & & & & 69 & & & 69 & & & 69 & & & 69 & & & & 9 & & & & 91 & & & 91 & & & & 91 & \\
\hline & 27 & 26 & 20 & 22 & 20 & 21 & 28 & 28 & 19 & 24 & 21 & 21 & & 61 & 63 & 49 & 59 & 52 & 51 & 59 & 64 & 48 & 60 & 52 & 53 & & 85 & 8 & & 80 & 84 & 80 & 82 & 84 & 85 & & 79 & 85 & 80 & 83 \\
\hline & 23 & 14 & 18 & 21 & 14 & 18 & 25 & 14 & 18 & 21 & 14 & 18 & $50 \%$ & 59 & 37 & 44 & 53 & 37 & 43 & 59 & 37 & 42 & 53 & 37 & 43 & & 83 & 7 & & 78 & 82 & 73 & 80 & 85 & 73 & & 78 & 83 & 73 & 80 \\
\hline 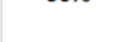 & 22 & 19 & 22 & 24 & 18 & 24 & 22 & 19 & 21 & 24 & 19 & 23 & 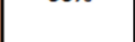 & 53 & 46 & 48 & 59 & 48 & 52 & 53 & 47 & 48 & 61 & 49 & 55 & 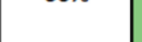 & 83 & 8 & & 82 & 86 & 82 & 86 & 83 & 80 & & 82 & 87 & 81 & 86 \\
\hline & & 21 & & & 20 & & & 21 & & & 20 & & & & 51 & & & 50 & & & 51 & & & 51 & & & & 8 & & & & 81 & & & 81 & & & & 82 & \\
\hline & 22 & 21 & 15 & 17 & 15 & 16 & 22 & 23 & 14 & 19 & 15 & 16 & & 53 & 55 & 40 & 51 & 42 & 43 & 51 & 56 & 38 & 52 & 43 & 44 & & 76 & 7 & & 70 & 75 & 69 & 73 & 76 & 77 & & 69 & 77 & 69 & 75 \\
\hline 78 & 18 & 9 & 13 & 16 & 9 & 13 & 20 & 9 & 13 & 16 & 9 & 13 & $75 \%$ & 50 & 27 & 33 & 45 & 27 & 33 & 50 & 27 & 32 & 45 & 27 & 33 & $75 \%$ & 75 & 5 & & 67 & 72 & 59 & 69 & 76 & 59 & & 66 & 74 & 59 & 69 \\
\hline & 17 & 14 & 17 & 19 & 13 & 18 & 16 & 14 & 16 & 19 & 14 & 18 & 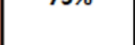 & 45 & 36 & 39 & 51 & 38 & 43 & 44 & 37 & 38 & 53 & 40 & 46 & $7 \%$ & 75 & 7 & & 73 & 79 & 72 & 78 & 74 & 69 & & 73 & 81 & 72 & 79 \\
\hline & & 16 & & & 15 & & & 16 & & & 15 & & & & 42 & & & 41 & & & 41 & & & 43 & & & & 7 & & & & 72 & & & 71 & & & & 73 & \\
\hline & 19 & 18 & 12 & 14 & 12 & 13 & 18 & 20 & 11 & 15 & 12 & 13 & & 48 & 51 & 35 & 47 & 37 & 38 & 46 & 51 & 34 & 48 & 38 & 40 & & 68 & 6 & & 59 & 66 & 59 & 64 & 67 & 69 & & 59 & 69 & 59 & 67 \\
\hline $100 \%$ & 15 & 6 & 10 & 13 & 6 & 10 & 17 & 6 & 10 & 13 & 6 & 10 & $100 \%$ & 45 & 21 & 28 & 40 & 21 & 28 & 46 & 21 & 27 & 40 & 21 & 28 & & 66 & 4 & & 56 & 63 & 45 & 59 & 68 & 45 & & 55 & 65 & 45 & 59 \\
\hline $1000 \%$ & 14 & 11 & 14 & 16 & 10 & 16 & 13 & 10 & 14 & 16 & 11 & 16 & $100 \%$ & 40 & 32 & 34 & 46 & 33 & 39 & 39 & 32 & 34 & 49 & 35 & 42 & $100 \%$ & 66 & 5 & & 64 & 72 & 63 & 71 & 66 & 58 & & 64 & 74 & 62 & 72 \\
\hline & & 13 & & & 12 & & & 13 & & & 12 & & & & 37 & & & 37 & & & 37 & & & 38 & & & & 6. & & & & 62 & & & 61 & & & & 64 & \\
\hline
\end{tabular}

Figure 2.8, Simulation results describing energy savings in percent presented as heatmaps with numeric values at low, medium, and high sensor resolution from left to right respectively. Results are presented with savings in each of the nine rooms, as well as average floor level savings in bold and italic below Red represents poorer energy savings and green represents greater savings. 


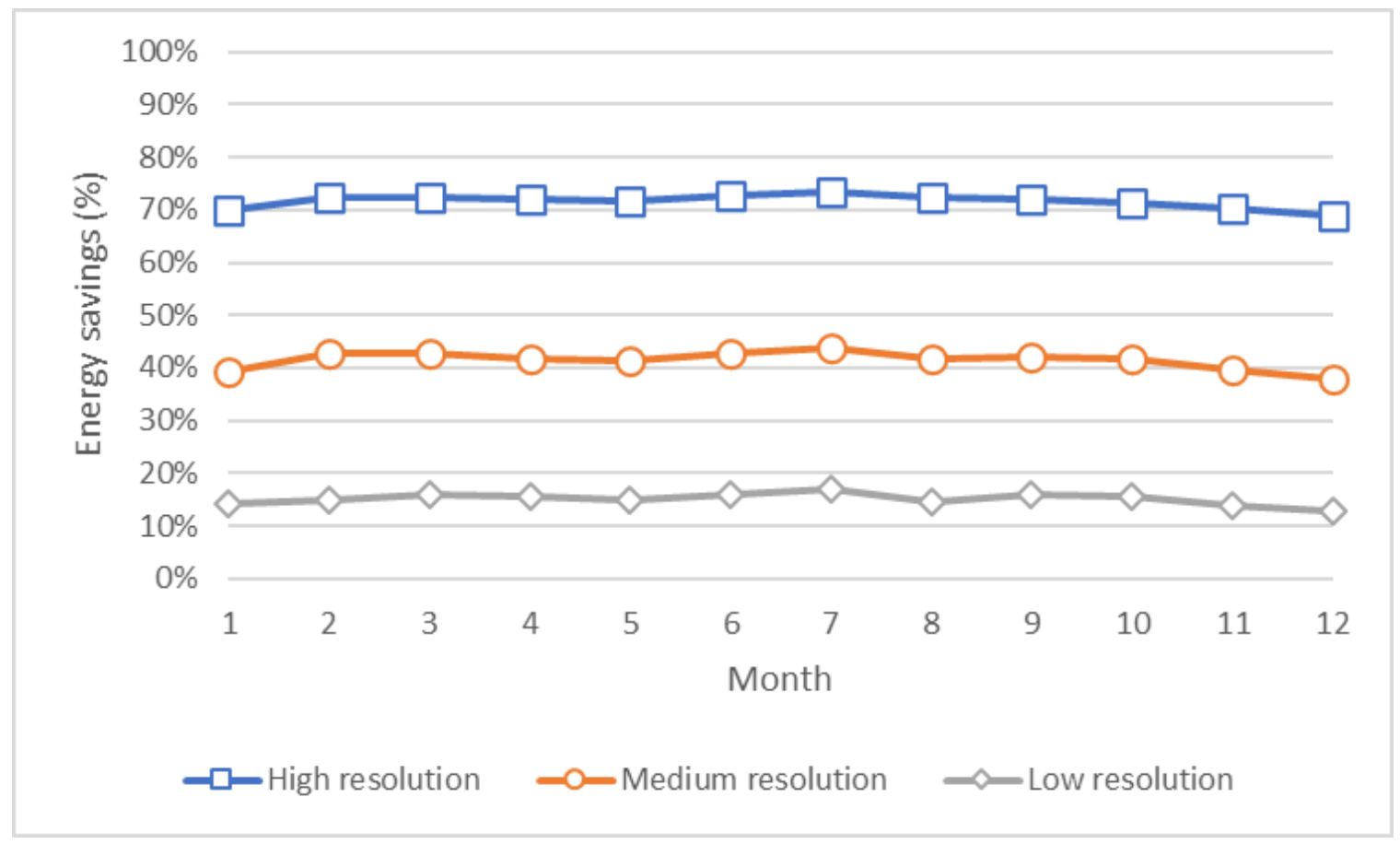

Figure 2.9, Monthly plot of energy savings results for Ottawa with tall windows and 75\% occupancy at high, medium, and low sensor resolution. Across all three sensor resolution scenarios energy savings are consistent throughout the year.

\subsubsection{Sensor resolution}

The number of workstations per control zone has the most profound impact on system energy savings potential of all measured parameters. Increasing the sensor density (and therefore the number of control zones) without making any changes to the luminaires yields significantly greater savings than with lower resolution controls. For Los Angeles with tall windows at $25 \%$ occupancy (identified as the best-case scenario) savings of $91 \%$ are observed at high sensor resolution, $69 \%$ at medium-resolution, and $31 \%$ at low-resolution. In a lower savings scenario (Ottawa with short windows at $75 \%$ occupancy) savings are $71 \%, 42 \%$, and $16 \%$. The more precipitous relative decrease observed in the latter scenario indicates that sensor-array lighting systems become increasingly sensitive to less favorable 
lighting conditions and higher relative occupancy as sensor resolution is decreased. These sharply reduced savings illustrate well the deficiencies of room-level control, where the dimmest workstation in a room must govern the brightness setting for all other luminaires, and a single occupied cubicle will engage electric lighting for the entire room.

\subsubsection{Relative occupancy}

Across simulations and at all sensor resolutions relative occupancy was, as expected, found to have a significant impact on savings. At the floor level, the savings for Ottawa with tall windows at high sensor resolution for example drop from $91 \%$ to $81 \%, 72 \%$, and $62 \%$ from the lowest to highest occupancy scenarios. The contribution of occupancy detection can be isolated from that of daylight harvesting by observing core space, which receives no daylight. At high sensor resolution core space in all cases drops from $87 \%$ to $73 \%, 59 \%$, and $45 \%$ savings between occupancy scenarios. These results isolated solely to occupancy detection indicate that spaces with partial occupancy can see significant savings even absent any useful daylight. Conversely, core spaces with low (room-level) sensor resolution saw only $24 \%, 14 \%, 9 \%$, and $6 \%$ savings between occupancy scenarios. With a perfectly even occupant distribution no savings would be expected for room-level control at $100 \%$ (of the NECB schedule [42]) occupancy - the small savings observed here are attributable to the fact that in hours of low occupancy some rooms are occasionally completely empty. A significant portion of open-plan office stock is located far enough from any glazing for useful daylight harvesting to occur - in these cases sensor-array systems may still be worthwhile given partial or irregular occupancy patterns and sufficiently high occupancy sensor resolution. 


\subsubsection{Location and glazing ratio}

Past daylight harvesting studies that make recommendations for window geometry and are constrained to one control zone per room require that the entire space be illuminated by daylight for any dimming to occur [41], [60]. In the current context, with high-resolution lighting control zones, the value placed on illuminating the entire room at a given time is lessened. The current results indicate that the importance of geographic location and glazing ratio in determining energy savings is less than that of the previously discussed sensor resolution and relative occupancy. A 91\% reduction in energy use relative to the baseline case is observed for all four daylight scenarios with $25 \%$ occupancy and high sensor resolution. The most significant gap in savings between daylight scenarios is seen between the four with $100 \%$ occupancy and high sensor resolution, where Ottawa saw $62 \%$ with both window types, but Los Angeles saw 61\% savings with short windows and 64\% with tall windows. This result demonstrates that larger windows are less significant in increasing the availability of daylight than may be initially assumed. As described by Tzempelikos et al. [53], increasing window-to-wall ratio beyond 30\% (approximately the ratio with short windows in the current study) offers only modest increases to workplane illuminance (a 9\% increase was observed when window-to-wall ratio was increased to 80\%). Additionally, as explained by Kapsis et al. [60], the highest portion of a window is the most important for effective daylight penetration. In the current study the top portion is preserved between tall and short windows.

Simulation results are sometimes counter-intuitive - in some cases, shorter windows yield slightly higher savings than taller windows. In the Ottawa scenarios with $25 \%$ 
occupancy and low sensor resolution, 32\% savings with short windows are observed vs. $31 \%$ with tall windows. Los Angeles achieves 33\% savings with short windows vs. $31 \%$ with tall windows. The trend of slightly higher savings with short windows is consistent at the room level for every low-resolution scenario. The implementation of the window shading model explains the counter-intuitive results observed. On average, greater availability of daylight will be negated by occupant's desire to reduce glare by drawing the shades. Simply put, there is a soft ceiling on the usefulness of additional daylight because occupants become uncomfortable when too much daylight is present and will take action to reduce it. This effect can cause additional daylight to actually increase lighting electricity use, as seen in cases where Ottawa (with shorter days) experiences greater savings than Los Angeles.

The incremental benefit of daylight harvesting is greatest in scenarios with higher occupancy. Overall savings of $91 \%$ are found in Los Angeles with tall windows at $25 \%$ occupancy and with high sensor resolution, relative to savings in the windowless core room of $87 \%$. The gap between overall and core savings is greater when occupancy is increased to $100 \%$, with $64 \%$ floor level savings vs. $45 \%$ core savings. The reduced benefit of daylight harvesting at lower occupancy scenarios may indicate that it is most appropriate where occupancy is expected to be higher and more consistent. 


\subsubsection{Room orientation and single façade vs corner space}

Results at room level are more complicated and require more effort to parse. Across every scenario, rooms with only one glazed façade (north, south, east, and west) display greater savings with a lower window to wall ratio. For Los Angeles at $100 \%$ occupancy and high sensor resolution, savings in the north-facing room increase from $59 \%$ to $69 \%$ when short windows are installed. For Ottawa with $75 \%$ occupancy and low sensor resolution, savings in the west-facing room increase from $16 \%$ to $18 \%$. The effect is observed in each room type but is most pronounced in the north-facing rooms. Conversely, corner rooms (northwest, northeast, southeast, southwest) with two glazed walls generally (but less consistently) have higher savings with tall windows instead of short. This is because illuminance may exceed 2000 lx in the corner office regardless of glazing ratio, causing shades to be drawn. In Los Angeles with 50\% occupancy and high sensor resolution, the southwest room for example increases from $83 \%$ to $87 \%$ when tall windows are installed. In Ottawa with $75 \%$ occupancy and medium sensor resolution the northeast room goes from $40 \%$ to $43 \%$ savings with tall windows. These opposing trends tend to cancel each other out, resulting in the consistent room level savings shown in the figure. Again, these phenomena are attributable to the shading model, wherein when a room is exposed to excessive daylight in any occupied cubicle, the shades are drawn. With a single glazed wall, crossing the 2000 lx threshold may occur much more easily with tall windows. For a corner room, the cubicles nearest the corner where windows meet are likely to cross that threshold regardless of window type, and so the real availability of daylight is more likely to govern savings. 
The contrast between similar rooms facings different orientations may be attributed to three factors. The amount of daylight available due to the sun's position in the sky, the relationship between occupied hours and time of day, and the time at which shades were drawn. Absent any operable shading system, south-facing rooms would be expected to have consistently higher savings - this is confounded by the other factors. The angle at which daylight enters space is important. A lower solar altitude angle in the morning and afternoon (north, east, and west) relative to midday (south) means that sunlight can penetrate more deeply into a space. This increases workplane illuminance farther back from the windows without necessarily peaking it at the cubicles nearest the windows and triggering the shades to close. By observing the occupancy schedule (Figure 2.4) it can be noted that occupancy is weighted towards the afternoon and extends into hours with lower daylight levels. This will have an expected effect of increasing the average effectiveness of daylight harvesting in the east-facing rooms more than the west oriented rooms. The governing effect however is the time at which shades are drawn in each room. East oriented rooms consistently see lower savings than west-facing rooms because those rooms experience peak daylight earlier in the workday, resulting in shades being drawn for most of the day. West-facing rooms on the other hands may not have shades drawn until later in the day, when they receive direct sunlight. For example, the east-facing room may have shades drawn at 10:00 am shortly after occupants arrive, whereas the west-facing room may not have its shades drawn until 3:00 pm. Between the hours of 10:00 am and 3:00 pm the west room will be experiencing direct daylight while the eastern room's shades will already have been drawn. 


\subsubsection{Scope of workflow applicability and its limitations}

This study sought to develop a simple, replicable workflow for the purpose of estimating the performance of occupancy detecting and daylight harvesting sensor arrays across a variety of scenarios. Occupants were modelled as being either fixed at their workstations or not present. The novelty of the workflow is that it considers individual occupants and workspaces, which is necessary for assessing the performance of a highresolution lighting control configuration. The main limit to applicability (in practice) is that the workflow involves several software tools and multiple intermediate files. Thus, such a workflow would be unlikely to be adopted except by advanced designers, as well as researchers, unless it is implemented into a single software tool and/or mandated by building codes and standards.

While a generic office space with a specific geometry and set of materials was selected, the workflow is independent of these characteristics. Similarly, the approach to stochastic occupancy modelling is sufficiently generic to allow other input occupancy schedules. However, the original model development was aimed and validated for office occupancy and thus it may not be appropriate for other spaces (e.g. homes, classrooms, etc.). In the current approach, occupants are assumed to arrive and depart independently. While the window shade use in the current demonstration of the workflow is deterministic, a stochastic model would be similarly feasible. Beyond the above model characteristics, the building model could also include shading from neighbouring buildings or fixed exterior shading. While the current focus is on annual results, the results could be presented at any timescale and for any location with an hourly weather file. 
The current daylight simulation tool that was used, DAYSIM, like any modelling tool, has numerical limitations that lead to errors. The tool approximates direct solar contributions by interpolating between approximately sixty-five adjacent daylight coefficients. When direct (non-diffuse) daylight is modelled, assumptions of lambertian reflectance properties on interior surfaces may not always hold. Detailed or curved geometry will not be accurately modelled. A commonly encountered element that may not be appropriate for modelling is the venetian blind [7], [61].

In the future, a more complex agent-based model which includes occupant mobility and pathfinding could be used to quantify how the frequency and patterns of occupant's movement impacts energy savings. At present, simplified, isolated lighting controls are utilized such that each luminaire operates independently and is assumed to not illuminate adjacent zones. More advanced central control where luminaires can communicate sensor data to one another and dim accordingly would yield additional savings. For example, if all luminaires surrounding a cubicle are on, they may provide sufficient illuminance for the luminaire in the subject cubicle itself to be off.

A simulation study cannot completely capture the challenges of real-world implementation and operation of lighting controls. Correlating workplane and ceiling illuminance can be nontrivial, requiring labour intensive manual calibration that may not be accurate (or remain accurate as conditions change). Occupancy detection with an array of ceiling-mounted sensors is effective, but still imperfect - false negatives are possible when occupants remain still. In this study system power use was modelled as linear and 
with a minimum of zero power draw. Controllers and sensors can introduce less predictable inefficiencies and result in a baseline energy use, even when all luminaires are off.

An economic analysis is not included in this study. The savings reported under different scenarios is however largely generalizable, and the workflow described in the present study may be used to estimate energy savings for virtually any combination of custom parameters in such analysis. The capital cost of installing sensor array systems varies greatly by configuration (such as $\mathrm{AC}$ power vs. power over ethernet), and maintenance costs are not well understood, owing to the present lack of commercial implementations. Researchers and building owners must consider these factors in their economic analysis. Moreover, it is noteworthy that the results are presented in terms of relative energy savings. The operating cost in absolute terms is trending downwards as lighting becomes more efficient. Accordingly, the payback period for high-resolution lighting controls will increase unless equipment and labour costs similarly decrease. 


\subsection{Conclusion and recommendations}

A sensor-array LED lighting system with daylight harvesting and occupancy sensing functionality was simulated to generate estimates of potential energy savings under a variety of conditions and configurations, including geographic location, window size, room orientation, relative occupancy, and sensor resolution. The daylight simulation tool DAYSIM was used for daylighting simulations, while MATLAB was used to model occupancy, shading, and lighting controls. The workflow developed in this study has proven to be appropriate for rapidly evaluating system effectiveness in a wide variety of scenarios. The results presented herein represent only a small cross section of possibilities and demonstrate the effectiveness of this approach.

Relative to scheduled lighting, energy savings of between $61 \%$ and $91 \%$ were found with high-resolution cubicle level sensing and controls. More modest savings of between $12 \%$ and $33 \%$ were observed with low-resolution room level control. Significantly greater savings were observed where occupancy levels were lower. Increased availability of daylight was found to have a low impact on savings at the room level, due to occupant's desire to reduce glare by drawing window shades when daylight becomes too intense. Higher sensor resolution and finer control zones ensure that electric lighting is used only where it is required. The greater the resolution, the less unoccupied or adequately lit spaces will be unnecessarily illuminated.

The modelling approach described in this chapter may be deployed to estimate the energy savings of sensor array lighting systems under any number of conditions. The model parameters calculated and presented provide a frame of reference for potential energy 
savings. The results presented in this study illustrate the inconsistency of reported savings by various field, experimental, and simulation studies; sensor-array lighting system performance is highly context-dependent. A useful estimate of system effectiveness must account for every parameter affecting the availability of daylight or the distribution of occupants. Future work should seek to validate simulation results against experimental studies by accurately capturing all experimental parameters (relative occupancy, room orientation, etc.). More complex façade and window geometries should also be explored to optimize savings and comfort. More advanced simulations that model occupants as moving agents, implement a centralized control algorithm, and allow luminaires to illuminate adjacent zones should be pursued. 


\section{Chapter 3: Evaluating sensor calibration of high-resolution daylight-controlled lighting in open-plan offices}

\subsection{Introduction}

Illuminating open-plan office spaces as efficiently as possible without causing occupant discomfort is a complex problem [22], [35]. Control solutions that offer significant savings and respect occupant comfort have been devised and demonstrated, but practical challenges remain. Current commercial lighting systems are generally controlled manually via a switch, on a fixed schedule, or (more recently) with illuminance and occupancy sensors. The commonality between most commercially available solutions is that lights are controlled as one large group, without the flexibility to illuminate only the parts of a space that require it. The next step in achieving more energy-efficient lighting is high-resolution, automated control of individual luminaires by pairing each light with its own illuminance and occupancy sensor. In these sensor array lighting systems, each luminaire may dim independently based on the availability of daylight and the proximity of occupants. These systems offer more savings than conventional room-level dimming, particularly when spatial continuous daylight autonomy is high and where occupancy is lower [3], [62], but offer some benefit in virtually all real-world scenarios. Effectiveness is predicated on high-resolution control; smaller control zones consistently translate to more significant savings [6], [62].

Commercial implementation of high spatial resolution sensor array lighting systems faces several practical hurdles. The labour and hardware costs involved in their installation, calibration, and maintenance can make the systems significantly more expensive than 
lighting controlled at the room level. Whether manual control, a schedule, or room level illuminance and occupancy sensors are used, installation is more straightforward than advanced control schemes with many sensors to calibrate [24], [63]. The process of calibrating many ceiling-mounted illuminance sensors to best estimate workplane illuminance is labour intensive and requires a specially trained installer to perform the procedure. Ceiling sensors, rather than workplane sensors, are used during operation because sensors placed directly on the workplane can quickly become obstructed. Conventionally though, portable illuminance sensors are placed on the workplane below each luminaire and ceiling-mounted illuminance sensor during calibration [64]. Readings from each workplane and ceiling sensors are taken and compared against one another to determine a correlation between workplane and ceiling illuminance levels. Once calibration is complete, permanent ceiling sensors are relied upon exclusively to estimate workplane illuminance and adjust luminaire dimming accordingly.

The current study explores the relationship between workplane and ceiling illuminance to determine whether a lighting system calibrated automatically, without the use of temporary workplane sensors, can perform comparably to one that is conventionally calibrated. The error and uncertainty inherent to sensor array lighting systems that operate by estimating workplane illuminance using ceiling sensors (irrespective of the calibration method used) is quantified across a variety of lighting scenarios. The magnitude of this inherent uncertainty is then compared against the uncertainties introduced by forgoing workplane sensors during calibration, relying on a completely automated calibration process using ceiling sensors alone. This analysis culminates in a performance evaluation 
between conventionally calibrated and automatically calibrated systems estimating workplane illuminance during operation.

Relative performance between conventionally calibrated and automatically calibrated systems hinges on two key questions.

\section{During operation, how variable is the correlation between workplane and ceiling}

illuminance? Varying daylight and electric light scenarios result in changes to the correlation between workplane and ceiling illuminance. The way light enters, reflects, and diffuses throughout a space is complex, and the sensor correlation will change depending on the incidence angle, intensity, and source of light striking the workplane and ceiling sensors. A single correlation for each sensor, derived using electric lighting during the calibration process, may differ significantly from correlations measured during a bright summer day. During operation, how significant a problem does this variability pose?

\section{Can calibration be achieved automatically without the use of workplane}

illuminance sensors? Can workplane illuminance be estimated to a reasonable degree of accuracy based only on the properties of the active luminaire and its height above the workplane? If so, an intelligent lighting system may perform a completely automated calibration at the time of installation and automated re-calibration at regular intervals afterwards. This automated re-calibration allows the system to account for changes in the room such as the addition of partition walls, a change in carpet color, etc. It also enables the system to detect any luminaire or sensor faults automatically. 
These two questions are explored using simulated data to evaluate the viability of automatically calibrated sensor array lighting systems.

\subsection{Key Terms}

Before the methodology, the following key terms are defined.

Correlation factor - The ratio of the ceiling to workplane illuminance. Usually a number less than one because ceiling illuminance is lower than workplane illuminance. This fixed value is used to estimate workplane illuminance during operation based on ceiling illuminance readings.

Coillumination table - An array describing the increase in workplane illumination in every lighting zone when each luminaire in the space is activated at $100 \%$ brightness. In a conventional calibration, this increase can be measured directly, in an automated calibration, it is derived using the correlation factors.

Calibration procedure - A process required to collect necessary data for the effective operation of a high-resolution sensor array lighting system. A correlation factor for each lighting zone is determined, and the coillumination table for the entire space is generated. Conventional calibration - An established method for system calibration whereby installers temporarily place illuminance sensors at desk height in each lighting zone to collect data on workplane illuminance directly.

Automated calibration - A novel calibration method wherein workplane sensors are not utilized and installers are not involved. Instead, workplane illuminance is estimated based on ceiling height and luminaire properties during calibration. 


\subsection{Background}

\subsubsection{General background}

Sensor array-controlled lighting may offer significant energy savings over conventionally controlled systems, dependent upon the availability of daylight, the level of occupancy, and the control resolution [3], [5], [38], [62]. Where every space of a room is fully occupied, and no daylight is available, little energy will be saved relative to conventional systems because all luminaires will be powered at near $100 \%$ brightness regardless. Similarly, an unoccupied space or a space with well-designed glazing on a clear day with complete daylight autonomy will require no electric lighting at all, regardless of the method of control. In either extreme, a high-resolution sensor array lighting system offers little advantage over commercially available single zone systems. The advantage of a high-resolution system is that it offers significant savings in the cases between these extremes, where occupancy is partial, and some but not all of the daylight required to illuminate a space fully is available. Many individually controlled lighting zones may exist in the same space, and electric lighting is only deployed where necessary to supplement available daylight and where there are occupants present.

\subsubsection{Controls}

Sensor array lighting systems are controlled by dimming (or turning off) luminaires individually or in small clusters based on readings from occupancy and illuminance sensors collocated with each luminaire or luminaire cluster. Each sensor must have a restricted field of view to detect occupants or measure illuminance in only its own control zone. This enables the system to distinguish where occupants are (and are not) located, as well as 
understand how workplane illumination varies throughout the space. Intelligent operation of sensor array lighting systems is achieved by one of the following three methods: isolated, distributed, or centralized control [24], [25], [64]. Isolated control in which each luminaire operates independently achieves sub-optimal energy savings and frequently exhibits a settling time where, for example, one light brightening may cause other nearby lights to dim in response, which then triggers other lights to brighten, taking time to a reach stable configuration [65]. Distributed controls allow for communication of sensor readings and dimming settings between luminaires, but allow each to be controlled individually. In centralized control, all luminaires report sensor readings to one controller (which may be locally hosted or cloud-based), which then analyzes all available data to determine an ideal dimming configuration for the room, then adjusts all lights simultaneously, avoiding the problem of settling and optimizing energy savings. In practice control algorithms may vary in complexity from a single linear equation for each luminaire to advanced approaches utilizing neural networks [33], [66].

\subsubsection{Calibration}

Labour-intensive manual calibration has been a necessary step in the installation and operation of experimental sensor array lighting systems [5], [66], [67]. In lighting design, every space is unique and differences in geometry, glazing, surface reflectance, furnishings, etc. cause light to behave differently [43], [68], [69]. Optimizing energy savings demands a thorough understanding of how light diffuses through a space, and of the relationships between lighting zones. Installers must correlate each illuminance sensor in the ceiling to the workplane illuminance below it (estimating the so-called correlation 
factors), and, in the case of efficient centralized control, the pairwise relationships between lighting zones must be estimated, which is referred to as the coillumination table.

A study by Dikel et al. explored the energy savings potential of sensor-array lighting controls in an experimental environment, performing a conventional calibration to correlate ceiling and workplane illuminance [5]. The study clustered luminaires into nine control groups, each containing either six or nine directional pot lamps and several sensors that were averaged to a single reading. The coillumination table was constructed by activating each control group in sequence, with no daylight present, and recording the resulting change in illuminance at each sensor. Daylight was measured at the workplane by placing illuminance sensors at desk level in different daylighting scenarios. The increase in workplane illuminance due to each luminaire group was also measured directly with desk-level sensors. By measuring workplane illuminance directly, this approach found precise correlations for each electric and daylighting scenario tested, for every sensor. Significant variability in the correlation between workplane and ceiling illuminance was, however, observed between daylighting scenarios. A second-order fit that followed the lowest of all the experimental daylighting correlation data was utilized. This conservative fit sacrifices some potential efficiency by tending to underestimate workplane illuminance, and thus over-illuminate the space in some scenarios, but ensures a zone is rarely underilluminated.

Another study by Ganapathy et al. examined the potential for auto-commissioning in an experimental environment [65]. The relationships between luminaire states and illuminance sensor readings, termed in this study the influence matrix, are also used to 
dynamically group luminaires into control groups, necessitated by the greater number of lamps than sensors. Here again, temporary workplane illuminance sensors are utilized alongside ceiling-mounted sensors during the calibration process. Accurate coillumination table or influence matrix data gathered using the workplane sensors assigns one or more luminaire to each sensor based on the increase in illuminance observed in each sensor due to the activation of every luminaire. The study was able to pair luminaires to sensors across every scenario tested effectively.

\subsection{Methodology}

\subsubsection{Overview}

In order to estimate workplane illuminance during operation by taking illuminance readings at the ceiling, advanced lighting systems must be properly calibrated. Calibration establishes correlation factors for each control zone independently, which relate workplane illuminance to illuminance measured at the ceiling as a simple ratio. If a correlation factor of 0.4 is determined during calibration, and $50 \mathrm{~lx}$ is measured at the ceiling, the system will estimate workplane illuminance as $50 \mathrm{~lx} \times(1 / 0.4)=125 \mathrm{~lx}$. This simple linear relation will remain unchanged unless the system is recalibrated. Calibration also establishes the coillumination table, which describes how turning on each luminaire will increase the workplane illuminance in its own and in every other control zone. This data is used to estimate the expected workplane illuminance throughout the room due to electric lighting, given any set of dimming configurations. Comparing expected workplane illuminance due to electric lighting against the value measured using ceiling sensors enables the disaggregation of illumination due to daylight. In the Sections 3.4.2, 3.4.3, and 3.4.4 the 
calibration procedure, correlation factors, and the coillumination table will be fully described. The specific implementation of these concepts as utilized in the current study are detailed, however the principles are broadly applicable to high-resolution sensor-array lighting systems.

In Sections 3.4.5 and 3.4.6 of the methodology, the configuration of the simulation space and the population of electric and daylighting scenarios simulated are described. The current study restricts analysis to an open-plan office setting in which individual workstations each have their own lighting control zone. Aside from changing the façade orientation, the configuration of the room itself does not change. The electric lighting scenarios representing the calibration process, that is, the scenarios where only one light in the room is on at a time, are simulated - as well as several scenarios with luminaires dimmed randomly. Daylight scenarios with different intensities, solar altitudes, and sky conditions are produced as well to assist with manual calibration and to be used in analyzing system performance.

\subsubsection{Calibration procedure}

The calibration procedure is a necessary step in preparing an intelligent sensor array lighting system for efficient operation. The procedure involves activating every luminaire in the space in sequence and for each luminaire recording the resulting change in illuminance at every sensor. In a conventional calibration, this includes both workplane and ceiling sensor readings; in an automated calibration, it includes only ceiling sensor data. The process is run once when the lighting system is installed and may be repeated 
over the life of the system to adjust to changes in the space or to detect faulty luminaires or sensors.

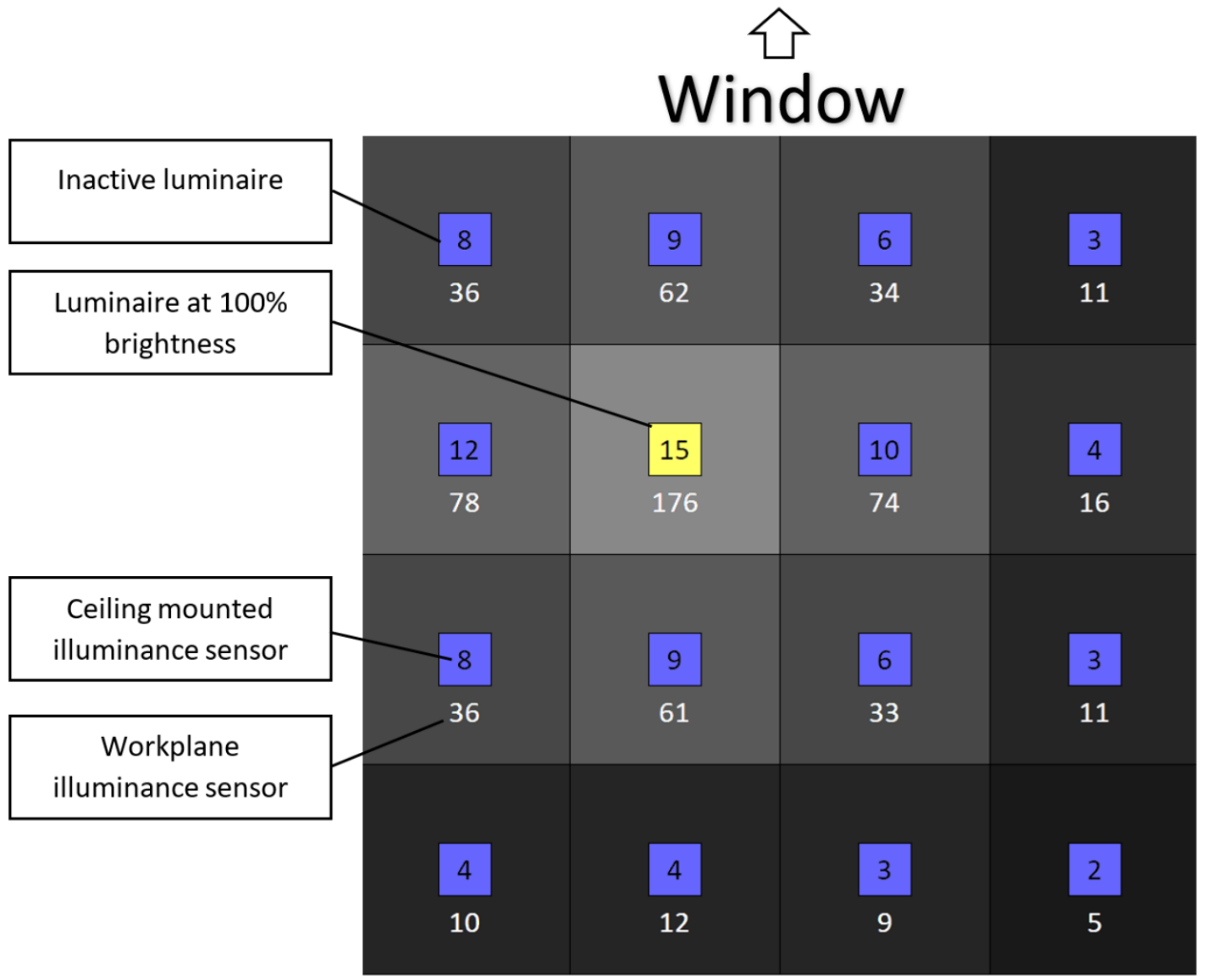

Figure 3.1, One step in the calibration sequence in which only one light (denoted by yellow coloring) is turned on and no daylight is present. Workplane and ceiling illuminance (in lux) are measured for every cubicle using DIALux evo and visualized.

Figure 3.1 illustrates the calibration procedure using simulated data produced as part of the present study. A conventional calibration may supplement this data with readings taken during periods when daylight was present. Daylight data is not used to build the coillumination table, which exclusively measures how electric lighting changes illuminance sensor readings, but does provide an additional population of sensor correlations to review when determining which value to use for the correlation factor 
during operation. If daylight data includes correlations lower than those due to electric lighting, the representative correlation factor selected may be lower than if daylight data were not measured, and thus result in fewer instances of under-illumination during operation. An automated calibration, which does not measure workplane illuminance directly, must instead assume how much workplane illuminance will increase when the luminaire directly overhead is active, based only on the properties of that luminaire and the height of the ceiling. This same value is assumed for every control zone regardless of its position in the space, and will be described in greater detail in the following sections.

\subsubsection{Correlation factor}

Correlation factors describe the relationship between workplane and ceiling illuminance in each individual control zone. This correlation is expressed as the ratio between ceiling and workplane illuminance sensor readings. For example, in Figure 3.1, the correlation factor for the active luminaire would be $15 / 176=0.085$. Accurately estimating workplane illuminance based on readings from the installed ceiling sensors is a necessary component of intelligent operation. Factory variations in each illuminance sensor, the placement and surface properties of objects, furnishings, flooring, etc. below the illuminance sensor, and variations in the composition of light illuminating the space mean that this correlation is highly context sensitive. One zone may have a sensor correlation of 0.1 , and another may be 0.2 or 0.4 , all at the same moment. Those same zones under different conditions, when exposed to intense direct sunlight, may have correlations that differ even more substantially. 
A single correlation factor for each control zone, calculated during calibration, is taken as representative during system operation even though the actual correlation between workplane and ceiling illuminance is variable and context sensitive. More advanced methods which adjust the correlation factor based on time of day, time of year, weather data, shade states, etc. may be practical in the future, but are not considered here. In a conventional calibration many correlations may be directly measured, including correlations found while there was intense direct or diffuse daylight, in addition to electric illumination. For each sensor, one correlation is taken from this population to be used during operation. Generally, one of the lower correlations from the population is chosen, as this results in underestimating rather than overestimating workplane illuminance, and thus reduces the risk of not delivering enough electric lighting where it is required.

An automated calibration procedure, which does not measure workplane illuminance directly, has only a single data point to take as the representative correlation factor. During calibration, a reading is taken at each sensor at the moment when the only luminaire active was the one in that sensor's own control zone. Without a measured workplane value to compare this against, a first principles-based value is assumed. When only a single luminaire placed directly overhead is active, estimating workplane illuminance is straightforward - ceiling height and the type of luminaire installed directly overhead are enough to produce a reasonable estimate. When the luminaire directly overhead is the only source of light, workplane illuminance is relatively context insensitive, varying by fairly small amounts regardless of where in the room it was installed. In the case of this study, ranging between 176 and 213 lx. To ensure a conservative estimate, the 
assumed value is calculated for the scenario with the lowest workplane illuminance - one without any reflecting surfaces nearby. In this study, $175 \mathrm{~lx}$ taken as the assumed value for workplane illuminance. In practice, an installer need only to enter the value for ceiling height and the model of luminaire, then software can select expected workplane illuminance from a table. These values can be derived experimentally, in simulation, or estimated by hand calculation. The calibration process is depicted in Figure 3.2, with branches for conventional and automated calibration.

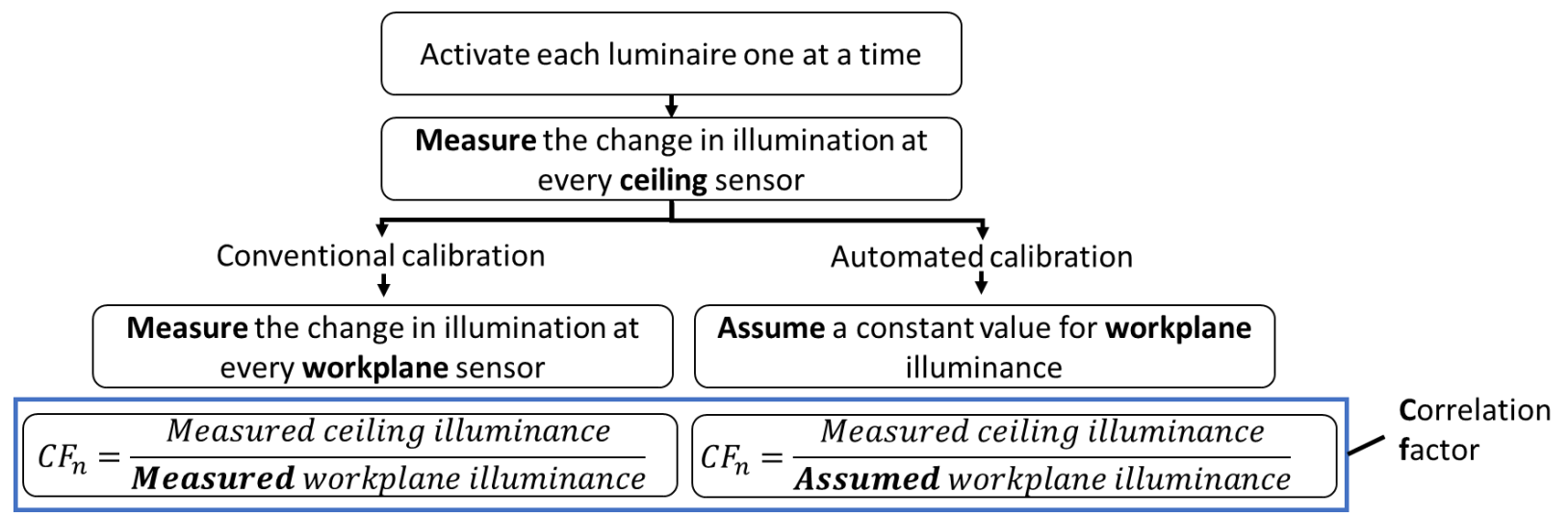

Figure 3.2, Flowchart describing the calibration procedure for determining correlation factors. Luminaires are activated in sequence and changes measured by every illuminance sensor are recorded. In a conventional calibration, workplane illuminance at each step is measured directly, in an automated calibration it must be assumed. The correlation factor $(C F)$ for each of $n$ control zones is calculated independently based on readings from the sensors in that zone.

\subsubsection{Coillumination table}

The coillumination table describes what effect turning on a particular light will have on each illuminance sensor in the space. This knowledge enables intelligent control that does not rely on continuous trial-and-error adjustment, which suffers from having a settling time that occupants may find distracting. For example, in Figure 3.1, we can see that when the 
luminaire indicated in yellow is activated, workplane and ceiling illuminance at the southeast corner of the room increases by only $5 \mathrm{~lx}$ and $2 \mathrm{~lx}$ respectively, but the closest sensors increase by as much as $78 \mathrm{~lx}$ at the workplane and $12 \mathrm{~lx}$ at the ceiling. This information allows an advanced control algorithm to predict what will happen throughout the room if the dimming setting on a light is changed. This solves the problem that a ceilingmounted illuminance sensor cannot differentiate between contributions from daylight and those from electric lighting. By interpolating the illuminance sensor reading expected due to electric lighting and subtracting that from the actual measurement, daylight can be disaggregated by assuming that it accounts for the remainder.

The process of estimating workplane illuminance due to electric lighting is performed for each control zone individually. During calibration, the coillumination table recorded that, for example, when the luminaire in control zone A was at $100 \%$ brightness, the workplane illuminance in control zone B increased by $601 x$. The control system can therefore estimate that if the luminaire at $\mathrm{A}$ is at $50 \%$ brightness, the workplane illuminance in zone $\mathrm{B}$ should increase by $30 \mathrm{~lx}$. The contribution of each luminaire, at its current dimming setting, is calculated in this way then summed together for each control zone to yield an estimate for illumination due to electric lighting in that zone. Subtracting this value from what is measured produces an estimate of the workplane illuminance attributable to daylight.

Disaggregating daylight is required to make effective control decisions. Ideally, electric lighting supplements daylight by no more than the amount required to reach the desired workplane illuminance. If, by the disaggregation method described above, workplane illuminance attributable to daylight in zone $\mathrm{A}$ is estimated to be $200 \mathrm{~lx}$, and the desired 
workplane illuminance is $400 \mathrm{~lx}$, the system understands it must provide $200 \mathrm{~lx}$ worth of electric lighting to the zone. Finding the ideal dimming configuration to achieve this is not trivial, because different zones will have different requirements, and illuminating one zone will help illuminate adjacent zones. Whereas simpler systems find a dimming configuration to supplement daylight by making continuous adjustments, an advanced system can find its ideal configuration computationally, using the same process with coillumination data described above. Only once an efficient, stable solution is determined luminaire dimming states in the room change.

Two assumptions enable the coillumination table to be utilized effectively. First, the luminous flux of each light is directly proportional to its dimming setting [70]. For example, if $100 \%$ dimming results in a 16 lx change in an adjacent sensor, $50 \%$ dimming will result in an $81 \mathrm{x}$ change. Second, light from different sources is additive [19]. Two separate lights which increase the illuminance sensor reading above a particular workstation by $12 \mathrm{~lx}$ and $13 \mathrm{~lx}$ independently will sum when both are active to increase the reading by $25 \mathrm{~lx}$. Combining the coillumination table with these two assumptions allows a control system to predict the illuminance at every sensor in a room, given any combination of dimming settings.

In a conventional calibration, the change in workplane illuminance is measured directly to produce a very accurate coillumination table. For an automated calibration, the correlation factor for each control zone must be utilized to estimate actual workplane illuminance in that zone using the reading at the ceiling sensor. While both conventionally and automatically calibrated systems must use the correlation factor to estimate workplane 
illuminance during operation, only an automatically calibrated system uses it to build the coillumination table. This additional layer of estimation during calibration results in less accurate results when predicting electric lighting contributions to ceiling sensor readings during operation.

\subsubsection{Simulation space}

To demonstrate the proposed methods, the current study simulates one room in an open plan office environment over a variety of electrical lighting and daylighting scenarios, measuring both workplane and ceiling illuminance throughout the space at a high resolution. All simulations are performed using DIALux evo version 8.1 software, which allows for detailed and accurate raytracing calculations for a diverse set of scenarios. DIALux is selected for its accuracy. Detailed raytracing enables simulated experiments to represent real-world measurements while offering a more controllable environment accurately.

The layout of the simulation space (Figure 3.3) is duplicated from prior research [62] and consists of a single room with one glazed façade and 16 cubicles of equal size, each with a single LED panel luminaire located directly overhead. Each cubicle has four workplane illuminance sensors and four ceiling illuminance sensors spaced in an equidistant grid, which are averaged to produce a single value for workplane and ceiling illuminance for each cubicle. Ceiling-mounted illuminance sensors have a restricted field of view of $45^{\circ}$, corresponding to a horizontal radius of $1.24 \mathrm{~m}$ on the floor. Workplane illuminance sensors, which have an unrestricted $180^{\circ}$ field of view, are placed at a height of $0.8 \mathrm{~m}$ and oriented directly upwards. 


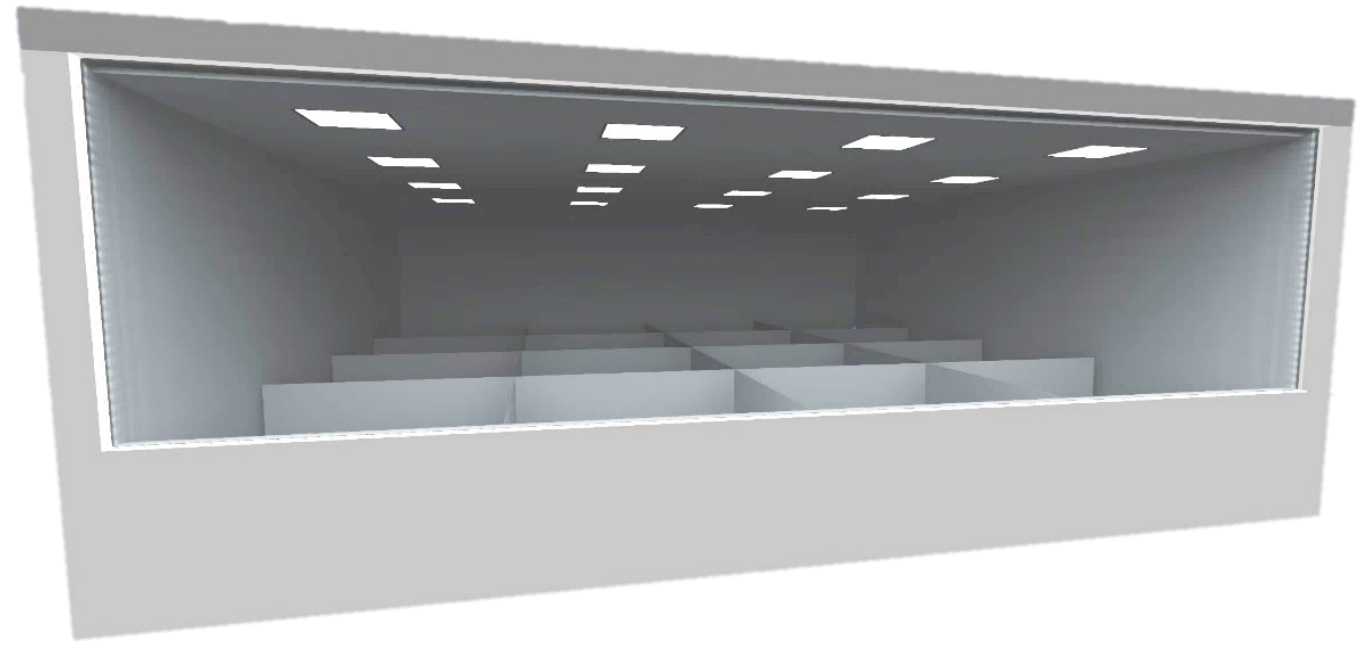

Figure 3.3, DIALux evo rendering of simulation space. One open plan office consisting of 16 cubicles is simulated.

The interior geometry of the room is simplified and consists of $1 \mathrm{~m}$ height partitions dividing each of the room's 16 cubicles. Cubicle walls act in the lighting simulation to limit daylight penetration more realistically and generally limit how readily light reflects and diffuses throughout the space. Actual office environments generally contain obstructions to light diffusion, including desks, computers, wall furnishings, plants, chairs, etc. To reduce model complexity, these objects are omitted. Complete dimensions are provided in plan (Figure 3.4) and elevation (Figure 3.5) projections of the simulation space. Interior reflectance values are 50\% for walls and partitions, $20 \%$ for floors, and $70 \%$ for the ceiling. 


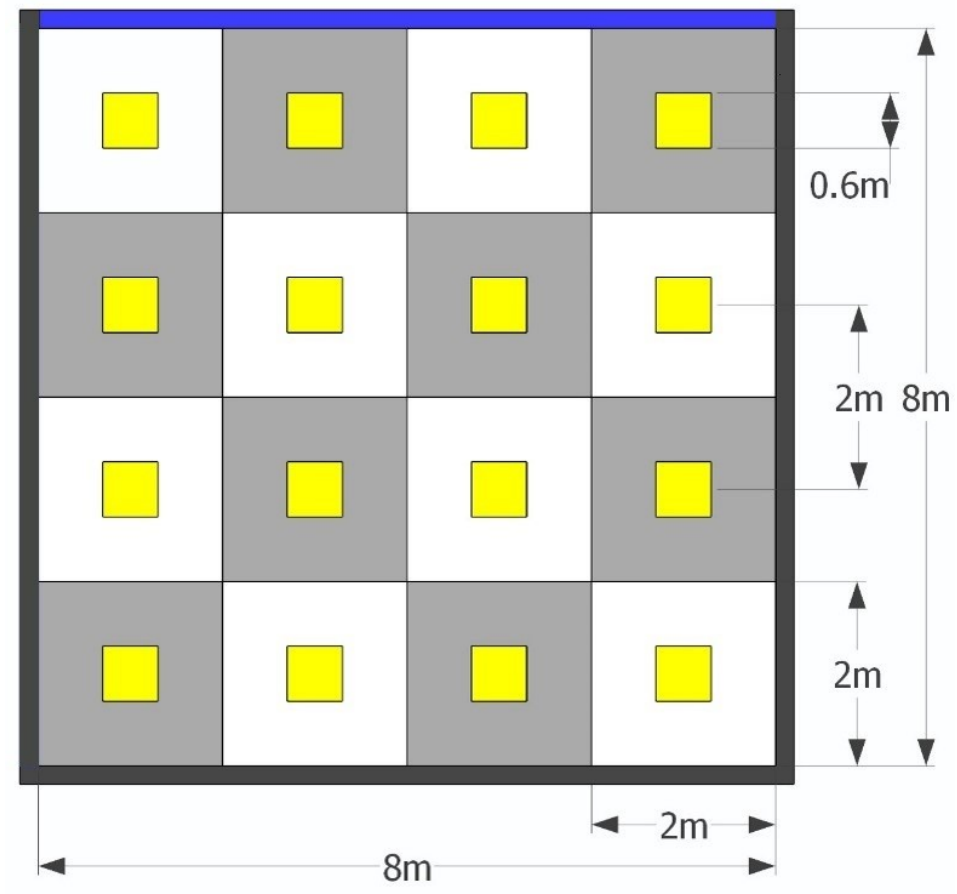

Figure 3.4, Floorplan with dimensions of simulation space. Sixteen cubicles of equal size, each of which has its own luminaire and illuminance sensor, are evenly spaced throughout the room.

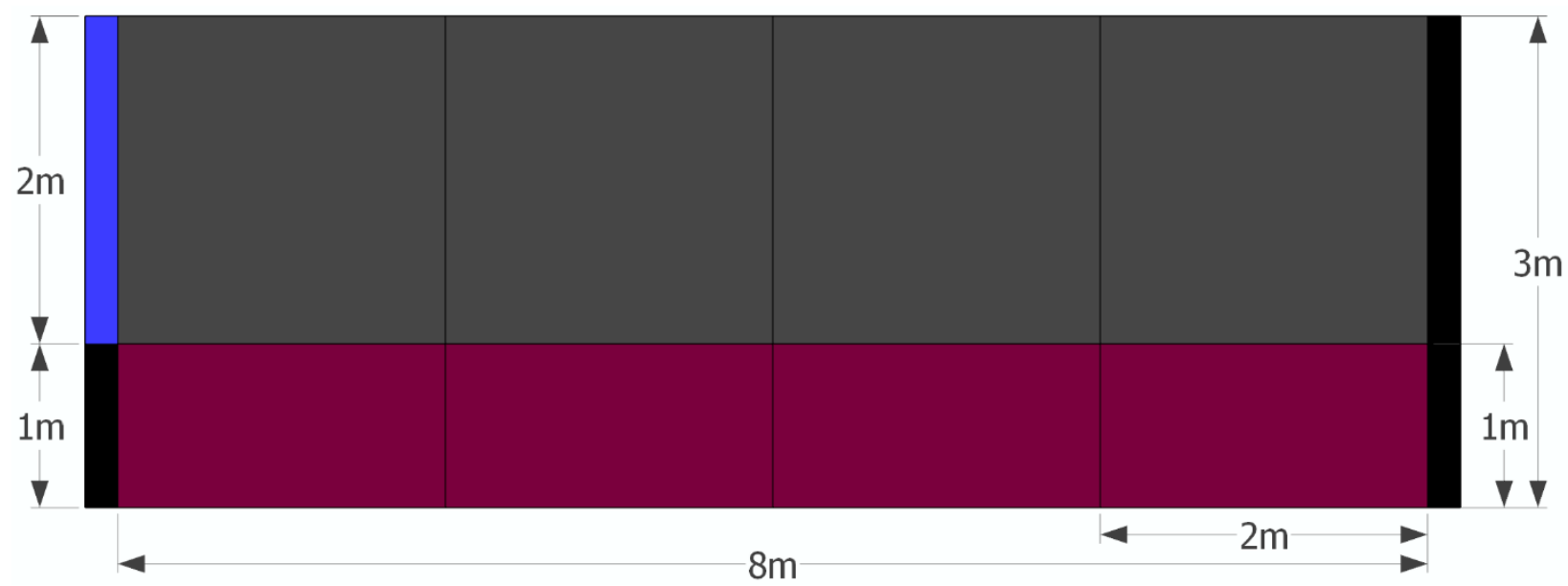

Figure 3.5, Elevation view of simulation space with dimensions. Short partition walls $1 \mathrm{~m}$ in height divide each cubicle. A single window spans the entire width and top 2/3 of one façade. 


\subsubsection{Lighting scenarios}

Sixteen daylight scenarios are considered. These scenarios are selected to compare sensor correlations when solar angle and intensity and the ratio of direct and diffuse daylight vary. Windows with a $2 \mathrm{~m}$ height running across the full width of the façade allow for significant daylight penetration, and a room depth of $8 \mathrm{~m}$ allows for a large difference in daylight illumination between cubicles near the window and those farther away, as seen in Figure 3.6. The office is located in Ottawa, Canada. The sixteen daylighting scenarios simulated represent every combination of three relevant parameters: atmospheric conditions, date and time, and façade orientation. Each option simulated for these three parameters is listed in Table 3.1. Daylight scenarios are selected to represent both intense direct and dim diffuse illuminance, as well as daylight that enters the façade at high angles with low penetration, and at low angles that penetrate deeper into the space.

\section{Table 3.1}

Options for three simulation parameters are selected to have representative samples across a variety of daylighting circumstances. Sixteen daylight simulations are performed, consisting of every combination of these parameters. As an example: one simulation specifies clear skies, happens at 8:00 am on December $22^{\text {nd }}$, and has the glazed façade oriented West.

\begin{tabular}{|l|l|l|}
\hline Atmospheric conditions & Date and time & Façade orientation \\
\hline Clear & July $21^{\text {st }}$ at $12: 00 \mathrm{pm}$ & North \\
\hline Overcast & December $22^{\text {nd }}$ at $8: 00 \mathrm{am}$ & East \\
\hline \multirow{2}{*}{} & South \\
\cline { 2 - 3 } & West \\
&
\end{tabular}


Daylighting data can be used as part of the conventional calibration process, providing a larger pool of sensor correlations to consider when determining the representative correlation factor for each zone. Daylighting data is not used during an automated calibration because workplane illuminance is not measured. In the current study, daylighting data is used to evaluate system performance in estimating actual workplane illuminance during operation (once workplane sensors have been removed) for both conventionally and automatically calibrated systems.

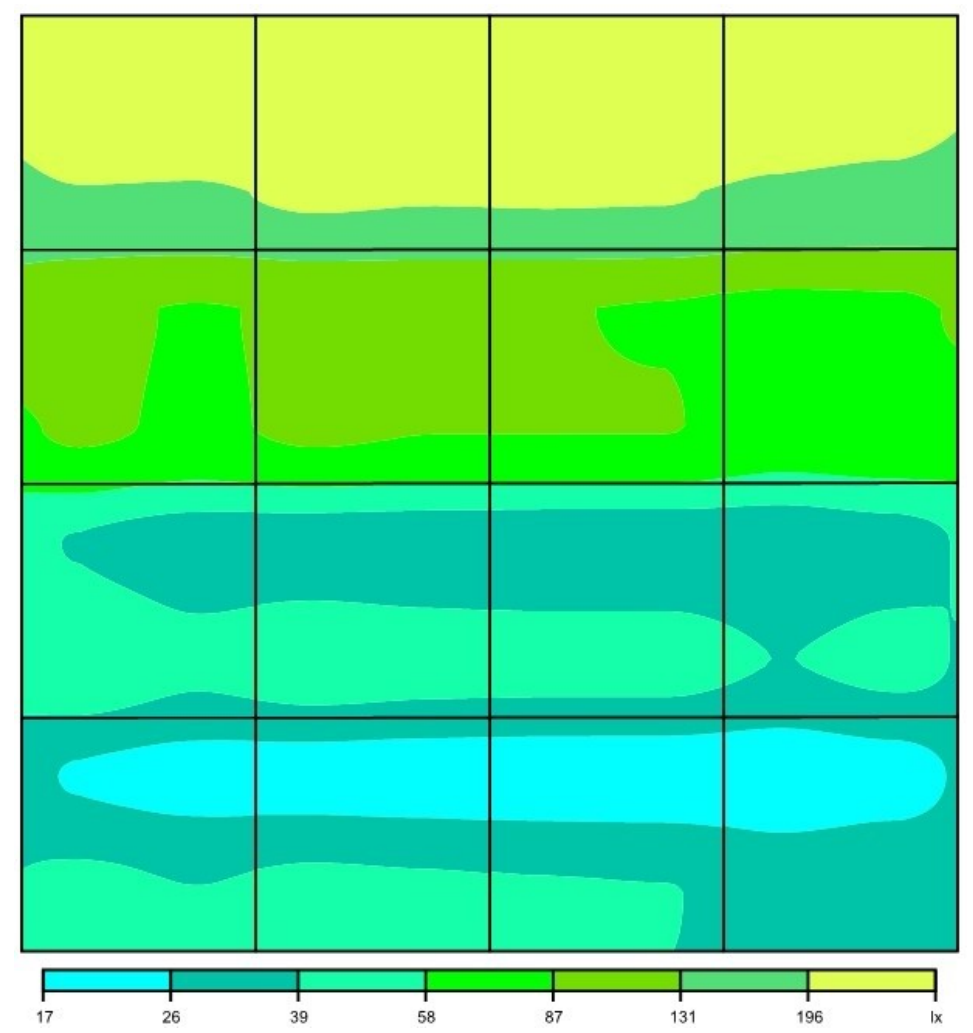

Figure 3.6, False color representation of workplane illuminance in lx due to daylight in the simulation space at 8:00 am on December $21^{\text {st }}$ in Ottawa, ON with a west facing façade and clear skies. Daylight illuminance near the window (top of figure) is 200 lx but drops below 20 lux at the rear of the room. 
Sixteen electric lighting simulations are performed. These represent the calibration procedure described in Figure 3.1, where each of the sixteen individual luminaires is activated in sequence while all others remain inactive. For both conventionally and automatically calibrated systems, this data is used to determine correlation factors for each control zone and the coillumination table for the room. As with simulated daylight data, the workplane and ceiling illuminance values measured in these electric lighting scenarios are used to evaluate overall system performance.

\subsection{Results and Discussion}

\subsubsection{Approach to analysis}

Variability in the correlation between actual workplane illuminance and illuminance measured at the ceiling means that any system which relies solely on ceiling mounted illuminance sensors during operation must accept and account for a level of uncertainty. The current study quantifies this uncertainty. It then quantifies the additional uncertainty introduced by replacing conventional calibration, which utilizes temporary workplane illuminance sensors, with automated calibration, which does not.

Section 3.5 .2 begins the analysis by describing how significant the variability in ceiling to workplane illuminance ratios are, establishing the causes of baseline uncertainty in system operation. 3.5.3 presents methods and results for establishing correlation factors in conventionally and automatically calibrated systems. 3.5.4 describes the coillumination tables generated by each calibration process, quantifying and visualizing the errors introduced by automated calibration. Finally, in Section 3.5.5, an ideal system that directly measures real workplane illuminance is compared against conventionally and 
automatically calibrated systems that must estimate workplane illuminance based on ceiling sensor readings during operation. The magnitude and distribution of the uncertainties inherent to operation and those introduced by the automated calibration process are compared to determine whether an automated calibration process is viable for real-world implementation.

\subsubsection{Correlation between workplane and ceiling illuminance levels}

Across 32 simulations, 16 electric lighting simulations and 16 which measured varying daylighting conditions, the correlation between workplane and ceiling illuminance is found to vary significantly. The entire dataset consists of 32 simulations with 16 control zones and thus 16 correlations in each, for a total of 512 individual correlations. Across each of these individual workplane to ceiling illuminance correlations, the lowest ceiling to workplane ratio observed is 0.027 and the highest is 0.201 . Figure 3.7 shows the variation in the correlation as a function of actual workplane illuminance on the horizontal axis. This exposes a broad inverse relationship between workplane and illuminance and sensor correlations. Figure 3.8 separates variability in sensor correlation to each of the sixteen unique control zones in the room, demonstrating that variability is sensitive to the position within a space. 


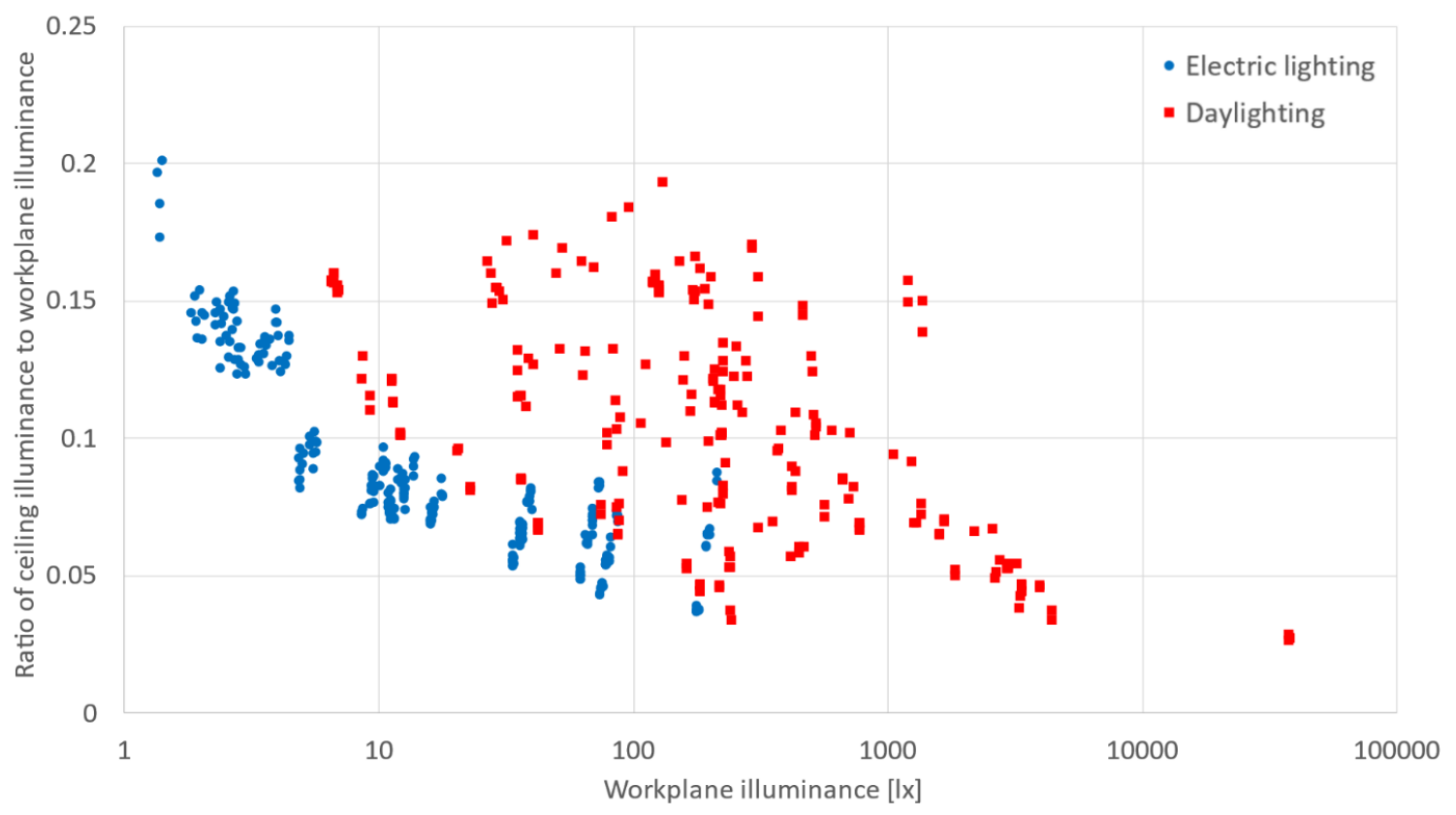

Figure 3.7, Actual correlation between ceiling and workplane illuminance for each sensor in every electric lighting and daylighting scenario simulated. Blue markers are correlations measured when electric lighting was activated, red are for daylighting. Correlation is expressed as a ratio of measured ceiling illuminance over workplane illuminance and is described relative to actual workplane illuminance on the horizontal

The ratio or correlation of ceiling to workplane illuminance is found to be higher when workplane illuminance is lower. This holds true for both electric lighting scenarios (where a lower workplane illuminance indicates a more distant active luminaire) and daylight scenarios. The highest correlation of 0.201 is found where workplane illuminance is only $1.4 \mathrm{~lx}$, caused by a single active luminaire at the opposite end of the room. The lowest correlation of 0.027 is found in a workstation next to the window on a particularly bright day, with a workplane illuminance of 37,403 1x. Significant variability in the correlation can be attributed to several factors. The angle at which light strikes a surface, the ratio of direct and diffuse illumination, and the number of bounces for a beam to reach either a workplane or ceiling sensor all contribute to this variability. During system operation, it is impractical to attempt to account for each of these parameters to intelligently adjust the 
correlation factor for a control zone. The control algorithm must use a single correlation factor regardless of these parameters. Selecting which of these correlations to take as representative will be discussed in Section 3.5.3.

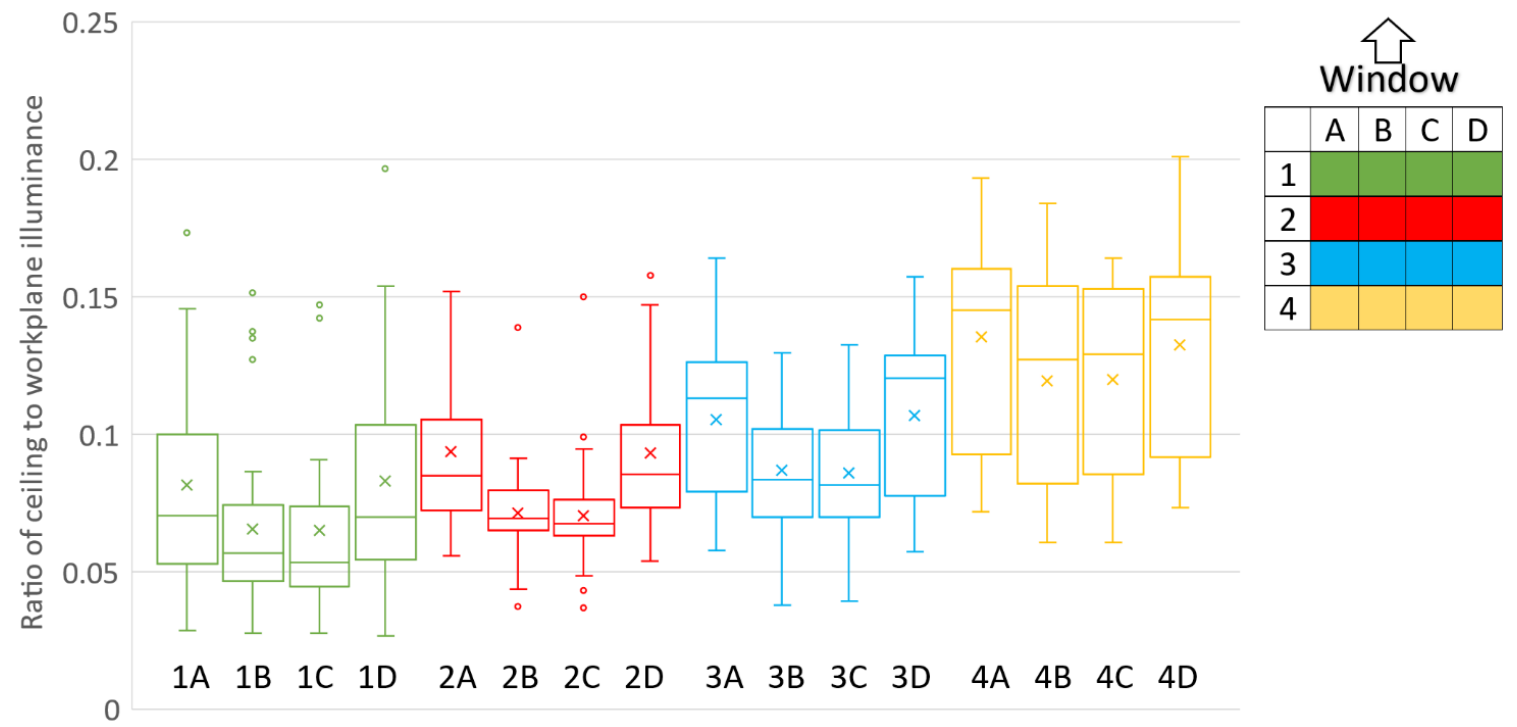

Figure 3.8, Correlation between ceiling and workplane illuminance for all electric and daylighting scenarios simulated divided into results for each of the 16 sensors in the room. Sensors are listed by (row, column) with the first column being the cubicles to the left of the window and the first row being the cubicles nearest the window. Greater variation in the correlation is observed around the perimeter of the room where reflected and diffused light off nearby walls plays a greater role in total workplane illuminance.

Figure 3.8, which includes both electric and daylighting data, demonstrates that the distribution of sensor correlation variability changes between control zones. Sensors around the perimeter of the room show greater variation than those in the center. This is due to the presence of nearby reflecting and diffusing wall surfaces which may play a greater or lesser part in illuminating the workplane depending on the orientation and composition of the light sources. Similarly, cubicles farther back from the façade vary more greatly than those nearer, again because of the relative significance of reflected 
illumination over that of illumination striking the surface immediately after entering through the façade.

Such significant variation in the ceiling to workplane illuminance correlation, foundational to daylight control via ceiling sensors, creates an upper limit on how efficient these systems can be without risking frequent incidences of under-illumination. If an average of these correlations is taken as representative for each sensor during operation, the system may either over or underestimate workplane illuminance due to daylight and consequently deploy too little or too much electric lighting. Taking a lower correlation as representative will result in frequently underestimating, but rarely overestimating, workplane illuminance. This will cause over-illumination and some additional wasted energy, but rarely under-illuminate the space. In practice, the latter option is preferable. Over-illumination, which results in some wasted energy, is acceptable, under-illumination causing occupant discomfort or eye strain in most contexts is not.

\subsubsection{Determining correlation factors without workplane illuminance data}

Figure 3.9 traces the process of correlating workplane to ceiling illuminance for each sensor using data generated during a conventional calibration. Illuminance values for each control zone are obtained during the calibration step, where only that workstation's luminaire was active. Workplane illuminance directly below each individually activated luminaire (Figure 3.9a) varies little. Zones in the middle of the room indicate lower workplane illuminance values of 176-177 1x, while those around the perimeter receive a greater contribution from light reflected off nearby walls and range from 180 to 213 lx. Measured illuminance at the ceiling (Figure 3.9b) varies more significantly, between 6.5 
and $18.61 \mathrm{x}$. Correlations between these values, the ratio of ceiling illuminance to workplane illuminance, (Figure 3.9c) range from 0. 037 to 0.087, expressed in the figure as a percentage.

(a)

(b)

\begin{tabular}{|l|l|l|l|l|l|l|l|l|l|l|l|}
\hline 198 & 180 & 180 & 198 & 12.9 & 6.8 & 6.8 & 13.3 & $6.5 \%$ & $3.8 \%$ & $3.8 \%$ & $6.7 \%$ \\
\hline 194 & 176 & 176 & 194 & 12.6 & 6.5 & 6.5 & 12.6 & $6.5 \%$ & $3.7 \%$ & $3.7 \%$ & $6.5 \%$ \\
\hline 195 & 177 & 177 & 195 & 12.7 & 6.7 & 6.9 & 12.7 & $6.5 \%$ & $3.8 \%$ & $3.9 \%$ & $6.5 \%$ \\
\hline 213 & 193 & 193 & 213 & 18.6 & 11.8 & 11.7 & 18.0 & $8.7 \%$ & $6.1 \%$ & $6.1 \%$ & $8.5 \%$ \\
\hline
\end{tabular}

Figure 3.9, A conventional calibration process where (a) workplane illuminance in each control zone is measured directly and compared against (b) ceiling illuminance in that control zone to generate (c) correlation factors for each sensor. The window is located at the top of each figure.

To prioritize occupant comfort over additional savings, a conservative correlation factor that will more frequently over-illuminate a space but less frequently under-illuminate it is preferred. A conventional calibration, which includes workplane illuminance sensors to capture daylighting data, may draw from a significantly larger pool of correlations to determine the best correlation factors to be used during operation. Figure 3.10 depicts the correlation factors if the $10^{\text {th }}$ percentile (a), $5^{\text {th }}$ percentile (b), or minimum (c) correlations found for each control zone individually (as seen in Figure 3.8) are taken to be representative. For example, if the $10^{\text {th }}$ percentile correlation is selected for a control zone, in $90 \%$ of the situations sampled workplane illuminance will be underestimated, and in $10 \%$ it will be overestimated. For zones in the middle of the room the $10^{\text {th }}$ and even $5^{\text {th }}$ 
percentile correlations exceed the correlation factors determined by the previous method (Figure 3.9c). In fact, for six zones, the lowest correlation in the dataset is found when the luminaire for that control zone is active.

(a)

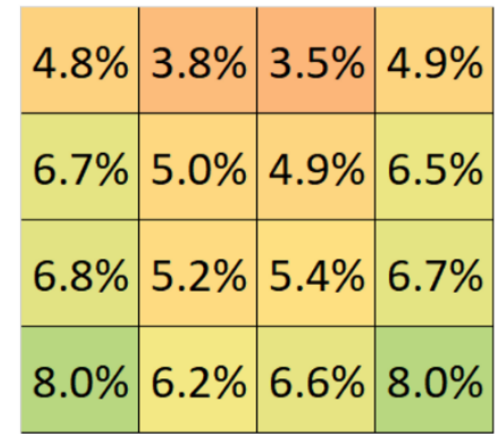

(b)

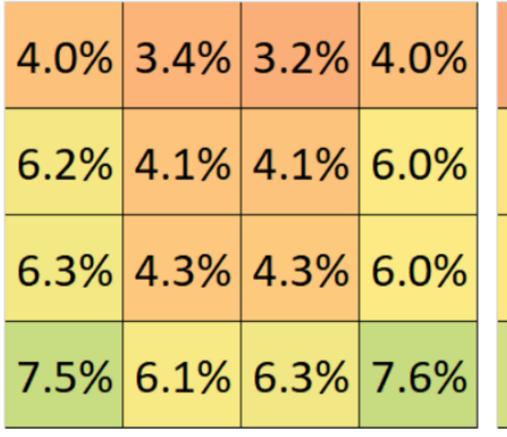

(c)

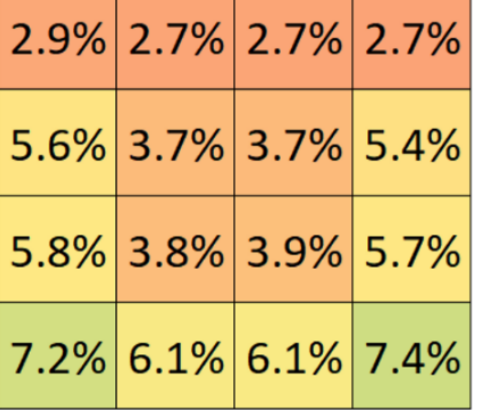

Figure 3.10, Alternative calibration factors derived from the conventional calibration process. (a) takes the $10^{\text {th }}$ percentile correlation from the entire dataset (including both electric light and daylight) to be representative, (b) takes the $5^{\text {th }}$ percentile, and (c) takes the minimum value.

In an automated calibration where workplane illuminance data is not gathered, a single value for expected workplane illuminance directly below an active luminaire must be assumed. This value may be derived experimentally, in simulation, or directly calculated, and is based on the specifications of the luminaire used and the distance between the luminaire and the workplane. Because the same value will be used regardless of where the luminaire is installed, a lower value corresponding to a lighting zone in the middle of a room farther from walls will be preferable, to ensure a more conservative estimate. Figure 3.11 depicts an automated calibration without knowledge of actual workplane illuminance, instead substituting a single conservative value of $175 \mathrm{~lx}$ (similar to what was measured in the middle of the room in Figure 3.9). Correlations determined by this method vary between 0.037 and 0.106 . 
(a)

\begin{tabular}{|l|l|l|l|}
\hline 175 & 175 & 175 & 175 \\
\hline 175 & 175 & 175 & 175 \\
\hline 175 & 175 & 175 & 175 \\
\hline 175 & 175 & 175 & 175 \\
\hline
\end{tabular}

(b)

\begin{tabular}{|c|c|c|c|}
\hline 12.9 & 6.8 & 6.8 & 13.3 \\
\hline 12.6 & 6.5 & 6.5 & 12.6 \\
\hline 12.7 & 6.7 & 6.9 & 12.7 \\
\hline 18.6 & 11.8 & 11.7 & 18.0 \\
\hline
\end{tabular}

(c)

\begin{tabular}{|l|l|l|l|}
$7.4 \%$ & $3.9 \%$ & $3.9 \%$ & $7.6 \%$ \\
\hline $7.2 \%$ & $3.7 \%$ & $3.7 \%$ & $7.2 \%$ \\
\hline $7.3 \%$ & $3.8 \%$ & $4.0 \%$ & $7.3 \%$ \\
\hline $10.6 \%$ & $6.7 \%$ & $6.7 \%$ & $10.3 \%$ \\
\hline
\end{tabular}

Figure 3.11, Automated calibration process where workplane illuminance (a) directly below an activated luminaire is always assumed to be 175 lx. Ceiling sensor values (b) are compared against this assumed value to generate alternative correlation factors (c) which do not require the use of workplane illuminance sensors to derive.

\subsubsection{Coillumination table without workplane illuminance data}

Figure 3.12 describes the error in coillumination data for an automated calibration relative to an ideal conventional calibration. Error is expressed in lux and as a function of the actual change in workplane illuminance. Significant discrepancies are found here. In $16 \%$ of cases, the error in estimating workplane illuminance exceeds the actual change in workplane illuminance. The most substantial errors occur when a more distant luminaire is the light source, i.e. the change in workplane illuminance is small. The automated calibration method tends to overestimate workplane illuminance when the luminaire is farther from the sensor and underestimate it when the luminaire is near, with values in the middle being more evenly distributed. 


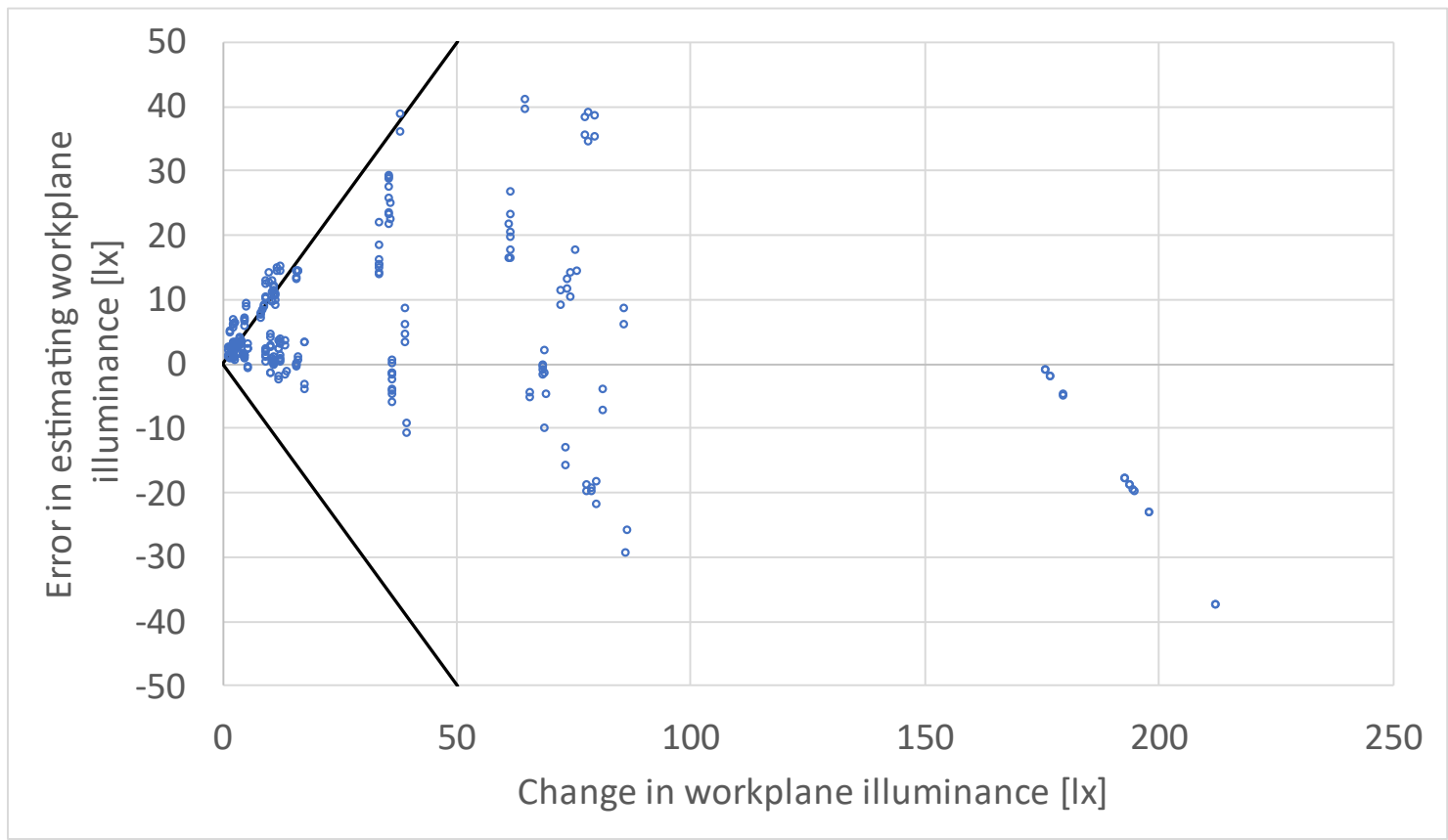

Figure 3.12, Error in estimating workplane illuminance during an automated calibration, expressed as a function of actual change in workplane illuminance. Diagonal $y=x$ and $y=-x$ lines are included for reference to show where errors in estimation exceed the actual workplane illuminance value. Positive values indicate overestimation of workplane illuminance and negative values indicate underestimation.

Figure 3.13a visualizes the complete coillumination table for the entire room when a conventional calibration is utilized. Figure $3.13 \mathrm{~b}$ depicts the coillumination table when an automated calibration procedure without workplane sensors is used. Figure 3.14 describes how the two coillumination tables differ from one another, with negative (red) values indicating that the automated calibration has underestimated the actual change in workplane illuminance. From these visualizations, it becomes clear that underestimation generally occurs in cubicles around the perimeter of the room, while overestimation occurs in cubicles farther from the walls in the middle of the room. 
(a)

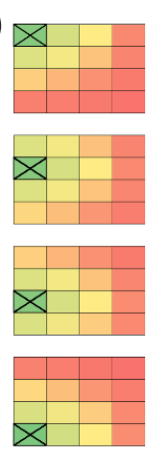

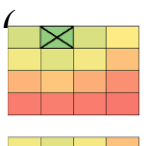
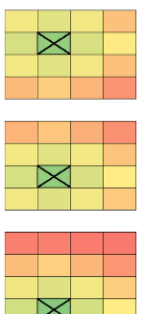
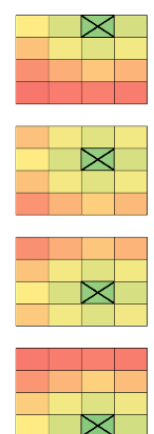
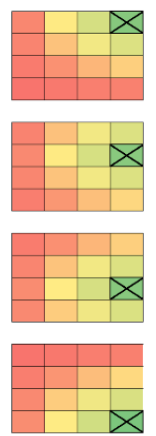

(b)
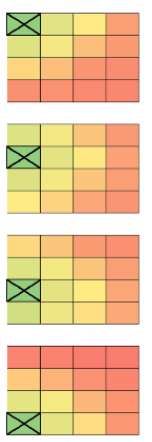
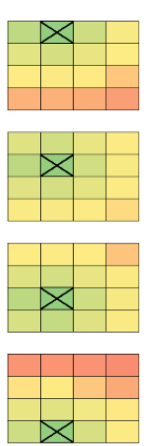
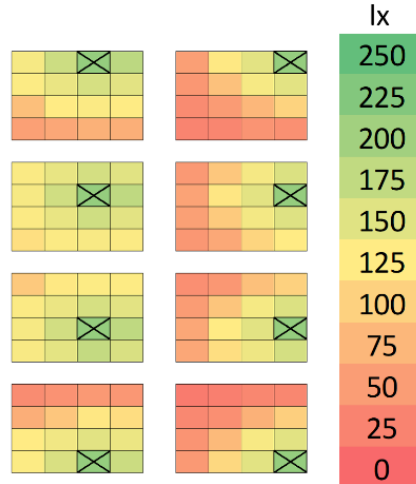

Figure 3.13, Heatmap of the coillumination table (the change in workplane illuminance when each luminaire is activated) measured directly via a conventional calibration (a) and estimated using an automated calibration process (b). Sixteen heatmaps for either calibration process are depicted, each of which includes sixteen individual measurements representing workplane illuminance in each workstation.

Each heatmap depicts a moment where only a single luminaire was active in the space, identified as the lamp in the zone marked with a cross.
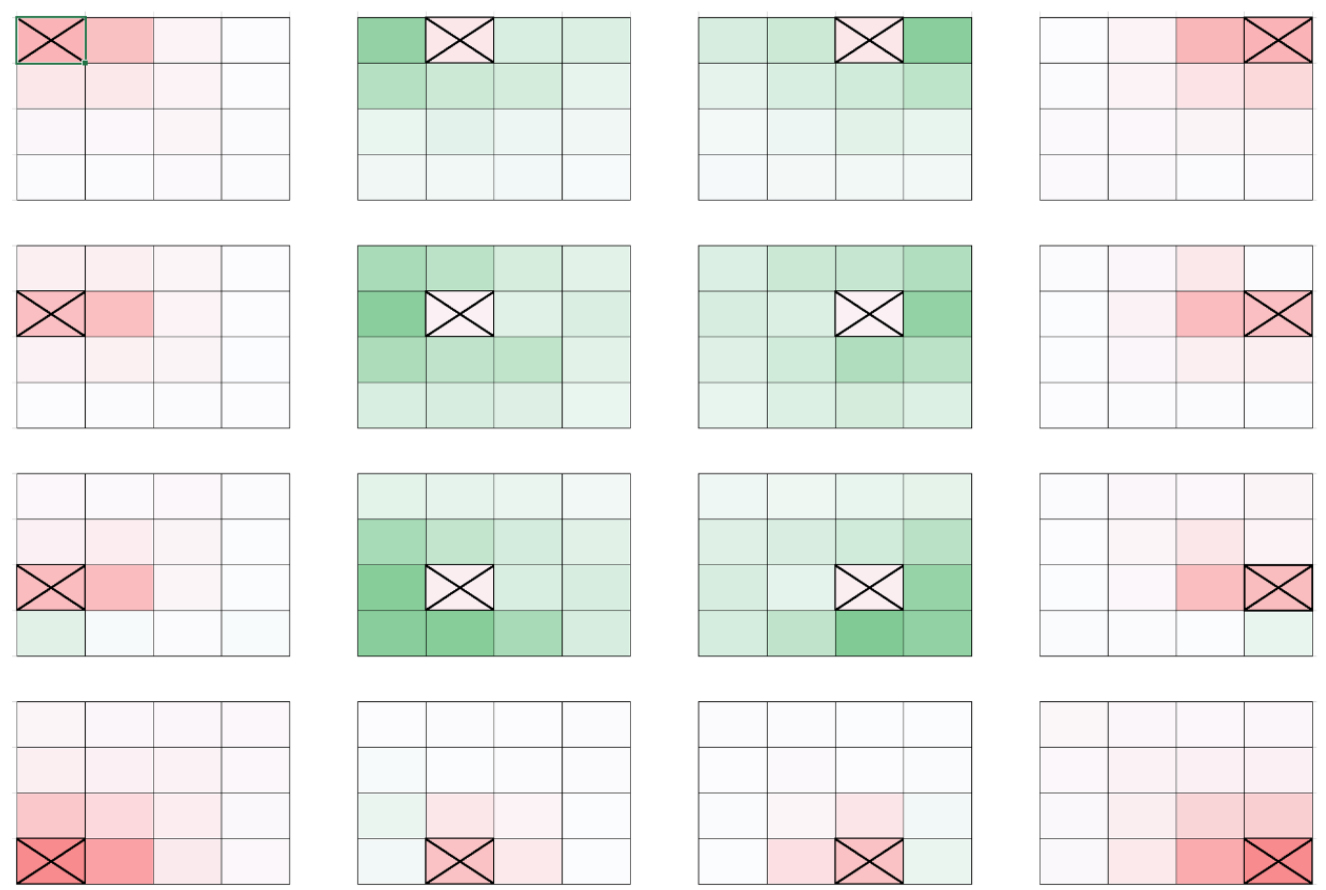

Ix

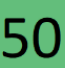

40

30

20

10

0

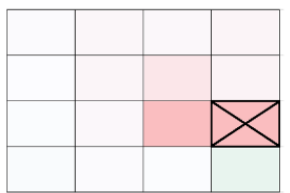

$-10$

$-20$

$-30$

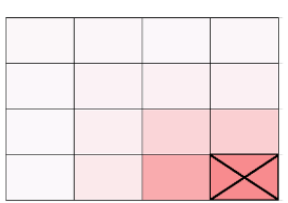

$-40$

$-50$

Figure 3.14, Error in estimating workplane illuminance in the coillumination table during an automated calibration. Each heatmap depicts the difference between corresponding calibration steps in figures $13 a$ and $13 \mathrm{~b}$. When luminaires near walls are activated the estimated workplane illuminance values tend to be lower than those measured directly. When luminaires farther from walls are activated, it is generally overestimated. Zone with cross indicates active luminaire. 


\subsubsection{Comparison of conventional and automated calibration}

Sensor-array lighting system performance is evaluated by comparing system estimates for workplane illuminance during operation to actual, measured workplane illuminance. Two systems are examined, one where a conventional calibration was used, and another where an automated calibration was employed. 102 lighting scenarios are examined. Each lighting scenario combines one of seventeen daylighting scenarios with one of six electric lighting scenarios. Sixteen simulated daylighting conditions and one condition without any daylight are considered. One of the six electric lighting scenarios has all luminaires active at $100 \%$ brightness, another has all luminaires inactive, and the remaining four have each individual luminaire dimmed to a random setting. Figure 3.15 visualizes the results of these 102 trials for each of the 16 control zones in the room. Cases where actual measured workplane illuminance exceeds $1000 \mathrm{~lx}$ are excluded from the analysis. Any differences in system performance beyond that point are irrelevant to the problem of lighting control in open-plan offices, where target workplane illuminance values generally fall in the 300 to 5001x range. 
(a)

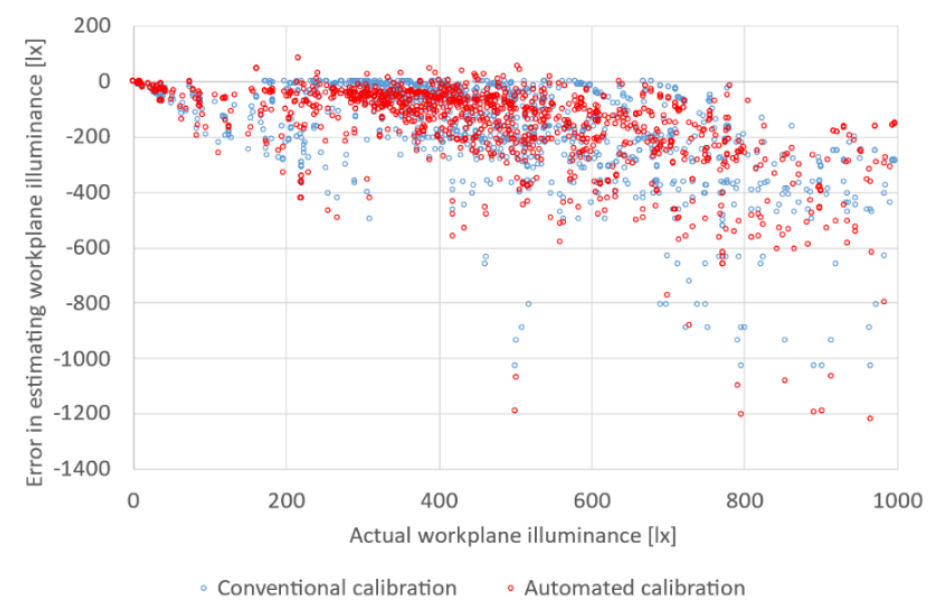

(b)

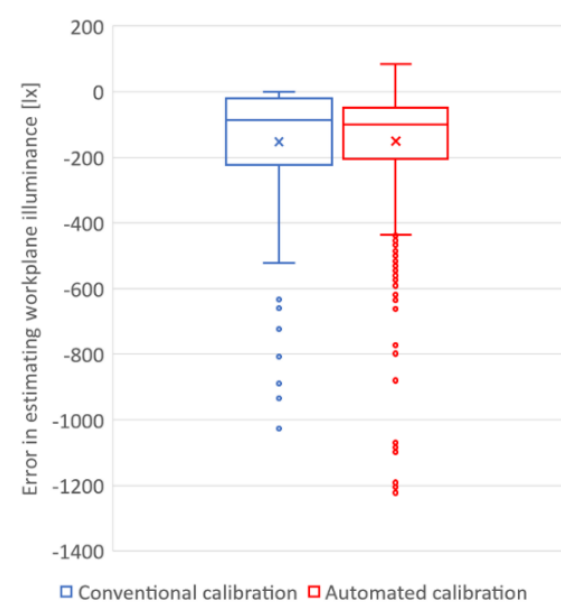

Figure 3.15, Accuracy of conventionally calibrated (blue) and automatically calibrated (red) systems in predicting workplane illuminance when subjected to a variety of daylighting and electric lighting scenarios. Datapoints where actual workplane illuminance exceeds $1000 \mathrm{~lx}$ are excluded as irrelevant. Positive values indicate that workplane illuminance was underestimated, negative values indicate it was underestimated. Results are expressed as a function of actual workplane illuminance on the $x$ axis in (a) and as a box and whisker plot in (b). Despite the errors introduced by an automated calibration, overall performance is generally similar.

The performance of conventionally and automatically calibrated systems in predicting workplane illuminance is comparable. Both systems experience significant errors, but the overall magnitude and distribution in error between approaches is similar, with generally comparable mean, median, and standard deviation. Conventional calibration underestimates workplane illuminance by an average of $152.61 \mathrm{x} \pm 12.2 \mathrm{~lx}$ at $99 \%$ confidence, and automated calibration underestimates it by an average of $150.31 \mathrm{x} \pm 11.5$ lx at $99 \%$ confidence. The most significant difference is that the conventionally calibrated system never overestimated workplane illuminance (only underestimated it), while the automatically calibrated system overestimated it in $2.9 \%$ of cases, with the most extreme overestimation being $83.7 \mathrm{~lx}$ in one control zone. Assuming a target workplane illuminance 
of $400 \mathrm{~lx}$, this might result in the system under-illuminating a zone by up to $21 \%$ in the worst-case scenario. This represents a relatively small and infrequent error, acceptable in the context of a commercial lighting installation. A high-resolution daylight-controlled lighting system calibrated automatically, without the use of workplane illuminance sensors, should therefore be considered as a practical alternative to manual calibration.

\subsection{Conclusion and recommendations}

By analyzing workplane and ceiling illuminance data generated under a variety of scenarios in a simulated environment, this study has evaluated the relative performance of conventionally and automatically calibrated high-resolution daylight-controlled lighting systems. The uncertainty inherent to estimating workplane illuminance using ceiling sensors during operation is significant. Correlations between ceiling and workplane illuminance vary significantly, ranging in the current study between 0.0266 and 0.201 . A calibration procedure can only provide one fixed correlation factor - but in reality, the correlation changes constantly depending on the state of electric lighting, the position of the sun, cloud cover, and many other factors. Estimating workplane illuminance using ceiling sensors is an inexact science.

The additional uncertainty introduced by an automated calibration that forgoes workplane sensors is small, relative to the uncertainties inherent to estimating workplane illuminance using ceiling sensors during operation, regardless of the calibration method. In actual ability to estimate workplane illuminance across many combined daylight and electric lighting scenarios, conventionally and automatically calibrated systems were found to perform similarly. Therefore, practical implementation of systems that can be calibrated 
and commissioned automatically at regular intervals should be further explored. Automatically calibrated systems may be installed at a lower cost, with significantly less human labour. Because these systems can be easily recalibrated at regular intervals, commissioning and fault detection may also be automated. Luminaire and sensor failures can be easily detected, and changes in the behavior of light in the room due to moving partitions, furnishings, etc. may be accounted for.

Future work should examine the balance between energy savings and occupant comfort when selecting the conservativeness of a correlation factor. Experimental studies should be performed to replicate and verify the results of this simulation study. A wider variety of room sizes and configurations should also be explored. The results in the current study are applicable to generally similar rooms of moderate size with standard height ceilings. The behavior of light and the performance of daylight-controlled systems may differ significantly in larger spaces with very high ceilings. 


\section{Chapter 4: Conclusion}

\subsection{Summary of findings}

High-resolution sensor-array lighting systems are a significant, untapped potential source of energy savings in an open-plan office setting. Commercial lighting has become significantly more efficient in recent years, due primarily to the adoption of efficient LED luminaires, but also to the implementation of daylight harvesting and occupancy sensing controls. Whereas commercial daylight and occupancy sensing systems have been implemented at only coarse spatial resolutions, typically an entire room, higher-resolution control will be required to realize additional savings. After the adoption of LED luminaires, incremental improvements to efficiency in individual luminaires will be slower. Creative solutions to lighting control that ensure only occupied areas, and areas without sufficient daylight, are illuminated electrically offer the most potential for additional efficiency in future commercial lighting systems.

The second chapter of this thesis demonstrated that energy savings from sensorarray lighting systems are highly context sensitive. It identified applications with the greatest savings potential to target for early adoption, and provided an understanding how and where savings are derived. The study confirmed that high-resolution control will outperform a conventional single control zone lighting system in any scenario. Further, it demonstrated that the greatest savings relative to conventional control are attained where some control zones receive adequate daylight and some do not, and where some zones are occupied and some are not. It showed that substantial energy savings are not contingent on high glazing ratios, particularly sunny climates, or specific façade orientations. With high- 
resolution control, savings for the entire floor were not lower than $61 \%$ and were as high as $91 \%$.

The third chapter demonstrated that automated calibration is a viable alternative to conventional manual calibration of sensor-array lighting systems. It showed that the uncertainties inherent to estimating workplane illuminance using ceiling-mounted sensors during operation significantly outweigh the errors introduced by omitting temporarily placed workplane illuminance sensors from the calibration process. Analysis showed that manually and automatically calibrated systems performed similarly in estimating workplane illuminance using ceiling sensors during operation. The chapter described a method whereby a worker needs only enter a value for ceiling height and the model of luminaire installed into the control software, and it will be able to calibrate itself and recalibrate itself, automatically, as often as is required.

\subsection{Key contributions}

- A simulation framework for understanding how effective sensor array lighting may be at saving energy given a known set of circumstances such as geographic location, room and glazing geometry, and relative occupancy was developed.

- The range and magnitude of energy savings when high-resolution control is utilized was demonstrated.

- The instability in the correlation between workplane and ceiling illuminance across changing circumstances of electric and daylighting was demonstrated.

- An automated calibration procedure that can serve as a more practical alternative to time-consuming manual calibration was introduced. 


\subsection{Gaps and future work}

The studies comprising this thesis represent only single steps on the path towards wide commercial implementation of intelligent sensor-array lighting systems. This thesis analyzed data produced in simulation tools not designed to interface directly with advanced control techniques. Data had to be analyzed outside of the simulation tools using spreadsheets and scripts, an inefficient workflow which placed limits on how ambitious these studies could be. A more advanced, more specialized software solution that can accurately model daylight, electric lighting, and occupancy, then allow a user to program controls as desired would be an invaluable tool. A fully customizable environment in which advanced control approaches could be quickly and accurately prototyped and iterated on. Future work should seek to develop such a software solution to hasten research and development in this field, and perform more thorough simulation studies with a greater number of parameters considered.

Simulation studies such as those performed in this thesis provide an excellent controlled environment that can be easily adjusted, but results must be verified experimentally. Experimental research testing system accuracy, energy savings, the energy use of control equipment, and calibration performance in a controlled environment should be performed in the future. Larger studies which include many variations of daylight availability, room configurations, occupancy patterns, and other relevant parameters should be performed to demonstrate experimentally how savings vary across differing circumstances. 
The additional complexity inherent to installing and operating these systems is a potential challenge. To supersede incumbent lighting solutions, they must not present a more daunting operation and maintenance task to operators. Simplicity and reliability are paramount. This thesis demonstrated a solution that meets these criteria in theory, but has not demonstrated it practically. Researchers and developers of commercial systems must demonstrate that automated calibration works in practice, that systems are reliable, and that auto-commissioning mitigates maintenance burdens imposed by additional complexity.

Future work must take the contributions found in this thesis and in other relevant research and perform an exhaustive, practical economic analysis to make a case for wide commercial implementation. This thesis represents a step towards demonstrating that highresolution daylight-controlled and occupancy-sensing lighting should be widely adopted, but without thorough economic analysis followed by real-world pilot projects, they will remain within the realm of research indefinitely. Significant energy savings across all common contexts and an ability to self-calibrate show that these systems are ready to become a part of our built environment. 


\section{References}

[1] “Commercial/Institutional Secondary Energy Use (Final Demand) by Energy Source, End Use and Activity Type.”

https://oee.nrcan.gc.ca/corporate/statistics/neud/dpa/showTable.cfm?type=HB\&sec tor $=$ com \&juris $=00 \& r n=1 \&$ page $=0$.

[2] C. Rands, "Lights still on in federal buildings in National Capital Region even as civil servants work from home," CBC News, 2021.

https://www.cbc.ca/news/politics/federal-buildings-lights-pandemic-1.5894350.

[3] I. Chew, D. Karunatilaka, C. P. Tan, and V. Kalavally, "Smart lighting: The way forward? Reviewing the past to shape the future," Energy Build., vol. 149, pp. 180-191, 2017, doi: 10.1016/j.enbuild.2017.04.083.

[4] Z. Nagy, F. Y. Yong, and A. Schlueter, "Occupant centered lighting control: A user study on balancing comfort, acceptance, and energy consumption," Energy Build., vol. 126, pp. 310-322, 2016, doi: 10.1016/j.enbuild.2016.05.075.

[5] E. E. Dikel, G. R. Newsham, H. Xue, and J. J. Valdés, "Potential energy savings from high-resolution sensor controls for LED lighting,” Energy Build., vol. 158, pp. 43-53, 2018, doi: 10.1016/j.enbuild.2017.09.048.

[6] W. O'Brien and H. B. Gunay, "Do building energy codes adequately reward buildings that adapt to partial occupancy?," Sci. Technol. Built Environ., vol. 25, no. 6, pp. 678-691, 2019, doi: 10.1080/23744731.2019.1581015.

[7] C. Reinhart and B. Pierre-Felix, "Experimental validation of autodesk ${ }^{\circledR} 3 \mathrm{ds} \max { }^{\circledR}$ design 2009 and daysim 3.0," LEUKOS - J. Illum. Eng. Soc. North Am., vol. 6, no. 
1, pp. 7-35, Jul. 2009, doi: 10.1582/LEUKOS.2009.06.01001.

[8] R. A. Mangkuto, "Validation of DIALux 4.12 and DIALux evo 4.1 against the Analytical Test Cases of CIE 171:2006," LEUKOS - Journal of Illuminating Engineering Society of North America, vol. 12, no. 3. Taylor and Francis Inc., pp. 139-150, Jul. 02, 2016, doi: 10.1080/15502724.2015.1061438.

[9] B. Von Neida, D. Manicria, and A. Tweed, "An analysis of the energy and cost savings potential of occupancy sensors for commercial lighting systems," J. Illum. Eng. Soc., vol. 30, no. 2, pp. 111-125, 2001, doi:

10.1080/00994480.2001.10748357.

[10] A. Nabil and J. Mardaljevic, "Useful daylight illuminance: A new paradigm for assessing daylight in buildings," Light. Res. Technol., vol. 37, no. 1, pp. 41-59, 2005, doi: 10.1191/1365782805li128oa.

[11] D. K. Tiller, X. Guo, G. P. Henze, and C. E. Waters, "Validating the application of occupancy sensor networks for lighting control," Light. Res. Technol., vol. 42, no. 4, pp. 399-414, 2010, doi: 10.1177/1477153510375524.

[12] D. K. Tiller, X. Guo, G. P. Henze, and C. E. Waters, "The application of sensor networks to lighting control," LEUKOS - J. Illum. Eng. Soc. North Am., vol. 5, no. 4, pp. 313-325, 2009, doi: 10.1582/LEUKOS.2008.05.04.004.

[13] V. Garg and N. K. Bansal, "Smart occupancy sensors to reduce energy consumption," Energy Build., vol. 32, no. 1, pp. 81-87, 2000, doi: 10.1016/S03787788(99)00040-7.

[14] J. Jennings, N. Colak, and F. Rubinstein, "Occupancy and time-based lighting 
controls in open offices," J. Illum. Eng. Soc., vol. 31, no. 2, pp. 86-100, 2002, doi: 10.1080/00994480.2002.10748395.

[15] C. De Bakker, T. Van De Voort, and A. Rosemann, "The energy saving potential of occupancy-based lighting control strategies in open-plan offices: The influence of occupancy patterns," Energies, vol. 11, no. 1, pp. 1-18, 2018, doi: 10.3390/en11010002.

[16] S. Tonzani, "Time to change the bulb," NATURE, pp. 312-314, May 2009.

[17] X. Guo, D. K. Tiller, G. P. Henze, and C. E. Waters, "The performance of occupancy-based lighting control systems: A review," Light. Res. Technol., vol. 42, no. 4, pp. 415-431, 2010, doi: 10.1177/1477153510376225.

[18] D. Caicedo, A. Pandharipande, and G. Leus, "Occupancy-based illumination control of LED lighting systems," Light. Res. Technol., vol. 43, no. 2, pp. $217-$ 234, 2011, doi: 10.1177/1477153510374703.

[19] V. Singhvi, A. Krause, C. Guestrin, J. H. Garrett, and H. Scott Matthews, "Intelligent light control using sensor networks," SenSys 2005 - Proc. 3rd Int. Conf. Embed. Networked Sens. Syst., pp. 218-229, 2005, doi: 10.1145/1098918.1098942.

[20] D. T. Delaney, G. M. P. O’Hare, and A. G. Ruzzelli, "Evaluation of energyefficiency in lighting systems using sensor networks," BUILDSYS 2009 - Proc. 1st ACM Work. Embed. Sens. Syst. Energy-Efficiency Build. Held Conjunction with ACM SenSys 2009, pp. 61-66, 2009, doi: 10.1145/1810279.1810293.

[21] Y. J. Wen and A. M. Agogino, "Control of wireless-networked lighting in open- 
plan offices," Light. Res. Technol., vol. 43, no. 2, pp. 235-248, 2011, doi: $10.1177 / 1477153510382954$.

[22] J. Y. Park and Z. Nagy, “The Influence of Building Design, Sensor Placement, and Occupant Preferences on Occupant Centered Lighting Control," in Computing in Civil Engineering 2019: Smart Cities, Sustainability, and Resilience - Selected Papers from the ASCE International Conference on Computing in Civil Engineering 2019, 2019, pp. 98-104, doi: 10.1061/9780784482445.013.

[23] Y. Gao, Y. Cheng, H. Zhang, and N. Zou, "Dynamic illuminance measurement and control used for smart lighting with LED," Meas. J. Int. Meas. Confed., vol. 139, pp. 380-386, Jun. 2019, doi: 10.1016/j.measurement.2019.03.003.

[24] D. Caicedo and A. Pandharipande, "Distributed illumination control with local sensing and actuation in networked lighting systems," IEEE Sens. J., vol. 13, no. 3, pp. 1092-1104, 2013, doi: 10.1109/JSEN.2012.2228850.

[25] F. Sun and J. Yu, "Indoor intelligent lighting control method based on distributed multi-agent framework," Optik (Stuttg)., vol. 213, p. 164816, Jul. 2020, doi: 10.1016/j.ijleo.2020.164816.

[26] H. Wang, A. Pandharipande, D. Caicedo, and P. P. J. Van Den Bosch, "Distributed lighting control of locally intelligent luminaire systems," Conf. Proc. - IEEE Int. Conf. Syst. Man Cybern., pp. 3167-3172, 2012, doi:

10.1109/ICSMC.2012.6378278.

[27] N. Van De Meugheuvel, A. Pandharipande, D. Caicedo, and P. P. J. Van Den Hof, "Distributed lighting control with daylight and occupancy adaptation," Energy 
Build., vol. 75, pp. 321-329, 2014, doi: 10.1016/j.enbuild.2014.02.016.

[28] T. Labeodan, C. De Bakker, A. Rosemann, and W. Zeiler, "On the application of wireless sensors and actuators network in existing buildings for occupancy detection and occupancy-driven lighting control," Energy Build., vol. 127, pp. 7583, 2016, doi: 10.1016/j.enbuild.2016.05.077.

[29] Y. J. Wen and A. M. Agogino, "Wireless networked lighting systems for optimizing energy savings and user satisfaction," 2008 IEEE Wirel. Hive Networks Conf. Proceedings, WHNC, 2008, doi: 10.1109/WHNC.2008.4629493.

[30] S. Li and A. Pandharipande, "Networked illumination control with distributed light-harvesting wireless sensors," IEEE Sens. J., vol. 15, no. 3, pp. 1662-1669, 2015, doi: 10.1109/JSEN.2014.2365671.

[31] A. Pandharipande and D. Caicedo, "Smart indoor lighting systems with luminairebased sensing: A review of lighting control approaches," Energy Build., vol. 104, pp. 369-377, 2015, doi: 10.1016/j.enbuild.2015.07.035.

[32] H. B. Gunay, W. O'Brien, and I. Beausoleil-Morrison, "Implementation and comparison of existing occupant behaviour models in EnergyPlus," J. Build. Perform. Simul., vol. 9, no. 6, pp. 567-588, 2016, doi:

10.1080/19401493.2015.1102969.

[33] A. Seyedolhosseini, N. Masoumi, M. Modarressi, and N. Karimian, "Daylight adaptive smart indoor lighting control method using artificial neural networks," $J$. Build. Eng., vol. 29, no. July 2019, p. 101141, 2020, doi: 10.1016/j.jobe.2019.101141. 
[34] C. Aghemo, L. Blaso, and A. Pellegrino, "Building automation and control systems: A case study to evaluate the energy and environmental performances of a lighting control system in offices," Autom. Constr., vol. 43, pp. 10-22, 2014, doi: 10.1016/j.autcon.2014.02.015.

[35] C. de Bakker, M. Aarts, H. Kort, E. van Loenen, and A. Rosemann, "Preferred Luminance Distributions in Open-Plan Offices in Relation to Time of Day and Subjective Alertness," LEUKOS - J. Illum. Eng. Soc. North Am., pp. 1-18, May 2019, doi: 10.1080/15502724.2019.1587619.

[36] F. Rubinstein and A. Enscoe, "Saving energy with highly-controlled lighting in an open-plan office," LEUKOS - J. Illum. Eng. Soc. North Am., vol. 7, no. 1, pp. 2136, 2010, doi: 10.1582/LEUKOS.2010.07.01002.

[37] C. de Bakker, M. Aarts, H. Kort, and A. Rosemann, "The feasibility of highly granular lighting control in open-plan offices: Exploring the comfort and energy saving potential,” Build. Environ., vol. 142, no. June, pp. 427-438, 2018, doi: 10.1016/j.buildenv.2018.06.043.

[38] C. de Bakker, M. Aries, H. Kort, and A. Rosemann, "Occupancy-based lighting control in open-plan office spaces: A state-of-the-art review," Build. Environ., vol. 112, pp. 308-321, 2017, doi: 10.1016/j.buildenv.2016.11.042.

[39] A. D. Galasiu, G. R. Newsham, C. Suvagau, and D. M. Sander, "Energy saving lighting control systems for open-plan offices: A field study," LEUKOS - J. Illum. Eng. Soc. North Am., vol. 4, no. 1, pp. 7-29, 2007, doi: 10.1582/LEUKOS.2007.04.01.001. 
[40] J. Page, D. Robinson, N. Morel, and J. L. Scartezzini, “A generalised stochastic model for the simulation of occupant presence," Energy Build., vol. 40, no. 2, pp. 83-98, 2008, doi: 10.1016/j.enbuild.2007.01.018.

[41] C. F. Reinhart and V. R. M. Lo Verso, "A rules of thumb-based design sequence for diffuse daylight," Light. Res. Technol., vol. 42, no. 1, pp. 7-31, 2010, doi: $10.1177 / 1477153509104765$.

[42] Natural Research Council of Canada (NRC), National Energy Code of Canada for Buildings. Natural Resources Canada (NRCan), 2015.

[43] N. Makaremi, S. Schiavoni, A. L. Pisello, and F. Cotana, "Effects of surface reflectance and lighting design strategies on energy consumption and visual comfort," Indoor Built Environ., vol. 28, no. 4, pp. 552-563, 2019, doi: 10.1177/1420326X18793170.

[44] L. Dumitrascu, "Empirical model for snow/ground reflectivity prediction," 2018, [Online]. Available: https://curve.carleton.ca/b3f06703-c1f5-4dc0-91cfcc4d3120a6ed.

[45] G. R. Newsham, "Manual Control of Window Blinds and Electric Lighting: Implications for Comfort and Energy Consumption," Indoor Built Environ., vol. 3, no. 3, pp. 135-144, 1994, doi: 10.1177/1420326X9400300307.

[46] C. F. Reinhart and K. Voss, "Monitoring manual control of electric lighting and blinds Reinhart, C.F.; Voss, K. NRCC-45701," Light. Res. Technol., vol. 35, no. 3, pp. 243-260, 2003, [Online]. Available: http://irc.nrc-cnrc.gc.ca/ircpubs.

[47] W. O’Brien, K. Kapsis, and A. K. Athienitis, "Manually-operated window shade 
patterns in office buildings: A critical review," Build. Environ., vol. 60, pp. 319338, 2013, doi: 10.1016/j.buildenv.2012.10.003.

[48] F. Nicole, "Characterising occupant behaviour in buildings: towards a stochastic model of occupant use of windows, lights, blinds heaters and fans," Proc. 7th Int. IBPSA Conf., pp. 1073-1078, 2001.

[49] K. Van Den Wymelenberg, "Patterns of occupant interaction with window blinds: A literature review," Energy Build., vol. 51, no. 2012, pp. 165-176, 2012, doi: 10.1016/j.enbuild.2012.05.008.

[50] H. Shen and A. Tzempelikos, "Daylighting and energy analysis of private offices with automated interior roller shades," Sol. Energy, vol. 86, no. 2, pp. 681-704, 2012, doi: 10.1016/j.solener.2011.11.016.

[51] A. Mahdavi, A. Mohammadi, E. Kabir, and L. Lambeva, "Shading and lighting operation in office buildings in Austria: A study of user control behavior," Build. Simul., vol. 1, no. 2, pp. 111-117, 2008, doi: 10.1007/s12273-008-8104-1.

[52] C. F. Reinhart, "Lightswitch-2002: A model for manual and automated control of electric lighting and blinds," Sol. Energy, vol. 77, no. 1, pp. 15-28, 2004, doi: 10.1016/j.solener.2004.04.003.

[53] A. Tzempelikos and A. K. Athienitis, "The impact of shading design and control on building cooling and lighting demand," Sol. Energy, vol. 81, no. 3, pp. 369382, 2007, doi: 10.1016/j.solener.2006.06.015.

[54] D. B. Floyd, D. S. Parker, and J. R. Sherwin, "Measured Field Performance and Energy Savings of Occupancy Sensors: Three Case Studies," Florida Sol. Energy 
Cent. (Online Publ., no. Nlpip, pp. 97-105, 2002, [Online]. Available: http://cgec.ucdavis.edu/ACEEE/1994-96/1996/VOL04/097.PDF.

[55] W. Hertog, A. Llenas, and J. Carreras, "Optimizing indoor illumination quality and energy efficiency using a spectrally tunable lighting system to augment natural daylight References and links,” 2015, doi: 10.1364/OE.23.0A1564.

[56] A. Nabil and J. Mardaljevic, "Useful daylight illuminance: A new paradigm for assessing daylight in buildings," Light. Res. Technol., vol. 37, no. 1, pp. 41-59, 2005, doi: 10.1191/1365782805li128oa.

[57] A. S. Choi and M. K. Sung, "Development of a daylight responsive dimming system and preliminary evaluation of system performance," Build. Environ., vol. 35, no. 7, pp. 663-676, Oct. 2000, doi: 10.1016/S0360-1323(99)00055-4.

[58] H. Zou, Y. Zhou, H. Jiang, S. C. Chien, L. Xie, and C. J. Spanos, "WinLight: A WiFi-based occupancy-driven lighting control system for smart building," Energy Build., vol. 158, pp. 924-938, 2018, doi: 10.1016/j.enbuild.2017.09.001.

[59] N. E. M. Association, "Energy Savings with Fluorescent and LED Dimming," 2015. [Online]. Available: file:///C:/Users/Bernard/Downloads/NEMALSD 732015 WATERMARKED.pdf.

[60] K. Kapsis, A. Tzempelikos, A. K. Athienitis, and R. G. Zmeureanu, "Daylighting performance evaluation of a bottom-up motorized roller shade," Sol. Energy, vol. 84, no. 12, pp. 2120-2131, 2010, doi: 10.1016/j.solener.2010.09.004.

[61] C. F. Reinhart, "Overview and Introduction to DAYSIM and Current Research Developments,” Massachusetts Institute of Technology, Building Technology 
Program, 2012. Accessed: Jul. 19, 2020. [Online]. Available: http://www.radianceonline.org/community/workshops/2012copenhagen/Day1/Jakubiec/jakubiec,reinhart_radiance-workshoppresentation_daysim.pdf.

[62] D. Lowcay, H. B. Gunay, and W. O'Brien, “Simulating energy savings potential with high-resolution daylight and occupancy sensing in open-plan offices," $J$. Build. Perform. Simul., vol. 13, no. 5, pp. 606-619, 2020, doi: $10.1080 / 19401493.2020 .1807604$.

[63] T. Polonelli, L. Benini, E. Popovici, M. Magno, and S. Member, "A Low-cost, Highly Scalable Wireless Sensor Network Solution to Achieve Smart LED Light Control for Green Buildings A Low Cost, Highly Scalable Wireless Sensor Network Solution to Achieve Smart LED Light Control for Green Buildings," Artic. IEEE Sensors J., vol. 15, no. 5, 2015, doi: 10.1109/JSEN.2014.2383996.

[64] D. Caicedo, S. Li, and A. Pandharipande, "Smart lighting control with workspace and ceiling sensors," Light. Res. Technol., vol. 49, no. 4, pp. 446-460, 2017, doi: $10.1177 / 1477153516629531$.

[65] S. Ganapathy, "Auto-commissioning and Resource Allocation Based Control of Smart Lights.” 2013, Accessed: Jan. 19, 2021. [Online]. Available: http://rave.ohiolink.edu/etdc/view?acc_num=osu1366026171.

[66] I. Chew, V. Kalavally, N. W. Oo, and J. Parkkinen, "Design of an energy-saving controller for an intelligent LED lighting system," Energy Build., vol. 120, pp. 19, 2016, doi: 10.1016/j.enbuild.2016.03.041. 
[67] S.-Y. Kim and R. Mistrick, "Recommended Daylight Conditions for Photosensor System Calibration in a Small Office," J. Illum. Eng. Soc., vol. 30, no. 2, pp. 176188, 2001, doi: 10.1080/00994480.2001.10748362.

[68] S. Norouziasl and A. Jafari, “Comparing Office Layouts Regarding Lighting Energy Saving Potentials Using Agent-Based Real-Time Simulation of Occupancy Behavioral Patterns," in Construction Research Congress 2020, Nov. 2020, pp. 972-981, doi: 10.1061/9780784482865.103.

[69] A. Tzempelikos, "Development and Implementation of Lighting and Shading Control Algorithms in an Airport Building," J. Archit. Eng., vol. 18, no. 3, pp. 242-250, Sep. 2012, doi: 10.1061/(ASCE)AE.1943-5568.0000062.

[70] L. T. Doulos, A. Tsangrassoulis, P. A. Kontaxis, A. Kontadakis, and F. V. Topalis, "Harvesting daylight with LED or T5 fluorescent lamps? The role of dimming," Energy Build., vol. 140, pp. 336-347, Apr. 2017, doi:

10.1016/J.ENBUILD.2017.02.013. 